\title{
WestVirginiaUniversity
}

THE RESEARCH REPOSITORY @ WVU

Graduate Theses, Dissertations, and Problem Reports

2003

\section{Pharmaceutical quality performance of folic acid supplements}

Islam Rasem Younis
West Virginia University

Follow this and additional works at: https://researchrepository.wvu.edu/etd

\section{Recommended Citation}

Younis, Islam Rasem, "Pharmaceutical quality performance of folic acid supplements" (2003). Graduate Theses, Dissertations, and Problem Reports. 1812.

https://researchrepository.wvu.edu/etd/1812

This Thesis is protected by copyright and/or related rights. It has been brought to you by the The Research Repository @ WVU with permission from the rights-holder(s). You are free to use this Thesis in any way that is permitted by the copyright and related rights legislation that applies to your use. For other uses you must obtain permission from the rights-holder(s) directly, unless additional rights are indicated by a Creative Commons license in the record and/ or on the work itself. This Thesis has been accepted for inclusion in WVU Graduate Theses, Dissertations, and Problem Reports collection by an authorized administrator of The Research Repository @ WVU. For more information, please contact researchrepository@mail.wvu.edu. 


\title{
PHARMACEUTICAL QUALITY PERFORMANCE OF FOLIC ACID SUPPLEMENTS
}

\author{
Islam Rasem Younis
}

\author{
THESIS \\ Submitted to the School of Pharmacy \\ at \\ West Virginia University \\ In partial fulfillment of the requirements \\ for the degree of \\ MASTER OF SCIENCE \\ In \\ Pharmaceutical Sciences \\ Paula J. Stout, Ph.D., Chair \\ Patrick S. Callery, Ph.D. \\ Mary Stamatakis, Pharm.D.
}

Department of Basic Pharmaceutical Sciences

Morgantown, West Virginia

2003

Key Words: Folic acid, nutraceuticals, disintegration, dissolution. 


\section{ABSTRACT}

\section{PHARMACEUTICAL QUALITY PERFORMANCE OF FOLIC ACID SUPPLEMENTS}

\section{Islam Rasem Younis}

The vitamin folic acid has received considerable attention in the 1990s because of its preventative role against diseases such as neural tube defects, cardiovascular diseases, and psychiatric illness.

A primary concern is the pharmaceutical quality, potency, and efficacy of commercially available folic acid products and label claims. The results showed that there has been significant progress since the 1990's in the improved quality of commercially available folic acid products in meeting USP standards.

Products were also tested in physiologically relevant solutions. Most notably, all the tested products failed to release more than $75 \%$ of the active ingredient in 60 minutes in simulated gastric fluid. While some excipient-related factors were preliminarily considered, it was ultimately hypothesized that the failure may be related to the folic acid $\mathrm{pH}$-solubility profile, confirmed by the increased release rate of folic acid from buffered tablets compared with nonbuffered tablets, when constant surface area dissolution was maintained. 


\section{ACKNOWLEDGMENT}

I would like to thank Dr. Paula Stout who provided constant assistance, confidence in me, and encouragement throughout the project. I would like to thank Dr. Patrick Callery and Dr. Mary Stamatakis who generously gave their time and agreed to serve on my committee. Also, thanks go out to the entire Basic Pharmaceutical Sciences faculty, staff, and students for all their assistance.

I also wish to express my appreciation for my loving parents, who through both teaching and example have provided a wonderful home, where the quest of knowledge has always been a pleasurable experience.

Lastly, I would like to thank my friends in Morgantown and United States for all their love, encouragement and support. 


\section{Table of Contents}

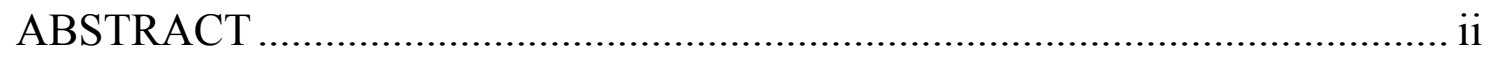

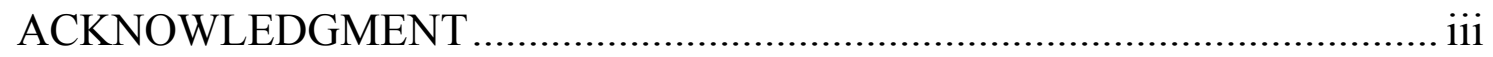

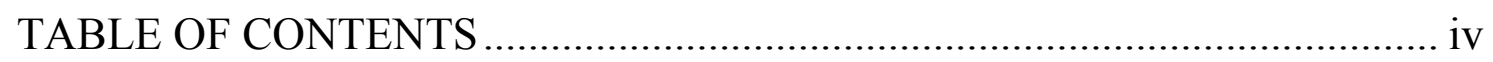

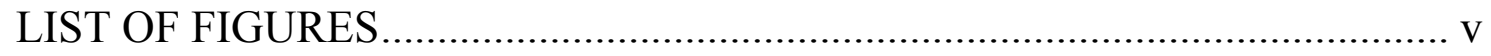

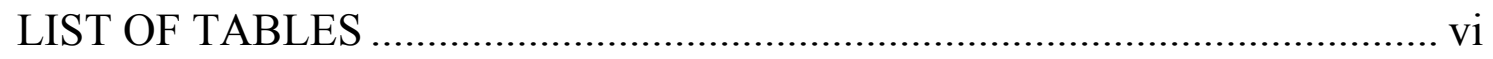

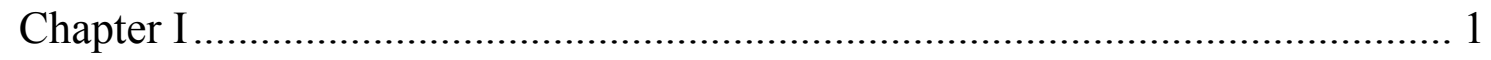

CLINICAL IMPORTANCE OF FOLIC ACID ...................................... 1

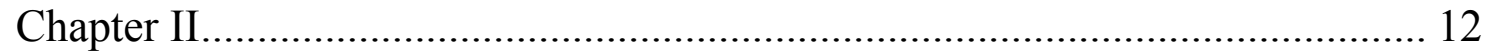

DISSOLUTION OF NUTRITIONAL SUPPLEMENTS ..................... 12

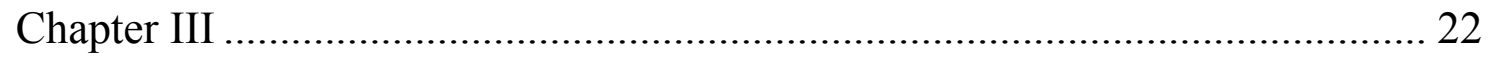

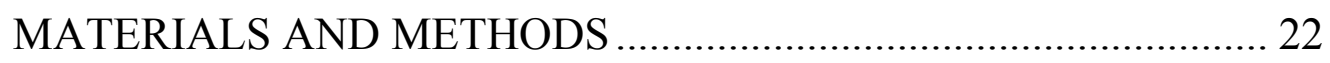

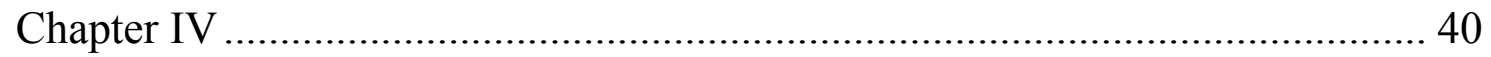

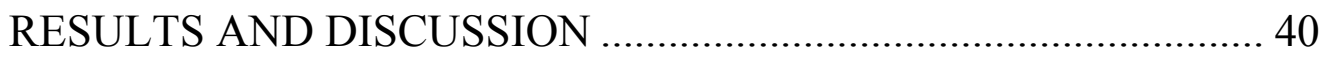

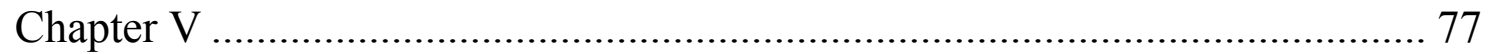

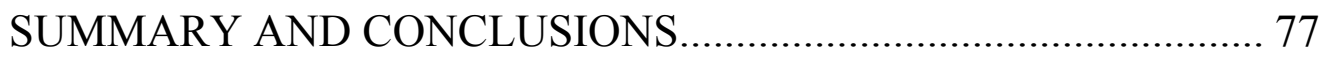

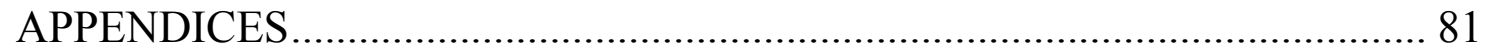

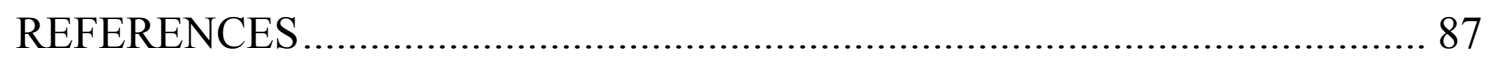




\section{List of Figures}

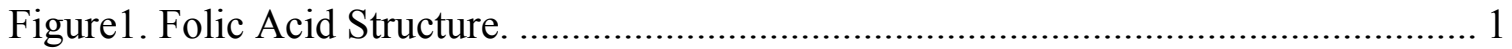

Figure 2. Homocysteine-methionine metabolism. ......................................................... 3

Figure 3.The linearity of folic acid HPLC assay. .................................................... 42

Figure 4. The linearity of single entity folic acid HPLC assay................................... 44

Figure 5. Pterine-6-carboxylic acid and p-aminobenzoyl-L-glutamic acid structures. .... 44

Figure 6 . Chromatogram of mixture of p-aminobenzoic acid $(5 \mu \mathrm{g} / \mathrm{ml}) \mathrm{p}$-aminobenzoyl-

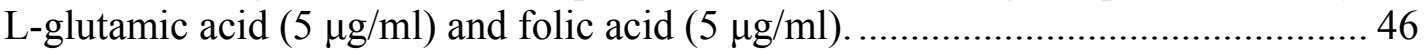

Figure 7. Chromatogram of folic acid degradation (100 ug/ml); A. Day 1, B. Day 15... 47

Figure 8. The linearity of folic acid HPLC assay in multivitamin dosage units.............. 49

Figure 9. Single Entity folic acid tablets average disintegration. .................................5 52

Figure 10 . Multivitamin dosage units containing folic acid average disintegration....... 52

Figure 11. Single entity folic acid tablets average disintegration as a function of $\mathrm{pH}$..... 53

Figure 12. Multivitamin dosage units containing folic acid average disintegration as a

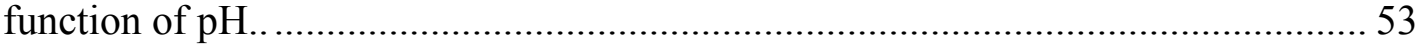

Figure 13. Folic acid (in single entity folic acid tablets) dissolution profile in distilled water.

Figure 14. Folic acid (in single entity folic acid tablets) dissolution profile in SIF. ........ 59

Figure 15. Folic acid (in single entity folic acid tablets) dissolution profile in SGF....... 60

Figure 16. Folic acid (in multivitamin units) dissolution profile in distilled water.......... 62

Figure 17 . Folic acid (in multivitamin units) dissolution profile in SIF....................... 63

Figure 18 . Folic acid (in multivitamin units) dissolution profile in SGF. ........................65

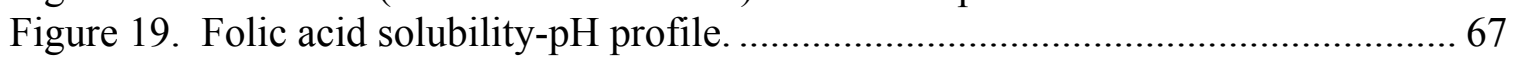

Figure 20. Laboratory formulated folic acid tablets dissolution profile in SIF ............... 69

Figure 21. Methyl cellulose laboratory formulated folic acid tablets dissolution profile in SIF

Figure 22. Microcrystalline cellulose laboratory formulated folic acid tablets dissolution

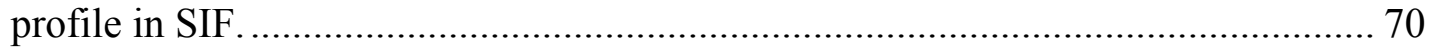

Figure 23. Laboratory formulated folic acid tablets dissolution profile in SGF.............. 71

Figure 24. Methyl cellulose laboratory formulated folic acid tablets dissolution profile in SGF.

Figure 25. Microcrystalline cellulose laboratory formulated folic acid tablets dissolution

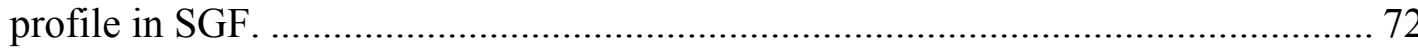

Figure 26. Comparison of fillers used in laboratory formulated folic acid tablets,

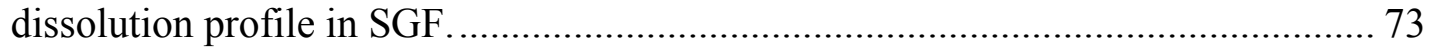

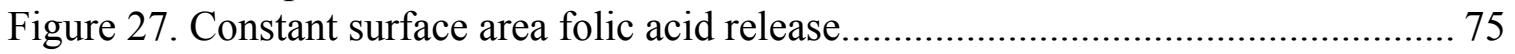




\section{List of Tables}

Table 1. Development of Nutritional Supplements Monographs in USP. ........... 13

Table 2. USP Classifications with respective dissolution test requirements......... 15

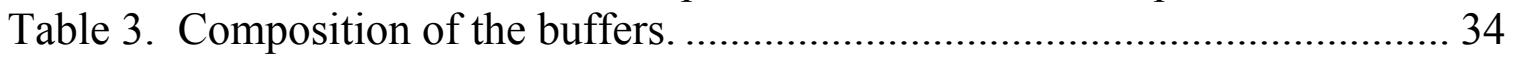

Table 4. Folic acid laboratory formulated tablets composition .............................. 37

Table 5. Coefficients of variation of HPLC folic acid assay................................. 42

Table 6. Coefficients of variation of single entity folic acid tablets HPLC assay. 43

Table 7. Coefficient of variation of folic acid HPLC assay in multivitamin dosage

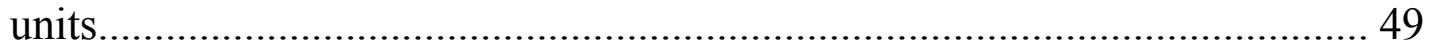

Table 8. Single entity folic acid tablets average disintegration time in minutes... 51

Table 9. Multivitamin dosage units containing folic acid average disintegration

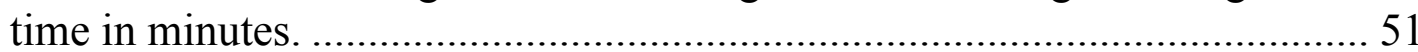

Table 10. Average percent of folic acid in single entity folic acid tablets. ........... 55

Table 11. Average percent of folic acid in multivitamin dosage units.................. 56

Table 12. Percent release of folic acid (in single entity folic acid tablets) in

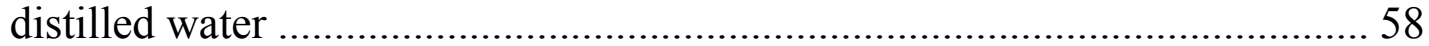

Table 13. Percent release of folic acid (in single entity folic acid tablets) in SIF. 58

Table 14. Percent release of folic acid (in single entity folic acid tablets) in SGF.59

Table 15. Percent release of folic acid (in multivitamin units) in distilled water in

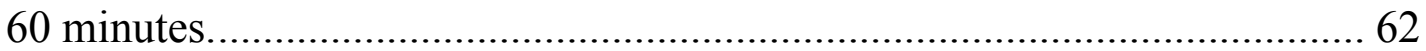

Table 16. Percent release of folic acid (in multivitamin units) in SIF in 60 minutes

Table 17. Percent release of folic acid (in multivitamin units) in SGF in 60

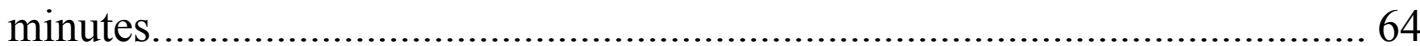

Table 18 . Folic acid solubility in buffers at different $\mathrm{pH}$...................................66

Table 19 . Laboratory formulated folic acid tablets: composition, weight variation,

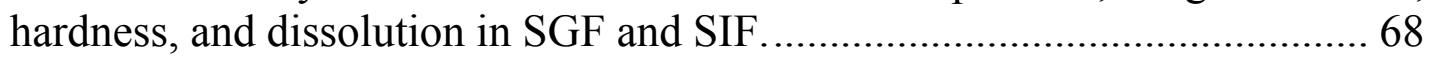




\section{Chapter I}

\section{Clinical Importance of Folic Acid}

Folate, historically known as Will's factor and vitamin M, was isolated in an unknown chemical form in 1941. The term folate refers to the many different naturally occurring forms of the compound, all of which are made up of a pteridine ring, p-aminobenzoic acid, and one to six glutamic acids moieties

(Figure 1). Dietary folate is in the chemical form of pteroylpolyglutamate, and, in order for it to be absorbed, it must be cleaved or hydrolyzed in the small intestine to the monoglutamate. The chemical form of the pharmaceutical folate is pteroylglutamate, which does not need to be hydrolyzed in order to be absorbed. Therefore, synthetic folic acid supplements can provide better bioavailability than folate from natural sources $(1,2)$.

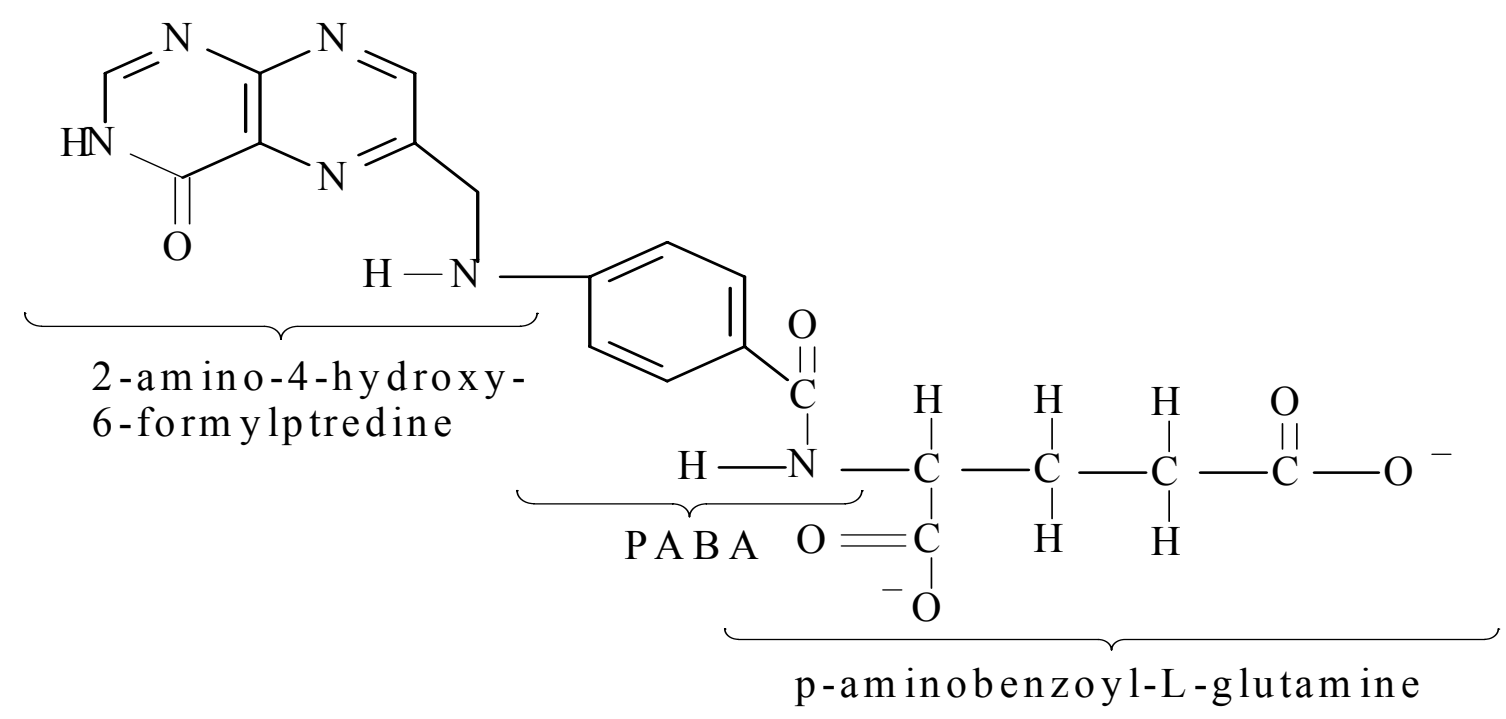

Figure1. Folic Acid Structure. 
Folic acid is a water-soluble vitamin that has been used to treat macrocytic anemia without neurologic disease (3). Folate deficiency is a common finding in:

- The elderly.

- Alcoholics.

- The poor.

- Rheumatoid arthritis patients receiving long-term methotrexate therapy.

- AIDS patients receiving sulfa drugs or pentamidine pnemocystis prophylaxis.

- Dialysis patients, since folic acid is removed from the body during dialysis in patients with chronic renal failure.

Folic acid deficiency may be caused by a variety of factors, including:

- Malabsorption.

- Malnutrition.

- Inadequate utilization.

- Increased requirement by the body for folic acid.

- Increased excretion or destruction.

Both dietary and pharmaceutical folates are converted to 5 -methyltetrahydrofolate $\left(5-\mathrm{CH}_{3}-\mathrm{THF}\right)$, which is the primary circulatory folate in serum, red blood cells (RBC), and cerebrospinal fluid $(4,5)$. The liver is the primary storage depot for 5- $\mathrm{CH}_{3}-\mathrm{THF}$, which donates its methyl group in conjunction with the cofactor vitamin $\mathrm{B}_{12}$ to homocysteine, resulting in the formation of methionine and tetrahydrofolate (THF) (Figure 2). Methionine is the 


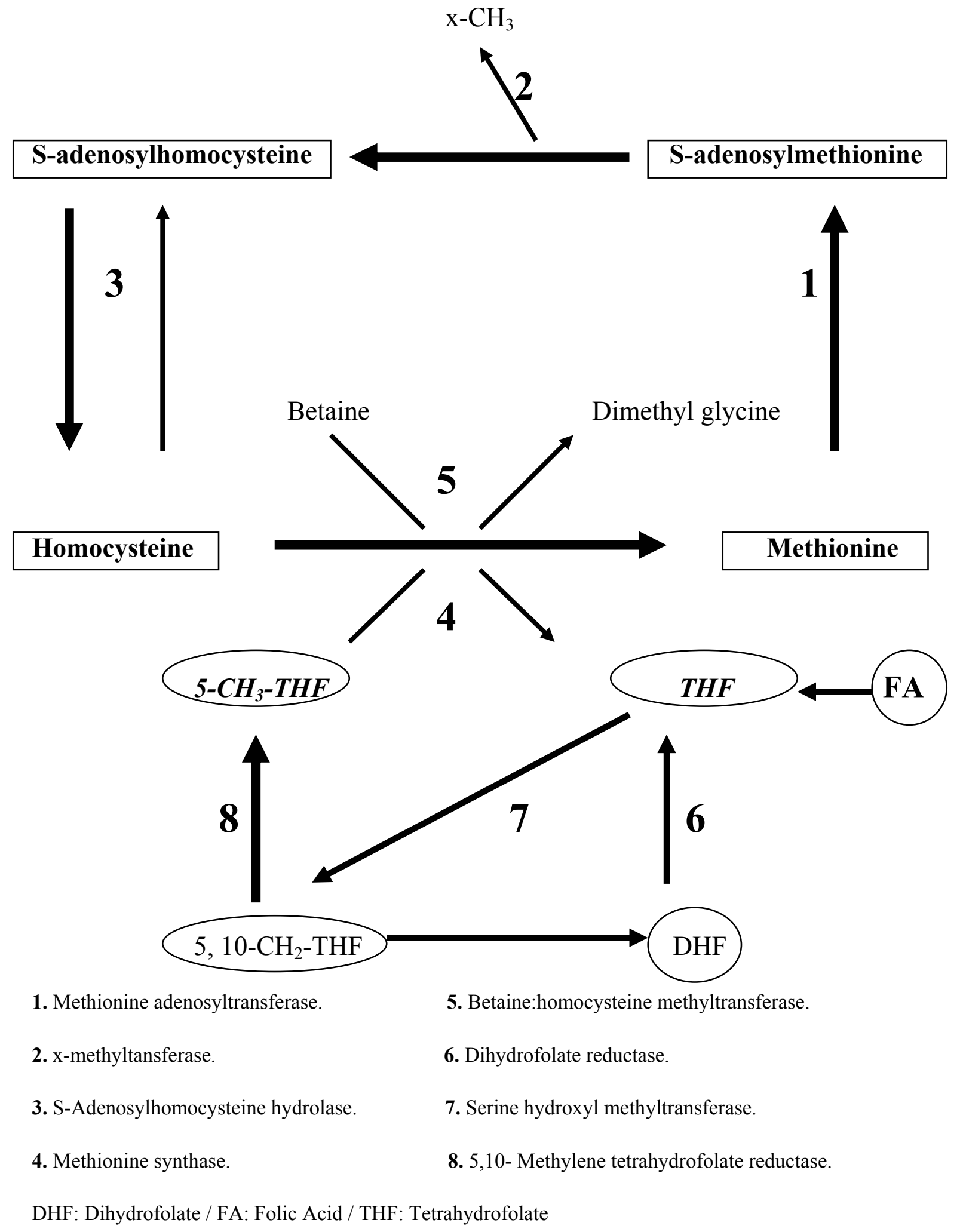

Figure 2. Homocysteine-methionine metabolism.

(Adapted from reference 6) 
precursor to $S$-adenosylmethionine (SAM), which is considered to be the universal methyl-group donor that is involved in many metabolic reactions $(4,5)$.

Deficiencies of both vitamin $\mathrm{B}_{12}$ and folate decrease methionine formation from homocysteine and may result in decreased SAM. It should be noted that methionine is available in the diet. During vitamin $\mathrm{B}_{12}$ deficiency alone, folate is trapped as 5- $\mathrm{CH}_{3}-\mathrm{THF}$, because only the enzyme methionine synthase, along with vitamin $\mathrm{B}_{12}$, can convert it to THF. This is called a functional folate deficiency, even though blood folate levels may be normal. Hyperhomocystinemia occurs with a deficiency of either folate or $\mathrm{B}_{12}$. Elevated homocysteine levels occur in mothers of children with neural tube defects, and in patients with peripheral vascular disease, stroke, coronary artery disease (CAD), myocardial infarction, isolated systolic hypertension, and thrombosis.

In the body, homocysteine is metabolized by two pathways (7):

1. Transsulfuration into cysteine which is then excreted in the urine.

2. Remethylation back to methionine which may be accomplished by two routes:

- Combining betaine and homocysteine in the presence of betainehomocysteine methyl transferase to make methionine and dimethyl glycine.

- The second and the most important route in vivo involves the conversion of SAM and homocysteine to methionine and tetrahydrofolate by methionine synthase.

Folate obtained from a pharmaceutical preparation is the most bioavailable, because $10 \%$ to $50 \%$ of dietary folate is lost in the cooking process (2). Thus, food enriched with folate may have limited amounts available. In 1998, the Institute of Medicine report described a new term called the Dietary Folate Equivalent (DFE), where one DFE is equal to $1 \mu \mathrm{g}$ of food folate, $0.5 \mu \mathrm{g}$ of supplemental folic acid 
(pharmaceutical preparations), and $0.6 \mu \mathrm{g}$ of food fortified with folate (2). This reinforced the fact that pharmaceutical preparations containing folic acid are more bioavailable than food folate. However, it did not make the pharmaceutical preparation a substitute for a balanced diet containing folate. Importantly, different over-the-counter pharmaceutical preparations have different potency and dissolution characteristics (8). Therefore, it cannot be assumed that all pharmaceutical preparations have the same bioavailability of folic acid.

The vitamin folic acid has received considerable attention in the 1990s because of its disease preventative role. The most significant literature exists in the area of periconceptional use of the vitamin to decrease the risk of neural tube defects (NTDs) such as spina bifida. It has also been suggested that folic acid may be effective in decreasing certain risks of cardiovascular disease and psychiatric illness, most notably dementia (6).

\section{Prevention of neural tube defect.}

The technical names of the two major neural tube birth defects reduced by adequate folate intake are anencephaly and spina bifida. Babies with anencephaly do not develop a brain and are stillborn or die shortly after birth. Those with spina bifida have a defect of the spinal column that can result in varying degrees of handicap, from mild and hardly noticeable cases of scoliosis (a curvature of the spine) to paralysis and bladder or bowel incontinence (3). With proper medical treatment, most babies born with spina bifida can survive to adulthood. However, they may require leg braces, crutches, and other devices to help them walk, and they may have learning disabilities. About 30 percent have slight to severe mental retardation.

In the developing fetus, the neural tube closes early in pregnancy at 23 to 27 days after conception, a time when many women do not realize that they are 
pregnant. Each year in the United States, approximately 4000 pregnancies result in neural tube defects such as spina bifida or encephalopathy (9). Approximately $40 \%$ of the pregnancies in the United States are unplanned (9). In 1992, the U.S. Public Health Service, joined in 1993 by the American College of Obstetricians and Gynecologists and the American Academy of Pediatrics Committee on Genetics, recommended that all women of childbearing age consume $400 \mu \mathrm{g}$ of folate daily from food or supplements. These recommendations effectively overrode the Recommended Dietary Allowance (RDA) of $180 \mu \mathrm{g}$ daily set in 1989 (reduced from $400 \mu \mathrm{g}$ daily established in 1968) $(3,9)$.

Numerous studies have demonstrated the association between levels of homocysteine and neural tube defects and other congenital defects (8). Many studies have shown that folic acid supplementation in early pregnancy markedly reduces the risk of neural tube defects (11). A $72 \%$ protective effect of folic acid against neural tube defects was obtained in a study of 1817 women at high risk of having pregnancies with neural tube defects (12). Neural tube defects risk declined markedly with modest increase of total folate in early pregnancy (11). Women with previously affected offspring who intend to become pregnant should take daily supplementation containing $0.4 \mathrm{mg}$ of folic acid in the preconception period to reduce the risk of reoccurrence of neural tube defects (1). Because of the established correlation between sufficient folic acid levels and healthy fetal development, and subsequent recent recommendations for folic acid supplementation, the pharmaceutical quality of commercially available folic acid supplements becomes of interest to public health.

\section{Prevention of heart disease.}

Multiple prospective and case-control studies have shown that a moderately elevated plasma homocysteine concentration is an independent risk factor for atherothrombotic vascular disease (13). High plasma homocysteine concentration 
is an independent risk factor for left arterial thrombus formation in patients with stroke caused by nonvascular atrial fibrillation (14). Prospective studies have shown that elevated plasma homocysteine concentrations increased the risk of cardiovascular disease by about two fold (15).

Lowering homocysteine levels in plasma would save lives from the disease of stroke in the middle aged and the elderly (16). Treatment is most conveniently administered as a folic acid supplement (400-1000 $\mu \mathrm{g})$ and a high potency multivitamin that contains at least $400 \mu \mathrm{g}$ of folate (17). Folic acid may be used to reduce homocysteine concentration in patients with coronary artery disease, either alone or combined with other B vitamins (18). Intake of folic acid and vitamin B6 above $180 \mu \mathrm{g}$ per day may be important in the primary prevention of coronary heart disease among women (19). Folic acid and vitamins B6 and B12 are the mainstay in hyperhomocystenemia therapy. Folic acid, among other drugs and protective procedures, should be utilized as an agent for reducing cardiovascular risk in diabetic patients (20).

\section{Prevention of colon cancer.}

Colorectal cancer is the second most common cause of cancer-related death in both men and women. Epidemiological studies have suggested that a diminished folate status is associated with increased risk of colon cancer (21). The results of animal studies generally support this epidemiologic observation and, in addition, provide strong evidence for a causal relation between folate status and colorectal carcinogenesis (22). Folate levels may be inversely related to colorectal cancer risk, possibly in combination with low methionine and high alcohol consumption (23). 


\section{Antioxidant efficiency.}

In a study dealing with the activity of various vitamins against the radicalmediated oxidative damage in human whole blood, the antioxidant activity of several lipid- and water-soluble vitamins has been assessed by biological assay and through two chemical methods. Antioxidant activities were observed for folic acid and pyridoxine, compared to ascorbic acid. The effectiveness of folic acid was almost three times as high as vitamin C (24).

\section{Prevention of gastric and gastrointestinal cancers.}

In a randomized, double blind, placebo controlled trial, a total of 216 patients with atrophic gastritis were randomly assigned in order to evaluate the role of folic acid in the chemoprevention of gastric and other gastrointestinal cancers. Folic acid displayed a highly significant decrease in the occurrence of and lowered the risk for, gastrointestinal cancers. The use of folic acid led to obvious improvement of gastric mucosal lesions, atrophy, inflammation, and pre-cancerous states. The trial revealed the interventional effect of folic acid on the development of gastrointestinal cancers. Also, folic acid may be used to treat atrophic gastritis by preventing or reversing precancerous lesions (25).

\section{Risk of low birth weight.}

Folic acid-iron daily supplements reduced the percentage of low birth weight babies from $43 \%$ to $34 \%$ in 4926 pregnant women and 4130 live born infants in a rural community in southeastern Nepal. Folic acid-iron and micronutrients (vitamins and minerals) increased head and chest circumference of babies, but not length. Antenatal folic acid-iron supplements modestly reduced the risk of low birth weight. Multiple micronutrients seemed to confer no additional benefit over folic acid- iron in reducing this risk (26). 


\section{Risk of breast cancer.}

In several epidemiologic investigations, folate intake has appeared to reduce the elevated risk of breast cancer associated with moderate alcohol consumption. Higher plasma levels of folate and possibly vitamin B6 may reduce the risk of developing breast cancer. Achieving adequate circulating levels of folate may be particularly important for women at higher risk of developing breast cancer because of higher alcohol consumption (27).

\section{Prevention of mood and cognitive disorders.}

In neonates, infants, children, and adolescents, inborn errors of folate transport and metabolism are associated with a variety of overlapping syndromes that are influenced by the age of clinical presentation.

In adult patients presenting with anemias due to folate deficiency, approximately two thirds have neuropsychiatric disorders which overlap considerably with those associated with anemia due to vitamin B-12 deficiency. The degree of anemia is poorly correlated with the presence of neuropsychiatric disorders, but, if these anemias were left untreated, nearly all patients would eventually develop neuropsychiatric complications (6).

Hyperhomocystenemia is an independent risk factor for homocysteine metabolism and cognitive function, from mild cognitive decline (age-related memory loss) to vascular dementia and Alzheimer's disease (28). The association of folate deficiency, as reflected by low concentrations of folate in serum, red cells, and cerebrospinal fluid and raised plasma concentrations of homocysteine, with depression and dementia has been confirmed in epileptic, neurological, psychiatric, geriatric and psychogeriatric patients and is supported by neuropsychological, neuropathological, and neurochemical studies. Some of the deficiency may be related to aging, some may be secondary to mental illness, and 
some primary. But whether it is primary or secondary, open and controlled treatment studies confirm an aetiological link with specific effects of the vitamin on mood, drive, initiative, alertness, concentration, psychomotor speed, and social activity. These observations are reinforced by cognitive studies in otherwise healthy subjects, suggesting that low folate levels are associated with patterns of impairment also found in aging (6).

Within the wide spectrum of depressive disorders, a subgroup has been identified in which folate and related methylation processes are involved. With respect to dementia, there is evidence that folate deficiency may contribute to the cognitive impairment of the aging brain, sometimes leading to reversible dementia but also increasing the risk of Alzheimer's disease and vascular dementia, perhaps by methylation related processes or by homocysteine mediated vascular or neurotoxic mechanisms. It is well known that depression may be a precursor of dementia in a range of neuropsychiatric syndromes (6).

A significant correlation has been found between risk of Alzheimer's disease and high plasma levels of homocysteine, as well as low levels of folic acid, and vitamins B6 and B12. Providing the nutritional cofactors for proper functioning of the methionine cycle may improve methylation and protect the brain from damage (28). It was shown that dietary restriction and supplementation with folic acid can reduce neuronal damage and improve behavioral outcome in a mouse model of Alzheimer disease and Parkinson disease (29). A high dose of folic acid and vitamins B6 and B12 reduces homocysteine levels in patients with Alzheimer disease (30).

9. Reducing the toxicity of chemotherapeutic agents.

Antimetabolites are active chemotherapeutic agents for many solid tumor and hematologic malignancies. Folate antagonists, purine analogues, and 
pyrimidine analogues are the three main categories of antimetabolites.

Methotrexate is the most widely studied folate antagonist, and is effective in many malignancies. Methotrexate resistance, which develops through several mechanisms, may lead to cell death. Antifolate drug development has focused on agents designed to overcome different aspects of methotrexate resistance.

Supplementation with folic acid and vitamin B12 has been shown to reduce the toxicity of the antifolate agent, pemetrexed, and increase its therapeutic index without affecting the efficacy of this novel agent (31).

Folic acid is gaining more clinical importance as a preventative agent for many diseases. Extensive clinical research is underway to elucidate its mechanism of action in preventing a disease, or to establish other potential clinical uses. Folic acid is likely going to play a critical and major role in the prevention therapy of many diseases in the future. 


\section{Chapter II}

\section{Dissolution of Nutritional Supplements}

Nutritional supplements such as vitamins, minerals, and botanicals (i.e. nutraceuticals) are now becoming increasingly popular in the West, although the Chinese have been using various nutritional supplements and herbs to cure many body and soul maladies for centuries (32).

Nutraceuticals, especially folic acid, have received considerable attention in the 1990s because of increasing clinical importance. Until the early 1990's, there were no guidelines or USP monographs that ensured the pharmaceutical quality of marketed nutraceutical products. In 1938, the FDA, through Food Drug and Cosmetic Act, categorized vitamins as food; thus, while vitamins need to be safe, they have not undergone the same quality requirements and review scrutiny as drug products, which are required to be safe and effective. However, during the past decade, through a rigorous process of proposal review and guideline selection, the United States Pharmacopoeia (USP) established its first protocols for testing the vitamin and mineral contents of nutritional supplements $(33,34)$. Additionally, the FDA focused serious attention on product claims and labeling practices.

A primary concern is the pharmaceutical quality, potency, and efficacy of nutritional supplements and their label claims. Under the 1994 Dietary Supplement Health and Education Act (DSHEA), the FDA-required premarket review of nutritional supplements is less in-depth than that of other products the agency regulates, such as drugs and food additives. Thus, nutraceuticals continue to be brought to market under less rigorous testing standards than are

pharmaceuticals. This means that consumers and manufacturers are responsible for checking the safety, efficacy and truthfulness of label claims. DSHEA also 
allowed manufacturers to make therapeutic claims for the first time legally, provided a "claim unfounded by the FDA" disclaimer was included.

USP monographs provide methods for evaluating the acceptability and stability of pharmaceuticals in approved applications. Since the FDA was not charged with regulating nutraceuticals as drugs in the early 1990s, USP addressed this matter of public health through a process that led to the development of monograph standards for many vitamins, mineral supplements and botanicals.

Table 1. Development of Nutritional Supplements Monographs in USP.

\begin{tabular}{|l|l|}
\hline 1991 & $\begin{array}{l}\text { USP holds an open conference on vitamins, minerals, and } \\
\text { nutritional supplements. The first proposals are discussed and } \\
\text { reviewed. }\end{array}$ \\
\hline 1993 & $\begin{array}{l}\text { Supplement } 8 \text { to USP XXII: The first standards are established, } \\
\text { including requirements for initial disintegration testing and for } \\
\text { dissolution testing if disintegration attempts fail. USP } \\
\text { Pharmacopeial Forum publishes a proposal for establishing } \\
\text { dissolution requirements for nutritional supplements. }\end{array}$ \\
\hline 1994 & $\begin{array}{l}\text { US Congress passes DSHEA. } \\
\text { requirement for nutritional supplements, including folic acid, } \\
\text { index vitamins, and index elements. }\end{array}$ \\
\hline 1995 & $\begin{array}{l}\text { Subsequent USP 23 supplements: fine-tuning of requirements, } \\
\text { test methods, and assays. }\end{array}$ \\
\hline $1995-1998$ & \begin{tabular}{l} 
Inclusion of botanicals in USP/NF monographs. \\
\hline 1998
\end{tabular}
\end{tabular}


Standards for vitamins, including disintegration and dissolution test requirements, first appeared in 1993 in the eighth supplement to USP 22/NF 17 (33). The USP section describes monograph test methods for vitamins and calcium supplements. Testing is based on the product's end use and strength. For example, if a calcium product is a compendial article and will be used as an antacid, the test is a disintegration test. However, if the article will be used as a calcium supplement for the treatment of osteoporosis, the test is a dissolution method. Because manufacturers have no control over a product's end use, it becomes their responsibility to see that a tested product would pass both disintegration and dissolution tests throughout its shelf life. Additionally, if the product is labeled "USP," it must be packaged, stored, and distributed as required in the monographs and in conformance with USP General Chapters. It should be noted that nutraceutical manufacturers are not required to meet USP monograph standards in order to market their products. However, use of a USP label claim on the product does require this, and failure to pass these standards would then be considered as "product mislabeling or misbranding", a punishable violation of FDA guidelines.

When establishing the test requirements for vitamins, USP considered the degree of difficulty of the test and the number of active ingredients in the formulation. For multivitamins, a list of index vitamins and minerals were chosen based on their solubility. It was presumed that if the least-soluble active ingredient in the formulation was dissolved, then the other actives in the product were also in solution. Furthermore, USP provides for a less work intensive test by combining aliquots from six tests for a single determination. These unique guidelines were developed in order to keep the cost of testing multivitamins manageable. Table 2 lists the dissolution test requirements for the six USP classes of vitamins, minerals, and vitamins with minerals. 
Table 2. USP Classifications with respective dissolution test requirements.

\begin{tabular}{|l|l|}
\hline \multicolumn{1}{|c|}{ Class } & \multicolumn{1}{c|}{ Dissolution } \\
\hline I. Oil-soluble vitamins & Not required \\
\hline II. Water-soluble vitamins & One index vitamin; folic acid if present \\
\hline $\begin{array}{l}\text { III. Water-soluble vitamins with } \\
\text { minerals }\end{array}$ & $\begin{array}{l}\text { One index vitamin and one index } \\
\text { element; folic acid if present }\end{array}$ \\
\hline IV. Oil- and water-soluble vitamins & $\begin{array}{l}\text { One index water-soluble vitamin; folic } \\
\text { acid if present }\end{array}$ \\
\hline $\begin{array}{l}\text { V. Oil- and water-soluble vitamins with } \\
\text { minerals }\end{array}$ & $\begin{array}{l}\text { One index water-soluble vitamin and } \\
\text { one index element; folic acid if present }\end{array}$ \\
\hline VI. Minerals & One index element \\
\hline
\end{tabular}

In general, the dissolution conditions for index vitamins and index minerals are

* Medium: $0.1 \mathrm{~N}$ hydrochloric acid, $900 \mathrm{~mL}$

* Apparatus 1: $100 \mathrm{rpm}$ for capsules

* Apparatus 2: $75 \mathrm{rpm}$ for tablets

* Time: $1 \mathrm{hr}$.

For formulations containing $>25 \mathrm{mg}$ of the index vitamin riboflavin, the dissolution medium should be $1800 \mathrm{ml}$ of $0.1 \mathrm{~N}$ hydrochloric acid, while for folic acid, the dissolution medium should be $900 \mathrm{ml}$ of distilled water. Folic acid is the first index vitamin in the selection of an index. It is notable that folic acid performance was considered critical enough by the USP that it is tested independent of the index vitamin system. 
The USP dissolution requirements are met if at least $75 \%$ of the labeled content of folic acid and at least $75 \%$ of the assayed content of the index vitamin or index element from the units tested are dissolved in 1 hour.

The USP monographs also contained other tests to ensure the pharmaceutical quality of nutritional supplements; this includes disintegration and uniformity of the dosage. Disintegration is designed to determine dosage unit compliance with disintegration specifications set in the nutritional supplements' individual monographs. Failure of the product to disintegrate completely within thirty minutes may be indicative of an ultimate poor and variable dissolution and bioavailability of the product. Content uniformity test indicates the uniformity of the distribution of the active over the number of the dosage units in the same batch. To meet the requirement of this test, the percentage of the active ingredient relative to the label claim in the dosage unit should be within the specified percentage range in the individual monographs. This test indicates the truthfulness of the label claim, and allows one to conclude whether the dosage unit passed the dissolution specifications.

Standards for nutritional supplements were first proposed in Pharmacopeial Forum in 1993 and accepted in 1995. The standards are provided in the Official Monographs and General Chapters-General Test and Assays sections of USP 25/NF20 (35). These include chapters $<2021>$ Microbial Limit Tests, $<2040>$ Dissolution of Nutritional Supplements, $<2091>$ Weight Variation, and $<2750>$ Manufacturing Practices for Nutritional Supplements. These standard are similar to those published as cGMP's (Good Manufacturing Practices) for pharmaceuticals in 21CFR 211. The standards in USP 25/NF 20 apply only to articles that are labeled "USP". If tested, these materials must comply with USP monograph standards, including those for dissolution and potency. 
Currently, there is an increased concern about folic acid and its importance in the treatment and prevention of disease and in the decreased risk of neural tube defects during fetal development. Additionally, patients are often titrated on medications based on their regular dietary intake of folic acid-containing products (5). Folic acid is a food additive in bread products and an ingredient in both multiple and prenatal vitamins. These vitamin preparations may be either nonprescription (OTC) and prescription products. A prescription product status does not imply that the product has been assessed as a drug, only that ingredient amounts are in higher doses. It is critical to disease treatment that the folic acid content of these products be as claimed on the label.

The increasing clinical importance of folic acid and the appearance of the nutritional supplement chapter in USP raised the concern about the pharmaceutical quality of commercially available folic acid products, whether single entity or in multivitamins preparations, and their compliance to USP specification. Many of those products were on the market before the appearance of the nutritional supplements chapter in USP.

Our laboratory was the pioneer dealing with those concerns. Stout, et al tested two vitamin classes, renal multivitamins and prenatal vitamins, using USP standard disintegration methodology, as well as simulated gastric and intestinal fluids. Product failure was determined based on USP guidelines. Of renal multivitamins tested, $50 \%$ failed/ $38 \%$ passed disintegration standards under all conditions. For prenatal vitamins, 54\% failed / 31\% passed under all conditions. The results suggested potential poor bioavailability of less soluble product components due to high variability in disintegration time; it also suggested the need for further analytical studies (36). Dissolution studies performed in the three worst performing (disintegration) products by an independent laboratory confirmed that these products failed dissolution. 
In the late 1990's, other laboratories showed that a majority of prenatal products tested did not meet the minimal USP standards. Only three out of nine multivitamin products met USP specifications for folic acid release, and most of the products missed the minimum standard by a wide margin, with two products releasing less than $25 \%$ of the labeled quantity (8).

Al-Achi and York compared three formulations of folic acid capsules on the basis of weight variation, dissolution, disintegration and content uniformity. The results of these pharmaceutical tests suggested that brands of folic acid capsules might not be necessarily equivalent. Currently, there is no USP monograph for folic acid capsules. Pharmacists recommending this dosage form must exercise caution since some brands may not deliver the minimum recommended daily dose of folic acid (37).

Six prenatal vitamin supplement products and one Prenate Advance ${ }^{\circledR}$ product were tested for folic acid release (38). Of the seven products tested, Prenate Advance ${ }^{\circledR}$ and another two of the vitamin supplement products met the USP standard for folic acid release. Dissolution ranged from $78 \%$ to $110 \%$ of the labeled folic acid content. With dissolution levels ranging from $0 \%$ to $38 \%$ of the labeled claim, the remaining four products failed to achieve the USP standard. The findings for multiple lots were consistent. Dissolution levels in one of the failing products lots never rose above $10 \%$ and one lot yielded a dissolution result of zero on initial testing.

Scuhrope, et al tested eleven brands of folic acid tablets (400 mcg), available commercially in the United Kingdom, for compliance with the British Pharmacopoeia (BP) test for dissolution. The requirement of this test is that, for tablets and capsules, the amount of active ingredient released in distilled water in one hour should not be less than 70 percent of the labeled amount. Six of the eleven formulations tested passed the BP test for dissolution, while four of the 
brands failed to release 70 per cent of the labeled active drug in the first hour of the test. One of the formulations failed to disintegrate and release the active ingredient. Two of the brands that passed the test released more than 150 per cent of the nominal $400 \mathrm{ug}$ drug content, which highlights the problem of dose uniformity (39).

As noted above, failure to meet USP specifications, which ensure the pharmaceutical quality of folic acid products, is observed in high percentages among tested products. Failure to meet the disintegration and dissolution requirements may lead to a reduced bioavailability of the drug, which will eventually reduce its therapeutic or preventative effect. Folic acid is absorbed in the proximal part of the small intestine. Thus, if the folic acid dosage unit fails to disintegrate and dissolve in the stomach, this will make folic acid less available for absorption. The drug will pass through its absorption window in the upper intestine without being completely absorbed, which will reduce its bioavailability.

Finally some manufacturers include more folic acid than the labeled amount per dosage unit in order to bypass dissolution failure. However, this practice might lead to elevated blood levels of folic acid that will initiate side effects or toxicity. It is known that large amounts of folic acid alter the function of anti-epileptic drugs. Moreover, consuming a high amount of folic acid can eliminate the anemia and its symptoms, leaving individuals and their doctors without the most obvious sign of too little vitamin B-12. But an individual can continue to suffer from less noticeable neurological deterioration related to the B12 levels. Thus, high levels of folic acid can mask vitamin B-12 deficiency.

The global objective of this research is to assess the pharmaceutical performance and quality of currently marketed folic acid nutraceuticals, compare this with that of previous products, and identify those factors which contribute to product failure. Specific goals include the following: 
1) By following USP monograph standards for disintegration, dissolution, and content uniformity, the currently marketed commercial products will be assessed for complying with USP monograph standards.

2) With an interest in product performance under physiological conditions, disintegration and dissolution will also be performed in physiologically relevant fluids (simulated gastric fluid, $\mathrm{pH} \mathrm{1,} \mathrm{and} \mathrm{simulated} \mathrm{intestinal} \mathrm{fluid,} \mathrm{pH} 7.5$ ). These studies have implications for both in vivo performance, as well as future USP standard test methodologies.

3) These results (items 1 and 2 above) will be compared with the results of previous studies in this laboratory as well as in others to determine whether the pharmaceutical quality of folic acid nutraceuticals has improved since the mid1990's, since this has implications for public health.

4) Assessment will be made as to whether one type of formulation (tablet vs capsule, multivitamin vs single entity), in general, exhibits better performance than the others.

5) One or more HPLC assays will be developed and validated in the laboratory for use in assaying folic acid and its products of degradation. These assays will include those recommended in USP monograph standards for folic acid/folic acidcontaining products. Historically, HPLC assays for folic acid have been challenging to adopt from other laboratories and run reproducibly.

6) Subsequent to completion of all testing of commercial products, a failures mode analysis will be performed to identify those factors that exhibit an influence on folic acid performance (ie: $\mathrm{pH}$, excipients, hardness). This will be useful in 
gaining a mechanistic understanding of product failure. Previously published studies of folic acid products have not performed this analysis.

7) Previously published studies have also not performed studies of independent variables that may contribute to product failure. To this point, the $\mathrm{pH}$-solubility profile of folic acid, as well as its stability, will be characterized. Laboratory formulated folic acid tablets will also be manufactured in order to observe the influence of both excipients and manufacturing conditions. Constant surface area dissolution studies using laboratory formulated buffered and non-buffered folic acid tablets will be conducted, to elucidate the effect of folic acid saturation solubility on the dissolution profile and its contribution to product failure.

8) The results of the fundamental, mechanistic studies (items 6 and 7 above) will be used to recommend formulation/ manufacturing conditions that may lead to product optimization and improved pharmaceutical performance. 


\section{Chapter III \\ Materials and Methods}

Consistent with the goals of this research, two types of studies were performed:

1) Those necessary to characterize the pharmaceutical quality of commercially available folic acid products

2) Studies needed to evaluate and identify the potential causes of folic acid product failure (i.e. mechanistic studies).

In order to test the pharmaceutical quality of commercially available folic acid products, the following tests were performed:

I. Disintegration

II. Dissolution.

III. Content uniformity.

Studies done to independently assess folic acid characteristics, so as to identify product failure causes and optimize product formulation, included:

I. Solubility.

II. Stability.

III. Laboratory formulated tablet dissolution.

IV. Buffered tablets constant surface area dissolution.

\section{$\underline{\text { Materials }}$}

Below is a list of the chemicals, folic acid products and reagents prepared to carry out the tests mentioned above.
A. Chemicals: 
Hydrochloric acid 12.1 N (Fisher), HPLC grade o-phosphoric acid 85\% (Fisher), 25\% ammonium hydroxide solution in water (Fluka), sodium hydroxide (Fisher), potassium monobasic phosphate (Fisher), sodium chloride (Fisher), methyl-4-hydroxybenzoate (Fisher), HPLC grade potassium monobasic phosphate (Fluka), N-(4-aminobenzoyl-L-glutamic acid) (Fluka), HPLC grade sodium perchlorate (Fisher), 4-aminobenzoic acid (Fluka), folic acid (Sigma), diethylenetriaminepentaacetic acid (pentitic acid) (Acros Organics), HPLC grade tetrabutylammonium hydroxide 1 Molar in water (Fisher), methyl cellulose (CCC), microcrystalline cellulose (Penwest Pharmaceutical Co.), croscarmellose ( Mylan Pharmaceutical), sodium citrate (Fisher), citric acid (Fisher), and calcium stearate (Fisher), and stearic acid (Fisher)

B. Commercial nutraceuticals:

Single entity folic acid tablets: Folic Acid 400 mcg (Rite Aid), Folic Acid $400 \mathrm{mcg}$ (Kroger), Folic Acid $400 \mathrm{mcg}$ (PharmAssure), Folic Acid $400 \mathrm{mcg}$ (Nature Made), Folic Acid 400 mcg (Nature's Bounty), Folic Acid 400 mcg (Naturally Preferred), and Folic Acid $400 \mathrm{mcg}$ (GNC).

Multivitamin tablets containing folic acid: Prenatal Tablets $800 \mathrm{mcg}$ (Kroger), Prenatal Tablets $800 \mathrm{mcg}$ (Rite Aid), Prenatal $800 \mathrm{mcg}$ (Eckerd), Stuart Natal $800 \mathrm{mcg}$ (Integrity), Stuart Natal Plus $3800 \mathrm{mcg}$ (Integrity), Nephron FA $1 \mathrm{mg}$ (Nephro-Tech, INC), and Nephro-Vite $800 \mathrm{mcg}$ (R \& D Laboratory, Inc).

Multivitamin capsules containing folic acid: Nephrocaps $1 \mathrm{mg}$ (Fleming \& Company Fenton).

C. Reagents:

\section{N Hydrochloric Acid}

Exactly measured $8.3 \mathrm{ml}$ of $12.1 \mathrm{~N} \mathrm{HCl}$ was added to $50 \mathrm{ml}$ distilled water in $100 \mathrm{ml}$ volumetric flask and the volume was adjusted with distilled water.

\section{$\underline{0.2 N \text { Sodium Hydroxide }}$}

Sixteen grams of $\mathrm{NaOH}$ were placed in a 2-liter volumetric flask, distilled water was added to volume and the solution was mixed. 


\section{N Sodium Hydroxide}

Four grams of $\mathrm{NaOH}$ were placed in a $100 \mathrm{ml}$ volumetric flask and diluted with distilled water to volume and the solution was mixed.

\section{$\underline{3 \text { N Phosphoric acid }}$}

Exactly measured $16.82 \mathrm{ml}$ of $85 \%$ HPLC grade o-phosphoric acid was transferred to a $250 \mathrm{ml}$ volumetric flask, distilled water was added to volume and the solution was mixed.

\section{N Ammonium Hydroxide}

Exactly measured $111.1 \mathrm{ml}$ of $25 \%$ ammonium hydroxide solution was transferred to a $250 \mathrm{ml}$ volumetric flask, distilled water was added to volume and the solution was mixed.

\section{0\% Ammonium Hydroxide}

Forty $\mathrm{ml}$ of $25 \%$ ammonium hydroxide solution was transferred to a $100 \mathrm{ml}$ volumetric flask, distilled water was added to volume and the solution was mixed.

\subsection{Tetrabutylammonium Hydroxide in Methanol}

Twenty five $\mathrm{ml}$ of HPLC grade $1 \mathrm{M}$ tetrabutylammonium hydroxide in water solution was placed in a $50 \mathrm{ml}$ low actinic volumetric flask, HPLC grade methanol was added to volume and the solution was mixed.

\section{Reagent 1}

Tetrabutylammonium hydroxide in methanol solution (25\%) was prepared by transferring $96.4 \mathrm{ml}$ of $1 \mathrm{M}$ tetrabutylammonium hydroxide in water to a 100 ml low actinic volumetric flask. HPLC grade methanol was added to volume and the solution was mixed.

\section{Reagent 2}

Five grams of pentetic acid was transferred to a $50 \mathrm{ml}$ low actinic volumetric flask and diluted to volume with $1 \mathrm{~N}$ sodium hydroxide solution.

\section{Simulated Gastric Fluid}

Simulated gastric fluid was prepared according to USP standards (40). Six grams of sodium chloride were placed in a 3-liter round bottom flask, and $2500 \mathrm{ml}$ 
of distilled water and $21 \mathrm{ml}$ of $1 \mathrm{~N} \mathrm{HCl}$ were added. The volume was adjusted and the solution $\mathrm{pH}$ was adjusted to 1.5 with either $1 \mathrm{~N} \mathrm{HCl}$ or $0.2 \mathrm{~N} \mathrm{NaOH}$. No enzymes were added to the fluid.

\section{Simulated Intestinal Fluid}

Simulated intestinal fluid was prepared according to USP standards (40). $20.4 \mathrm{~g}$ of potassium monobasic phosphate were placed in a 3-liter round bottom volumetric flask, and $570 \mathrm{ml}$ of $0.2 \mathrm{NaOH}$ were added. The volume was adjusted with distilled water. The solution $\mathrm{pH}$ was adjusted to 7.5 with either $1 \mathrm{~N} \mathrm{HCl}$ or $0.2 \mathrm{~N} \mathrm{NaOH}$. No enzymes were added to the fluid.

\section{Methods}

\section{Testing of performance of commercially available folic acid products}

\section{Disintegration:}

Disintegration was performed according to section 701 of the USP (41) using the three basket disintegration apparatus (Vankel). The apparatus consists of a basket-rack holding six open-end glass tubes. Each is $7.75 \pm 0.25 \mathrm{~cm}$ long and has an inside diameter and wall thickness of approximately 21.5 and $2 \mathrm{~mm}$, respectively. Attached by screws to the underside of the lower plate holding the tubes are a 10 mesh stainless steel wire cloth. The basket rack is suspended through an arm immersed in a one liter beaker containing an appropriate fluid at $37 \pm 2^{\circ} \mathrm{C}$. The basket rack is raised and lowered through a distance of 5 to $6 \mathrm{~cm}$ at a rate of 28 to 32 cycles per minute. The volume of the fluid is such that, during the operation, the basket rack is never less than $2.5 \mathrm{~cm}$ below the surface of the fluid or above the bottom of the beaker. The three beakers are held within a water bath to maintain constant temperature.

To perform the test, one tablet was placed in each of the six tubes of the basket, and $900 \mathrm{ml}$ of the disintegration medium was brought to $37 \pm 2^{\circ} \mathrm{C}$. All products tested fell within USP's size diameter requirement for use of the six tube basket. In each beaker, the baskets were hung from the moving arm, centered over 
the beaker and the study begun. Disintegration was timed from the start of the arm's movement. At frequent time intervals, the apparatus was stopped, the basket was lifted from the fluid, and the tablets were evaluated for disintegration.

According to USP (41), the disintegration medium should be $900 \mathrm{ml}$ of distilled water, and disintegration should be run for thirty minutes. Complete disintegration is defined as that state in which any residue of the unit, except fragments of insoluble coating or capsule shell, remaining on the screen of the test apparatus is a soft mass having no palpably firm core. In order to meet USP specifications, six tablets should first be tested. If 1 or 2 tablets failed to disintegrate completely, the test should be repeated on an additional twelve tablets. Not less than 16 out of 18 tablets tested should disintegrate completely.

Unlike USP specifications, the test was performed in three media: simulated gastric fluid (SGF) $(\mathrm{pH}$ 1.5), simulated intestinal fluid (SIT) (pH 7.5) and distilled water (DW) ( $\mathrm{pH} 5-6$ ). The disintegration times for eighteen randomly selected tablets from each product were measured at the same time if a preliminary study of disintegration time gave disintegration time greater than 5 minutes; otherwise, six tablets were measured at a time. The test was not stopped at 30 minutes, but continued until every tablet had disintegrated completely or up to 8 hours, whichever occurred first. The same tests were applied for the multivitamin capsule product containing folic acid. Times were noted for the disintegration time of each tablet, and there times $(\mathrm{n}=18)$ averaged to determine the "average time for disintegration and variability" for that specific product. These data were then used to determine:

1. Whether the product passed the USP monograph standard for disintegration.

2. Exhibited a significantly short or long disintegration time.

3. Exhibited disintegration sensitivity to $\mathrm{pH}$ conditions.

4. Showed broad variability in disintegration to $\mathrm{pH}$ conditions. 


\section{Dissolution}

1) Dissolution for single entity folic acid tablets

Dissolution was measured using USP apparatus II and the test conditions specified for folic acid tablets in USP (41). USP apparatus II consists of a covered glass vessel that contains the dissolution medium. The tablet is placed in the vessel and the dissolution fluid is stirred at $50 \mathrm{rpm}$ with a paddle that is positioned one inch above the bottom of the dissolution vessel. The $500 \mathrm{ml}$ dissolution media was equilibrated to $37 \pm 1^{\circ} \mathrm{C}$.

To meet the USP specifications, folic acid tablets should release more than $75 \%$ of label claim in distilled water in 45 minutes (42). Unlike the USP method, which requires one end-point measurement, dissolution was followed for one hour and $0.5 \mathrm{ml}$ from the dissolution medium from each vessel of the dissolution apparatus was withdrawn every 15 minutes and transferred to a common sampling receptacle. This allowed for the generation of a more complete dissolution profile for each product. The dissolution media was replaced with fresh media after the withdrawal of each sample. Sample collection took less than two minutes. Pooled samples were filtered through $0.2 \mu \mathrm{m}$ Nylon Membrane filters (by Whatman) into an amber vial and the vial was immediately capped. Samples were assayed using the set forth HPLC assay method for single entity folic acid tablets. The assay was therefore performed on a pooled sample and provided an average of the folic acid release across the six dosage forms at every sampling point. For every product tested, dissolution was performed in three different media: simulated gastric fluid $\mathrm{pH}$ (1.5), simulated intestinal fluid $(\mathrm{pH} 7.5)$ and distilled water $(\mathrm{pH} 5-6)$. Each test was repeated three times for a total of eighteen tablets, with three pooled samples per sample point/time $(\mathrm{n}=3)$.

HPLC assay of folic acid in tablets containing only folic acid as active ingredient (42). Mobile Phase: $35.1 \mathrm{~g}$ of sodium perchlorate and $1.4 \mathrm{~g}$ of HPLC grade potassium monobasic phosphate were transferred to a 1-Liter volumetric flask, and $7.0 \mathrm{ml}$ of 
$1 \mathrm{~N}$ potassium hydroxide and $40 \mathrm{ml}$ of methanol were added .The mixture was diluted with water to volume, mixed and filtered ( 0.45 um filter). The solution $\mathrm{pH}$ was adjusted to 7.2 using either $1 \mathrm{~N}$ potassium hydroxide or $3 \mathrm{~N}$ phosphoric acid. HPLC system: The chromatographic system used consisted of the following: Pump: Waters 515 HPLC pump.

Sampler: Waters 712 WISP auto sampler.

Detector: Waters 2487 UV detector.

Integrator: Millennium 3.1 chromatography software.

Column: Beckman octyl C18 ODS/ column $4.6 \mathrm{~mm}$ x $25 \mathrm{~cm}$.

Flow rate: $1.0 \mathrm{ml} / \mathrm{min}$

Detection wavelength: $245-\mathrm{nm}$.

Folic Acid standard stock solution: Exactly $100 \mathrm{mg}$ of folic acid standard (USP) was placed in a $100 \mathrm{ml}$ low actinic volumetric flask. Two $\mathrm{ml}$ of $10 \%$ ammonium hydroxide were added to dissolve the folic acid and the volume was adjusted with mobile phase.

Standard preparation: One $\mathrm{ml}$ of folic acid stock solution was diluted to $100 \mathrm{ml}$ in the mobile phase to make a diluted stock solution $(10 \mu \mathrm{g} / \mathrm{ml})$.

Assay Preparation: Diluted stock solutions of 0.1 to $1.0 \mathrm{ml}$ were diluted to $10 \mathrm{ml}$ in distilled water to prepare standards for injection. The concentration range of the standards was 0.1 to $1.0 \mu \mathrm{g} / \mathrm{ml}$.

Method Validation: The method was validated for linearity, accuracy and reproducibility. Standard preparations were prepared and each sample was injected three times on three different days, and the area under the folic acid peak was integrated. Linearity of the calibration curve was calculated, and the relative standard deviation of the repeated injections was calculated to reflect accuracy and reproducibility. 


\section{2) Dissolution for folic acid in multivitamin dosage unit.}

Dissolution was measured using USP apparatus I for capsules and II for tablets along with the test conditions specified for folic acid tablets in the USP (disintegration and dissolution of nutritional supplements) (43). USP apparatus II consists of a covered glass vessel containing $900 \mathrm{ml}$ of dissolution fluid. The tablet is placed free in the bottom of the vessel and the dissolution fluid is stirred at 75 rpm with a paddle that is positioned one inch above the bottom of the dissolution vessel. USP apparatus I consists of a covered glass vessel containing $900 \mathrm{ml}$ of dissolution fluid. The vessel is partially immersed in a suitable water bath placed in a heating jacket. The tablet is placed within the basket positioned one inch above the bottom of the dissolution vessel and the vessel is held by a shaft that rotates and stirs the dissolution medium at $100 \mathrm{rpm}$. The $900 \mathrm{ml}$ dissolution media was equilibrated to $37 \pm 1^{\circ} \mathrm{C}$.

In order to meet USP standards, $75 \%$ of the label amount of folic acid must be released out of the multivitamin unit in 60 minutes (43). Unlike the USP method, which gives a single point measurement, dissolution was followed for one hour and $0.5 \mathrm{ml}$ from the dissolution medium from each vessel of the dissolution apparatus was withdrawn every 15 minutes and transferred to a common sampling receptacle. This allowed for the generation of a more complete dissolution profile. The dissolution media was replaced with fresh media after the withdrawal of each sample; sample collection took less than two minutes. Pooled samples were filtered through $0.2 \mu \mathrm{m}$ Nylon Membrane filters (by Whatman) into an amber vial and the vial was immediately capped. Samples were assayed using the set forth HPLC assay of folic acid as an ingredient of pharmacopeial preparations containing other active constituents (44). The assay was therefore performed on a pooled sample and provided an average of the folic acid release across the six dosage forms. For each product tested, dissolution was performed in three different media: simulated gastric fluid ( $\mathrm{pH} 1.5)$, simulated intestinal fluid $(\mathrm{pH} 7.5)$ 
and distilled water ( $\mathrm{pH} 5-6)$. Each test was repeated three times for a total of eighteen tablets, with three pooled samples per sampling point/ time $(\mathrm{n}=3)$.

\section{HPLC assay of folic acid as an ingredient of pharmacopeial preparations} containing other active constituents (44).

Mobile phase: $2.0 \mathrm{~g}$ of monobasic potassium phosphate were placed in 1-liter volumetric flask, and dissolved in about $650 \mathrm{ml}$ of distilled water. $12.0 \mathrm{ml}$ of $25 \%$ tetrabutylammonium hydroxide in methanol, $7.0 \mathrm{ml}$ of $3 \mathrm{~N}$ phosphoric acid, and $240 \mathrm{ml}$ of methanol were added. The solution was allowed to cool to room temperature, then adjusted with either $3 \mathrm{~N}$ phosphoric acid or $6 \mathrm{~N}$ ammonium hydroxide to a $\mathrm{pH}$ of 7 and mixed. The solution was then filtered using a $0.45 \mathrm{um}$ filter and the $\mathrm{pH}$ was rechecked before use.

HPLC system: The chromatographic system used consisted of the following: Pump: Waters 515 HPLC pump.

Sampler: Waters 712 WISP auto sampler.

Detector: Waters 2487 UV detector.

Integrator: Millennium 3.1 chromatography software.

Column: Nova-Pak Waters C18 / column $3.5 \mathrm{~mm}$ x $15 \mathrm{~cm}$.

Flow rate: $1.0 \mathrm{ml} / \mathrm{min}$

Detection wavelength: $280-\mathrm{nm}$.

Diluting solvent: $200 \mathrm{mg}$ of monobasic potassium phosphate was placed in a 100 $\mathrm{ml}$ low actinic volumetric flask and dissolved in approximately $60 \mathrm{ml}$ of distilled water. Then, $22 \mathrm{ml}$ of methanol, $1.9 \mathrm{ml}$ of reagent $1,0.7 \mathrm{ml}$ of $3 \mathrm{~N}$ phosphoric acid, and $3 \mathrm{ml}$ of reagent 2 were added to the mixture and the $\mathrm{pH}$ was adjusted to a $\mathrm{pH}$ of 9.8. Nitrogen was bubbled through the solution for 30 minutes.

Internal standard solution: $25.0 \mathrm{mg}$ of methylparaben was dissolved in $2.0 \mathrm{ml}$ of methanol, diluted with the diluting solvent described above to $50 \mathrm{ml}$ and mixed. 
Standard folic acid solution: Accurately weighed $20 \mathrm{mg}$ of folic acid standard (USP) was placed in a $100 \mathrm{ml}$ low actinic volumetric flask and dissolved in the diluting solvent described above.

Standard Preparation: $2.0 \mathrm{ml}$ of standard folic acid solution was transferred to a low actinic, $50 \mathrm{ml}$ volumetric flask. $2.0 \mathrm{ml}$ of the internal standard solution was added and the solution was adjusted to volume with the diluting solvent described above and mixed.

Assay for injection: Standard preparation solutions of 0.5 to $5.0 \mathrm{ml}$ were diluted to $10 \mathrm{ml}$ in distilled water to prepare standards for injection. The concentration range of the standards was 0.2 to $2.0 \mu \mathrm{g} / \mathrm{ml}$.

Method Validation: The method was validated for linearity, accuracy and reproducibility. Standard preparations were prepared and each sample was injected three times on three different days, and the area under the folic acid peak was integrated. Linearity of the calibration curve was calculated, and the relative standard deviation (i.e. coefficient of variation $=(\mathrm{SD} /$ average $) \mathrm{X} 100)$ of the repeated injections was calculated to reflect accuracy and reproducibility.

\section{Uniformity of dosage units.}

The uniformity of dosage units can be demonstrated by either of two methods, weight variation or content uniformity. A content uniformity test is performed to ensure that the folic acid containing dosage unit does not have less or more than the specified percent of folic acid relative to label claim.

1) Content uniformity determination of single entity folic acid tablets:

To meet USP requirements, folic acid tablets should contain not less than 90.0 percent and not more than 115.0 percent of the labeled folic acid amount (42).

Twenty-five tablets of commercially available single entity folic acid products equivalent to $10 \mathrm{mg}$ of folic acid were finely powdered and transferred to a $50 \mathrm{ml}$ volumetric flask. A solvent containing $1 \mathrm{~g}$ of sodium perchlorate and $2 \mathrm{ml}$ 
of $10 \%$ ammonium hydroxide dissolved in $100 \mathrm{ml}$ distilled water was used to dilute the powdered folic acid tablets. The mixture was shaken gently until folic acid had dissolved and adjusted to volume with the same solvent. The mixture was filtered by using a dry filter and discarding the first portion of the filtrate. A portion of the clear filtrate was diluted quantitatively and stepwise with the same solvent mentioned above to obtain a solution having approximated concentration of 0.05 to $0.2 \mathrm{mg} / \mathrm{ml}$. Folic acid standards for injection in the concentration range of $0.05-0.2 \mathrm{mg} / \mathrm{ml}$ were prepared as described under the HPLC assay of folic acid in single entity tablets (p.27). A folic acid calibration curve was first constructed, then the assay preparations were analyzed. Both the standard preparations and the assay preparation were injected in equal volumes in the HPLC system described for the single entity folic acid tablets (p.27), and the response of the major peak recorded. The area under the major peak was integrated. The procedure described (i.e. injection of standard and assay preparations) above was repeated three times.

Average amount of folic acid per tablet was calculated by:

1. Determining sample concentration from calibration curve.

2. Adjusting for sample dilutions.

3. Divide by twenty five to obtain amount per tablet.

Content uniformity determination of folic acid in multivitamin dosage unit:

To meet the USP requirements for the uniformity of the dosage form, folic acid containing multivitamin tablets should contain, on average, not less than $90.0 \%$ and not more than $150.0 \%$ of the labeled folic acid amount (43).

Internal standard preparation: Accurately weighed $40 \mathrm{mg}$ of methylparaben was transferred to a 1-liter volumetric flask, and $220 \mathrm{ml}$ of methanol was added to dissolve the methylparaben. In a separate beaker, $2.0 \mathrm{~g}$ of monobasic potassium phosphate was dissolved in about $300 \mathrm{ml}$ of distilled water. This solution was quantitatively transferred to the flask containing the methylparaben solution, and then an additional $300 \mathrm{ml}$ of distilled water was added. $19 \mathrm{ml}$ of Reagent 1, $7.0 \mathrm{ml}$ 
of $3 \mathrm{~N}$ phosphoric acid, and $30 \mathrm{ml}$ of Reagent 2 were added. The solution $\mathrm{pH}$ was adjusted to 9.8 using $6 \mathrm{~N}$ ammonium hydroxide. Nitrogen was bubbled though the solution for 30 minutes and the solution was diluted with distilled water to volume and mixed.

Assay Preparation: 30 tablets of commercially available multivitamin dosage unit containing folic acid were weighed and finely powdered. Three portions of the powder, equivalent to about $0.4 \mathrm{mg}$ of folic acid, were weighed. Each portion was placed in a $50 \mathrm{ml}$ amber-colored centrifuge tube. $25.0 \mathrm{ml}$ of internal standard solution preparation were added, a stopper was added, and the mixture was shaken for ten minutes and centrifuged for ten minutes at $4000 \mathrm{rpm}$. A portion of the clear supernatant fluid was filtered and used for assay.

Standard preparation: Folic acid standard solutions in the concentration range 10$40 \mu \mathrm{g} / \mathrm{ml}$ were prepared as indicated in the standard preparation under HPLC assay of folic acid as an ingredient of pharmacopeial preparations (p.30).

Procedure: Folic acid standards were used to construct a calibration curve then the assay preparations were analyzed. Folic acid standard and assay preparations were injected separately in equal volumes in the chromatographic system described under the HPLC assay of folic acid as an ingredient of pharmacopeial preparations (p.30). The response of the major peak was recorded and the area under the peak was integrated.

Average amount of folic acid per tablet was calculated by:

1. Determining sample concentration from calibration curve.

2. Adjusting for sample dilutions.

3. Divide by thirty to obtain amount per tablet.

\section{Product failure analysis: Independent studies}

\section{Solubility}

As an acid, folic acid is expected to have a higher solubility in basic $\mathrm{pH}$ than in acidic $\mathrm{pH}$. In order to determine the solubility of folic acid in different 
$\mathrm{pHs}$, a solubility-pH profile of folic acid was generated by measuring the solubility of folic acid at five different $\mathrm{pH}$ 's in buffers at $\mathrm{pH} 1,3,4,7$ and 10 (Table 3) .

\begin{tabular}{|c|c|}
\hline $\mathrm{pH}$ & Buffer Composition \\
\hline 1 & $25 \mathrm{ml}$ of $0.2 \mathrm{M} \mathrm{KCl}+67.0 \mathrm{ml}$ of $0.2 \mathrm{M} \mathrm{HCl}$. \\
\hline 3 & $50 \mathrm{ml}$ of $0.1 \mathrm{M}$ potassium hydrogen phthalate $+22.3 \mathrm{ml}$ of $0.1 \mathrm{M} \mathrm{HCl}$. \\
\hline 4 & $50 \mathrm{ml}$ of $0.1 \mathrm{M}$ potassium hydrogen phthalate $+0.1 \mathrm{ml}$ of $0.1 \mathrm{M} \mathrm{HCl}$. \\
\hline 7 & $50 \mathrm{ml}$ of $0.1 \mathrm{M}$ potassium monobasic phosphate $+29.1 \mathrm{ml}$ of $0.1 \mathrm{M} \mathrm{NaOH}$. \\
\hline 10 & $50 \mathrm{ml}$ of $0.025 \mathrm{M}$ borax $+18.3 \mathrm{ml}$ of $0.1 \mathrm{M} \mathrm{NaOH}$. \\
\hline
\end{tabular}

Table 3. Composition of the buffers.

Using a 50-ml volumetric flask, a saturated solution of folic acid was prepared in a buffer at each $\mathrm{pH}$, by adding an excess amount of folic acid. The flasks were then placed in a water bath maintained at $37 \pm 1{ }^{\circ} \mathrm{C}$ with constant shaking. Samples from each flask were withdrawn every day, diluted with mobile phase and assayed using the set forth HPLC assay method for folic acid. The measurement was stopped when the folic acid concentration was constant for three consecutive days, indicative of the solution reaching a saturated state. The HPLC chromatograms were checked for presence of degradation products every time samples were assayed, by observing the presence of any representative peaks. Saturation solubility was calculated by determining the samples concentration from calibration curve and adjusting for sample dilutions.

HPLC assay of folic acid (45)

Mobile phase: $2.0 \mathrm{~g}$ of HPLC grade monobasic potassium phosphate were placed in a 1-liter volumetric flask, and dissolved in about $650 \mathrm{ml}$ of distilled water. 7.0 $\mathrm{ml}$ of $3 \mathrm{~N}$ phosphoric acid, $15.0 \mathrm{ml}$ of solution of $0.5 \mathrm{~N}$ tetrabutylammonium 
hydroxide in methanol, and $270 \mathrm{ml}$ of methanol were added. The solution was allowed to cool to room temperature, then adjusted with either $3 \mathrm{~N}$ phosphoric acid or $6 \mathrm{~N}$ ammonium hydroxide to a $\mathrm{pH}$ of 5 and mixed. The solution was then filtered using a $0.45 \mu \mathrm{m}$ filter and $\mathrm{pH}$ was rechecked before use.

HPLC system: The chromatographic system used consisted of the following:

Pump: Waters 515 HPLC pump.

Sampler: Waters 712 WISP auto sampler.

Detector: Waters 2487 UV detector.

Integrator: Millennium 3.1 chromatography software.

Column: Agilent Hypersil C18 ODS/ column $4.0 \mathrm{~mm}$ x $25 \mathrm{~cm}$.

Flow rate: $1.2 \mathrm{ml} / \mathrm{min}$

Detection wavelength: $280 \mathrm{~nm}$.

Internal standard solution: $50.0 \mathrm{mg}$ of methylparaben was dissolved in a $1.0 \mathrm{ml}$ of methanol, diluted with the mobile phase to $50 \mathrm{ml}$ and mixed.

Standard folic acid solution: Accurately weighted $100 \mathrm{mg}$ of folic acid standard (USP) was transferred to a $100 \mathrm{ml}$ low actinic volumetric flask; $2 \mathrm{ml}$ of $10 \%$ ammonium hydroxide was added to dissolve the folic acid. The solution was adjusted to volume with the mobile phase.

Standard Preparation: $2.0 \mathrm{ml}$ of standard folic acid solution was transferred to a low actinic $50 \mathrm{ml}$ volumetric flask. $4.0 \mathrm{ml}$ of the internal standard solution was added and the solution was adjusted to volume with the mobile phase and mixed. Standards for injection: Standard preparation solutions of 0.125 to $5.0 \mathrm{ml}$ were diluted to $10 \mathrm{ml}$ in distilled water to prepare standards for injection. The concentration range of the standards was 0.0005 to $0.2 \mathrm{mg} / \mathrm{ml}$.

Method Validation: The method was validated for linearity, accuracy and reproducibility. Standard preparations were prepared and each sample was injected three times in three different days, and the area under the folic acid peak was integrated. Linearity of the calibration curve was calculated, and the relative 
standard deviation (i.e. coefficient of variation $=(\mathrm{SD} /$ average $) \mathrm{X} 100)$ of the repeated injections was calculated to reflect accuracy and reproducibility.

\section{Degradation.}

The folic acid HPLC assay (p34) was tested for its ability to detect paminobenzoyl-L-glutamic acid and p-aminobenzoic acid peaks. The two degradation products were obtained from Fluka. In aqueous solution, paminobenzoyl-L-glutamic acid and pterine-6-carboxylic acid are the major degradation products of folic acid, along with traces of p-aminobenzoic acid (47).

Stock solutions were prepared of each of them in the same manner described for folic acid in page 34. Different dilutions of the two compounds in the concentration range $1-25 \mathrm{ug} / \mathrm{ml}$ were prepared and assayed by the folic acid HPLC assay. Mixtures of the two compounds with folic acid and methylparaben in different proportions were also prepared and assayed using the folic acid HPLC assay, in order to simulate the folic acid degradation process. The obtained chromatograms were visually inspected for resolution and ability to pick up degradation products in low proportions. Regression analysis of the area under the peaks was performed to validate the ability of the method to quantitatively measure those degradation products.

The HPLC assay for folic acid in single entity dosage units (p.27) was also tested for its ability to detect folic acid degradation products. To perform this, folic acid standard solution $(1 \mathrm{mg} / \mathrm{ml})$ was prepared in the same manner described for folic acid on page 27 . Then, this solution was diluted to $100 \mu \mathrm{g} / \mathrm{ml}$ with distilled water, and assayed using the HPLC assay for folic acid in single entity dosage units. The solution was then placed in a capped transparent glass container, and maintained at room temperature to induce degradation of folic acid. Samples from this solution were withdrawn and assayed every day until the folic acid peak disappeared. The obtained chromatograms were visually inspected for resolution 
between the diminishing folic acid and the increasing folic acid degradation products peaks.

\section{Laboratory-prepared tablet formulations}

To determine whether the formulation excipients have pronounced effect on the dissolution of folic acid tablets in simulated gastric fluid, laboratory formulated folic acid tablets ( 800 and $600 \mathrm{mcg}$ ) were prepared, starting with folic acid and filler. Other excipients were then selected based either on their use in the commercial products or their functional use. Exipients were then added to the formulation, as listed in Table 4.

\begin{tabular}{|c|l|c|c|}
\hline \multicolumn{1}{|c|}{ Ingredients } & $\begin{array}{c}\text { Tablet Weight } \\
(\mathrm{mg})\end{array}$ & FA (mcg) \\
\hline M & MC + FA & 400 & 800 \\
\hline M1 & MC + FA + Stearic Acid (1\%) & 400 & 800 \\
\hline M2 & MC + FA+ Stearic Acid (5\%) & 400 & 800 \\
\hline M3 & MC + FA+ Calcium Stearate (1\%) & 400 & 800 \\
\hline M4 & MC + FA +Calcium Stearate (5\%) & 400 & 800 \\
\hline M5 & $\begin{array}{l}\text { MC + FA+ Calcium Stearate (1\%)+ } \\
\text { Croscarmellose (10\%) }\end{array}$ & 400 & 800 \\
\hline A & MCC+ FA & 300 & 600 \\
\hline A1 & MCC+FA + Stearic Acid (1\%) & 300 & 600 \\
\hline A2 & MCC + FA+ Stearic Acid (5\%) & 300 & 600 \\
\hline A3 & MCC + FA + Calcium Stearate (1\%) & 300 & 600 \\
\hline A4 & MCC + FA+ Calcium Stearate (5\%) & 300 & 600 \\
\hline A5 & $\begin{array}{l}\text { MCC + FA+ Calcium Stearate (1\%)+ } \\
\text { Croscarmellose(10\%) }\end{array}$ & 300 & 600 \\
\hline NBT & MC + FA & 400 & 800 \\
\hline BT & $\begin{array}{l}\text { MC + FA +25\% citrate buffer (sodium } \\
\text { citrate and citric acid 2:1) }\end{array}$ & 400 & 800 \\
\hline
\end{tabular}

MC: Methyl Cellulose.

FA: Folic Acid.

MCC: Microcrystalline Cellulose.

NBT: Non-Buffered Tablets.

BT: Buffered Tablets.

Table 4. Folic acid laboratory formulated tablets composition 
Folic acid tablets were manufactured in the following manner. First, $16 \mathrm{mg}$ of folic acid were accurately weighed. Then, the other inactive ingredients were also accurately weighed according to their desired percentage in the total batch weight. All the weighed powders were transferred to a V-shaped mixer and were mixed manually (200 revolutions); this number of revolutions provides a homogenous mixing for the formulation ingredients. The total weight of each batch was eight grams.

An accurately weighed portion of the powder $(0.3 \mathrm{~g}$ or $0.4 \mathrm{~g})$ was transferred to a stainless steel die. The powder was then compressed for 10 seconds using a Carver laboratory press. The tablets were visually inspected to confirm that they were free from flaws, such as lamination and capping. All tablets were made twenty four hours prior to the dissolution run, and kept under a clean inverted $25 \mathrm{ml}$ beaker until the time of the run. Eighteen tablets were made in each batch. All the produced tablets were weighed. Six tablets were tested for hardness using a Vector / Schleuniqer hardness tester. The remaining tablets were tested for dissolution in the same manner mentioned for single entity folic acid tablets (p.27). The products' dissolution profiles were compared to assess whether an individual excipient (i.e. lubricant) or manufacturing condition (i.e. mixing time) might contribute to the dissolution failure of folic acid tablets.

\section{Self-Buffering tablets and constant surface area dissolution.}

To determine whether the saturation solubility of folic acid as a function of $\mathrm{pH}$ influences the dissolution of folic acid, a buffered tablet was formulated for constant surface area dissolution. Two folic acid formulations were prepared. One contained folic acid and methyl cellulose, and the other contained folic acid, methyl cellulose and $25 \%$ citrate buffer sodium citrate and citric acid 2:1 (Table 4). In a separate experiment, the $\mathrm{pH}$ of this buffer was measured to be 4.5. Folic acid tablets from each formulation were prepared the same way described above 
for laboratory tablet formulations. The tablet was then compressed into the die so that the exposed surface of the tablet was flush with the die opening.

The die, holding the tablet, was then hung in a beaker containing simulated gastric fluid kept at $37 \pm 1{ }^{\circ} \mathrm{C}$ by a water bath, with no stirring, and remained in the die for the study. This configuration allows the dissolution to be measured from a constant surface area, eliminating particulate surface area changes. It allows for a more sensitive measure of the effect of concentration gradient and solubility upon dissolution kinetics. Samples were withdrawn frequently directly from the area below the surface of tablet and assayed by HPLC assay for single entity folic acid tablets (p.27). Samples were withdrawn at 0, 15, 30, 45, 60, 75, 90, 120, 180, 240, and 300 minutes, and a dissolution profile generated. The profiles for the non and self-buffered tablets were compared to assess the influence of surface $\mathrm{pH}$ on folic acid release kinetics. 


\section{Chapter IV}

\section{Results and Discussion}

\section{Assay Development}

Quantitative analysis of folic acid is usually associated with analytical problems. The compound is easily oxidized and is decomposed in the presence of light, high temperature and metal ions (46). HPLC analysis with UV detection is the most effective method for folic acid quantification, since folic acid fluoresces after activation by ultraviolet radiation (47). However, nine different HPLC assay methods have been reported for folic acid HPLC assay (48).

Folic acid HPLC analysis is not a straight forward procedure that can be performed easily. Sensitivity and high background noise are analytical problems in the folic acid assay. The glassware used should be low actinic, so as to reduce the degradation of folic acid catalyzed by light. The low solubility of folic acid in water makes stock solutions difficult to prepare. Alkalinization of folic acid solutions (usually with $10 \% \mathrm{NH}_{3}$ ) enhances solubilization.

Modification of the reported methods is a strategy to improve the quality of the assay. Modifications might be sometimes mandatory depending on the instrument used and operating conditions. Validation of the method is required, along with generation of a calibration curve with each assay of unknown samples.

The HPLC methods used were validated for linearity, precision and reproducibility. The linearity of the method is a measure of how well a calibration plot response against concentration approximates a straight line. Reproducibility ensures that same response will be produced for a certain concentration each time the assay is performed. Precision is indicated by low variation upon repeated injections. 


\section{HPLC assay of folic acid}

The dependence of detector response on the amount of the injected folic acid was examined to determine which of the elaborated conditions for HPLC folic acid assay described in chapter III are most favorable for the assay of folic acid. This dependence was examined in the concentration range $0.5 \mu \mathrm{g} / \mathrm{ml}$ to 200 $\mu \mathrm{g} / \mathrm{ml}$, which covers the solubility range of folic acid at different $\mathrm{pH}$ values. Folic acid solutions were prepared at the following concentrations: $0.5 \mu \mathrm{g} / \mathrm{ml}, 1.0 \mu \mathrm{g} / \mathrm{ml}$, $6.25 \mu \mathrm{g} / \mathrm{ml}, 12.5 \mu \mathrm{g} / \mathrm{ml}, 25.0 \mu \mathrm{g} / \mathrm{ml}, 37.5 \mu \mathrm{g} / \mathrm{ml}, 50 \mu \mathrm{g} / \mathrm{ml}, 75 \mu \mathrm{g} / \mathrm{ml}, 100 \mu \mathrm{g} / \mathrm{ml}$, $150 \mu \mathrm{g} / \mathrm{ml}$ and $200 \mu \mathrm{g} / \mathrm{ml}$. Each solution was injected on the column three times. The described solutions were freshly prepared three times at three different days and the area under the peak of folic acid was integrated. The linear dependence of detector response on the folic acid concentration was obtained. The regression coefficient was 0.999 (Figure 3). The method accuracy and reproducibility in the linear range was also determined on the basis of the relative standard deviation. For all the tested solutions, the coefficient of variation was less than $3 \%$ upon repeated injections (Table 5). Retention time was 12.0 minutes for folic acid and 24 minutes for methylparaben. 


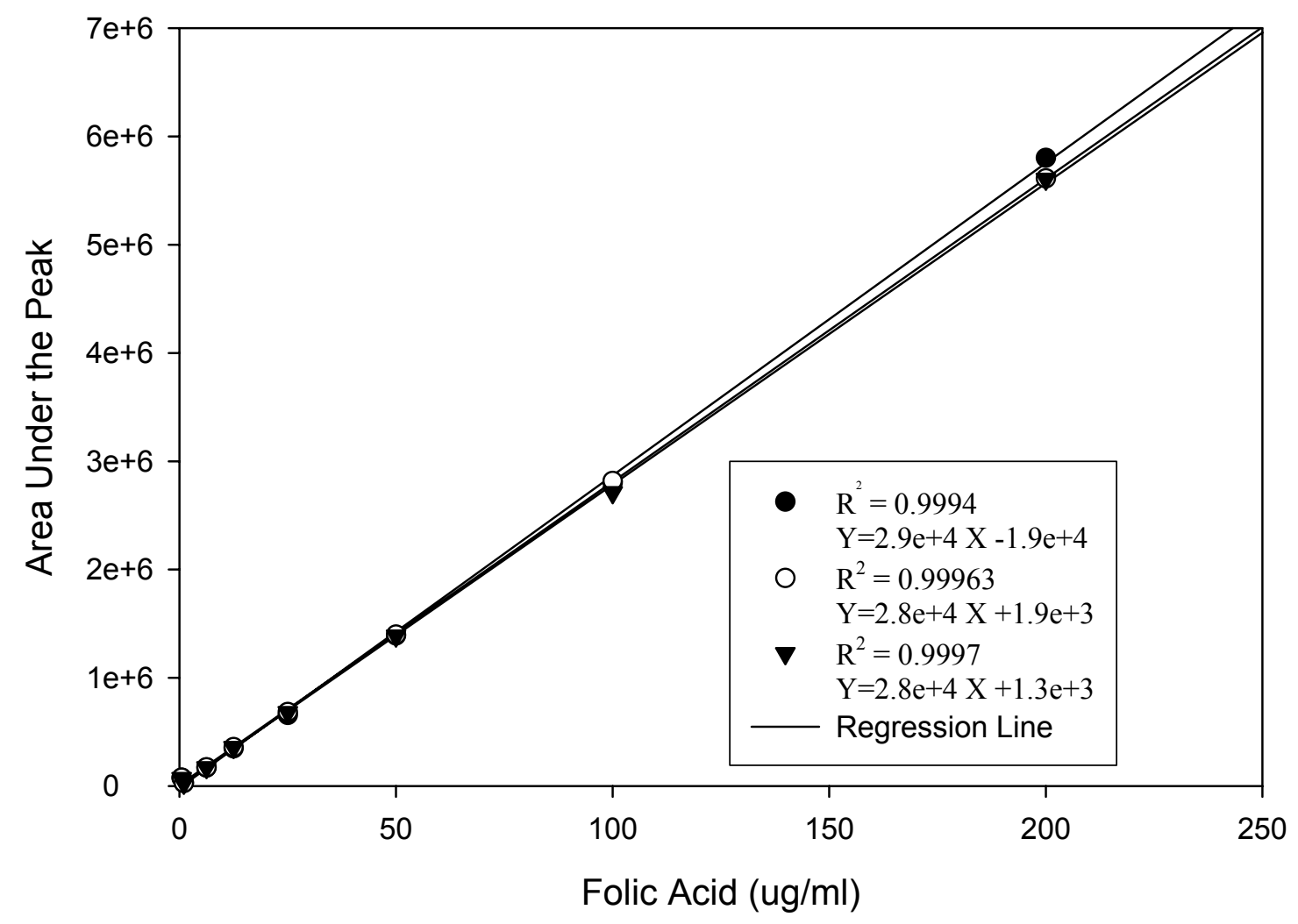

Figure 3.The linearity of folic acid HPLC assay.

\begin{tabular}{|c|c|}
\hline $\begin{array}{c}\text { Folic Acid } \\
(\mu \mathrm{g} / \mathrm{ml})\end{array}$ & $\mathrm{CV}$ \\
\hline 0.5 & 2.26 \\
\hline 1.0 & 1.18 \\
\hline 6.25 & 0.94 \\
\hline 12.5 & 1.74 \\
\hline 25 & 2.23 \\
\hline 50 & 0.37 \\
\hline 100 & 2.08 \\
\hline 200 & 1.97 \\
\hline
\end{tabular}

Table 5. Coefficients of variation of HPLC folic acid assay. 


\section{HPLC assay for single entity folic acid tablets.}

Individual standard solutions of folic acid in the concentrations $0.1 \mu \mathrm{g} / \mathrm{ml}$, $0.2 \mu \mathrm{g} / \mathrm{ml}, 0.4 \mu \mathrm{g} / \mathrm{ml}, 0.8 \mu \mathrm{g} / \mathrm{ml}$, and $1.6 \mu \mathrm{g} / \mathrm{ml}$ were prepared. This is the concentration range where single entity folic acid tablet dissolution data are expected to occur. In each set of the standard solutions, a linear relationship between the area under the peak and concentration was observed in the specified range. Regression analysis of the data $(n=3)$ are reported in Figure 4. The results showed good accuracy and reproducibility, as revealed by the coefficient of variation (Table 6). The retention time for folic acid was 10.0 minutes ( no internal standard was used for this assay).

\begin{tabular}{|c|c|}
\hline $\begin{array}{c}\text { Folic Acid } \\
(\mu \mathrm{g} / \mathrm{ml})\end{array}$ & CV \\
\hline 0.1 & 2.18 \\
\hline 0.2 & 1.21 \\
\hline 0.4 & 2.41 \\
\hline 0.6 & 0.25 \\
\hline 0.8 & 1.38 \\
\hline 1 & 2.77 \\
\hline 1.6 & 0.97 \\
\hline
\end{tabular}

Table 6. Coefficients of variation of single entity folic acid tablets HPLC assay. 


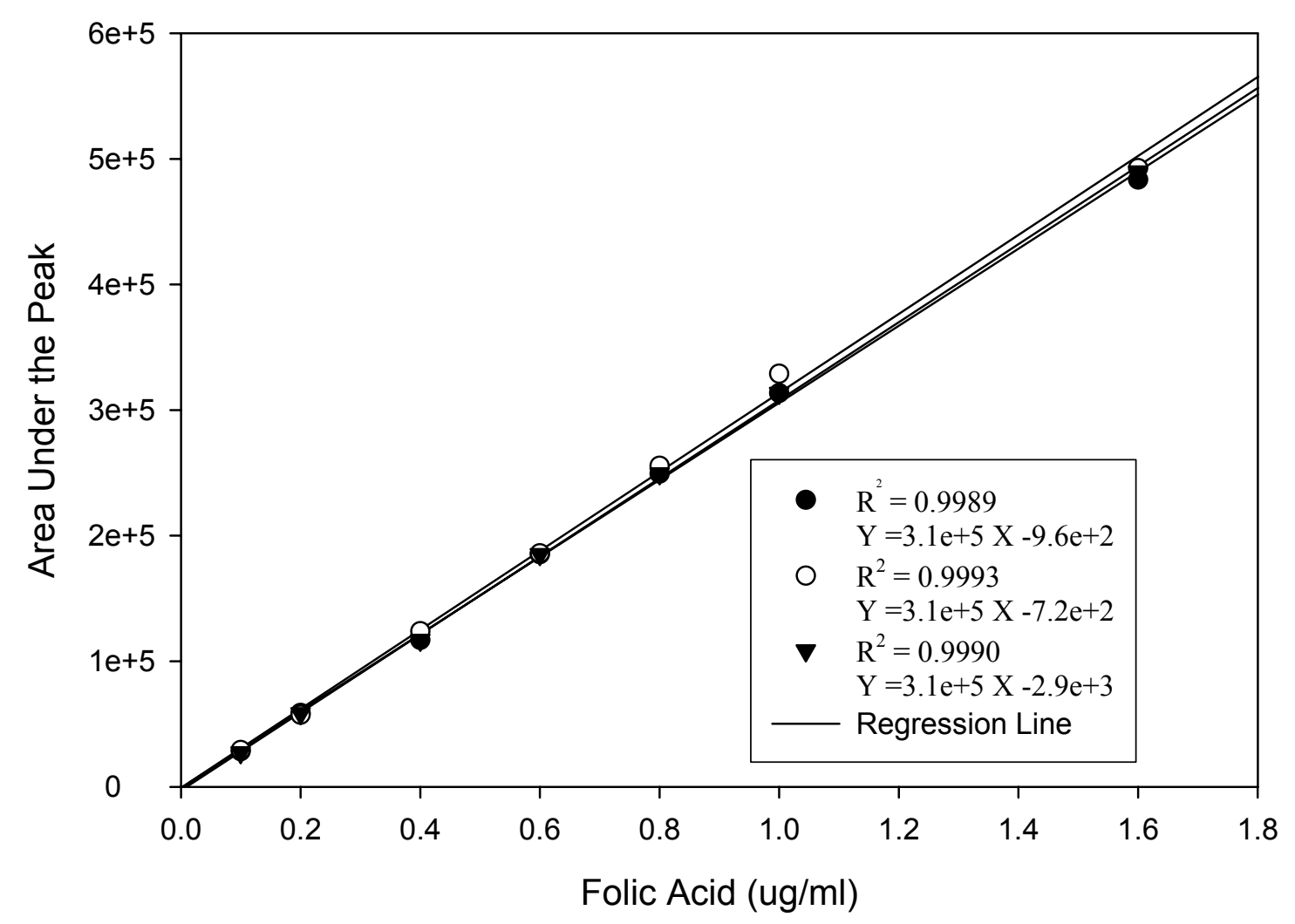

Figure 4. The linearity of single entity folic acid HPLC assay.

\section{Ability of the assay methods to detect degradation products.}

Folic acid is sensitive to heat, light and $\mathrm{pH}$. It degrades by hydrolysis and photolysis. In aqueous solution, p-aminobenzoyl-L-glutamic acid and pterine-6carboxylic (Figure 5) acid are the major degradation products of folic acid, along with traces of p-aminobenzoic acid (47).

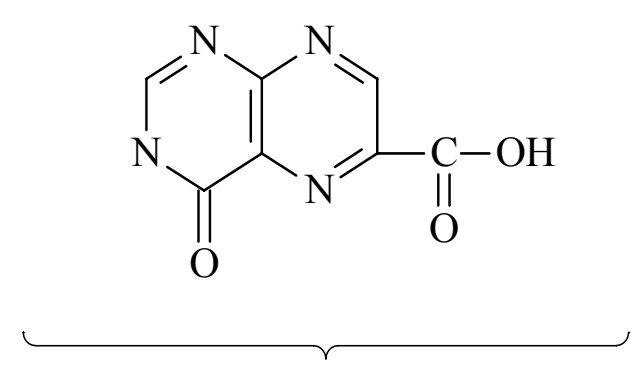

Pterine-6-carboxylic acid

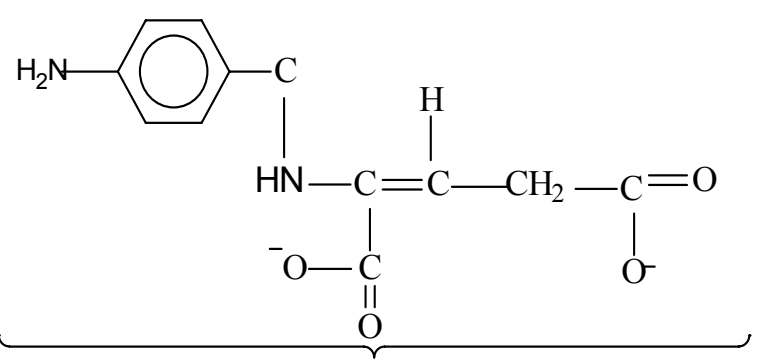

p-aminobenzoyl-L-glutamic acid

Figure 5. Pterine-6-carboxylic acid and p-aminobenzoyl-L-glutamic acid structures. 
Degradation of the active ingredient, whether it is during the formulation process or in the final dosage unit, might be the reason behind failure of the dosage unit to meet the dissolution requirement; i.e. the amount of active ingredient available for dissolution is less than the label claim due to loss of the active by degradation. To address that, the HPLC methods being used were assessed for their ability to detect at least one of the degradation products, so as to determine qualitatively and quantitatively if major loss of the active ingredient had occurred.

The folic acid HPLC assay was evaluated for its ability to detect paminobenzoyl-L-glutamic acid and p-aminobenzoic acid. The two degradation products were obtained from Fluka. Stock solutions were prepared of each of them in the same manner described for folic acid (p 34). Dilutions of the two compounds in the concentration range of $1-25 \mu \mathrm{g} / \mathrm{ml}$ were prepared and assayed by folic acid HPLC assay.

Regression analysis of the data $(n=3)$ indicated the validity of the method to detect the presence of the two degradation products, with $\mathrm{r}^{2}$ values obtained $>0.99$ and $\mathrm{RSD}<5 \%$ upon replicate sample analysis. A mixture of the two degradation products with folic acid was prepared in different proportions and measured. The results showed a good resolution and separation between the peaks. Peaks corresponding to traces of $\mathrm{p}$-aminobenzoic acid and p-aminobenzoyl-Lglutamic acid ( $\sim 3.0 \%$ of the total solution) were detected. Retention times were 3.7, 6.0 and 12.0 minutes for p-aminobenzoic acid, p-aminobenzoyl-L-glutamic acid, and folic acid, respectively (Figure 6). These results demonstrated the sensitivity of the assay for folic acid to the presence of degradation products in pure drug samples (for example, saturation solubility studies) and the assay's ability to quantitate these products. 


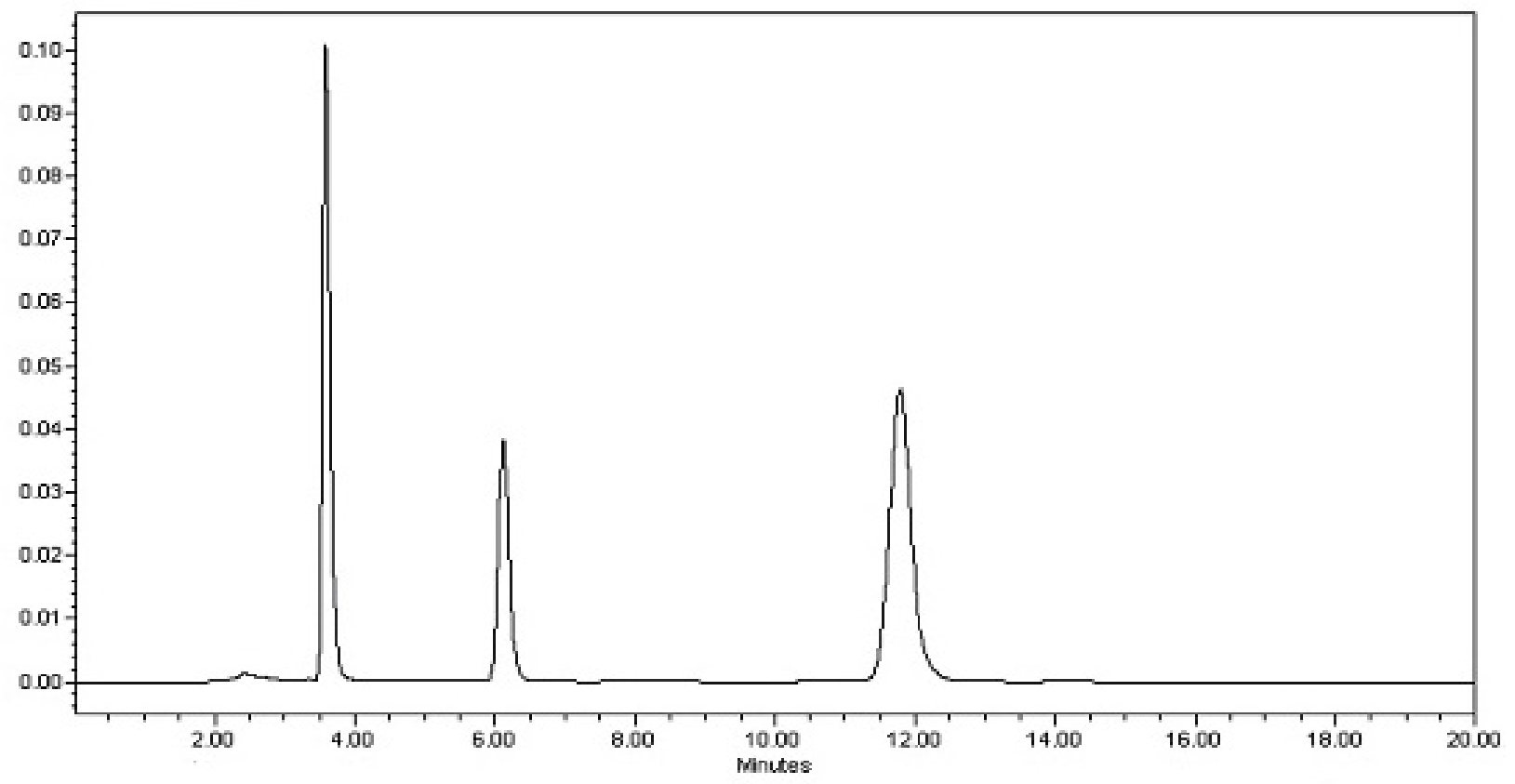

Figure 6. Chromatogram of mixture of p-aminobenzoic acid ( $5 \mu \mathrm{g} / \mathrm{ml}) \mathrm{p}$-aminobenzoylL-glutamic acid $(5 \mu \mathrm{g} / \mathrm{ml})$ and folic acid $(5 \mu \mathrm{g} / \mathrm{ml})$.

The HPLC assay for folic acid in single entity dosage units was also tested for its ability to detect folic acid degradation products. To perform this, folic acid standard solution $(1 \mathrm{mg} / \mathrm{ml})$ was prepared in the same manner described on page 27. Then, this solution was diluted to $100 \mu \mathrm{g} / \mathrm{ml}$ with distilled water, and assayed using the HPLC assay for folic acid in single entity dosage units. The solution was then placed in a capped transparent glass container, and kept at room temperature to induce degradation of folic acid. Samples from this solution were withdrawn and assayed every day until the folic acid peak (RT 10.3 minutes) was reduced by $>90 \%$ Two peaks other than the folic acid peak were obtained, corresponding to p-aminobenzoyl-L-glutamic acid (RT 2.8 minutes) and pterine-6-carboxylic acid (RT 5.5 minutes), respectively (Figure 7). Since pterine-6-carboxylic acid was not available commercially, no calibration curves were generated for this degradation product in this study. However, the study did demonstrate a sensitivity of the HPLC assay method for single entity dosage units to the presence of these two degradation products. 
A.

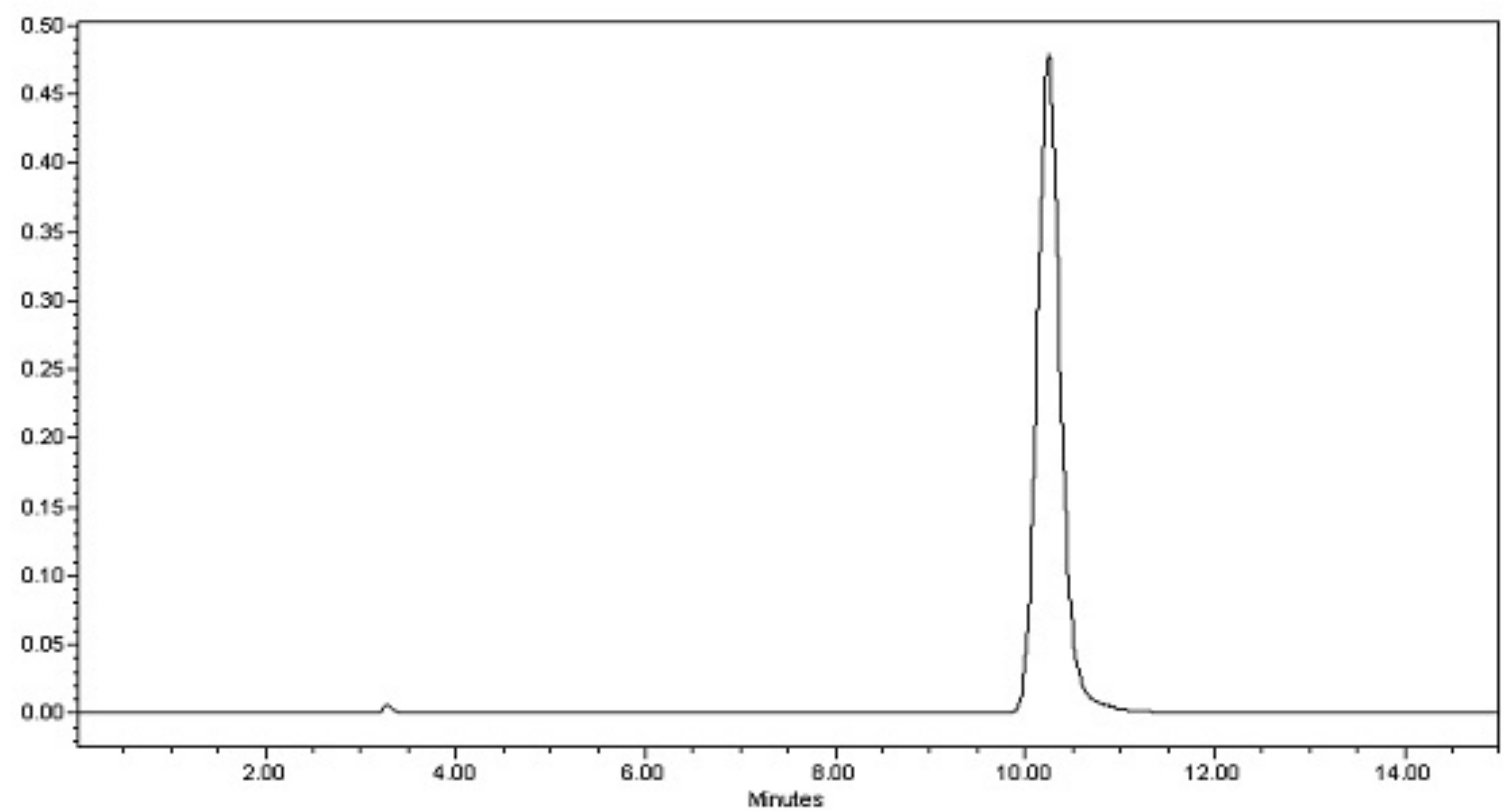

B.

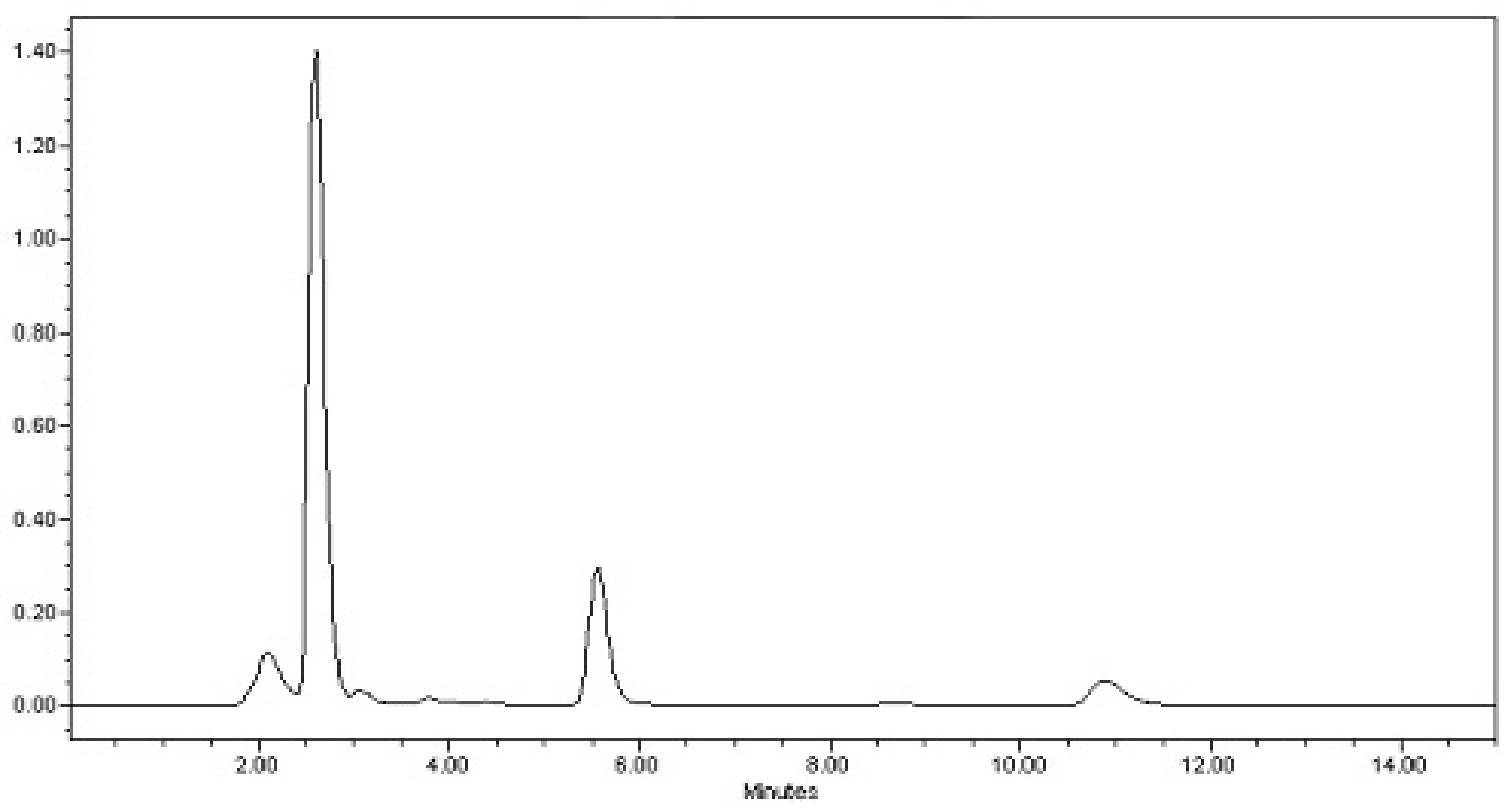

Figure 7. Chromatogram of folic acid degradation (100 ug/ml); A. Day 1, B. Day 15. 


\section{HPLC assay of folic acid in multivitamin dosage units.}

The response of the area under the peak against the amount of the injected folic acid was examined to determine if the described assay conditions may be applied for the assay of folic acid in multivitamin tablets. This response was examined in the concentration range of $0.2 \mu \mathrm{g} / \mathrm{ml}$ to $2.0 \mu \mathrm{g} / \mathrm{ml}$, which covers the dissolution range of folic acid in the tested multivitamin preparations. To execute this, folic acid solutions were prepared at the following concentrations: $0.2 \mu \mathrm{g} / \mathrm{ml}$, $0.4 \mu \mathrm{g} / \mathrm{ml}, 0.6 \mu \mathrm{g} / \mathrm{ml}, 0.8 \mu \mathrm{g} / \mathrm{ml}, 1.0 \mu \mathrm{g} / \mathrm{ml}, 1.2 \mu \mathrm{g} / \mathrm{ml}, 1.4 \mu \mathrm{g} / \mathrm{ml}, 1.6 \mu \mathrm{g} / \mathrm{ml}, 1.8$ $\mu \mathrm{g} / \mathrm{ml}$ and $2.0 \mu \mathrm{g} / \mathrm{ml}$. Each solution was injected on the column three times. The described solutions were prepared fresh three times at three different days and the area under the peak of folic acid was integrated.

The linear dependence of area under the peak on the folic acid concentration, in the examined range of concentration, was obtained. The regression coefficient was 0.99 (Figure 8). The method accuracy and reproducibility in the linear range was also determined on the basis of the relative standard deviation. For all the tested solutions, the coefficient of variation was less than $3 \%$ upon repeated injections (Table 7). The retention time was 3.1 minutes for folic acid and 15 minutes for methylparaben. The assay did not show sensitivity for folic acid degradation products. The short retention time for folic acid makes it difficult to resolve folic acid peak from its degradation products peaks when a mixture of folic acid and p-aminobenzoyl-L-glutamic acid was assayed. 


\begin{tabular}{|c|c|}
\hline $\begin{array}{c}\text { Folic Acid } \\
(\mu \mathrm{g} / \mathrm{ml})\end{array}$ & $\mathrm{CV}$ \\
\hline 0.2 & 1.67 \\
\hline 0.4 & 1.25 \\
\hline 0.6 & 2.19 \\
\hline 0.8 & 0.32 \\
\hline 1.0 & 2.18 \\
\hline 1.2 & 1.95 \\
\hline 1.4 & 1.49 \\
\hline 1.6 & 1.56 \\
\hline 1.8 & 1.21 \\
\hline 2.0 & 1.44 \\
\hline
\end{tabular}

Table 7. Coefficient of variation of folic acid HPLC assay in multivitamin dosage units.

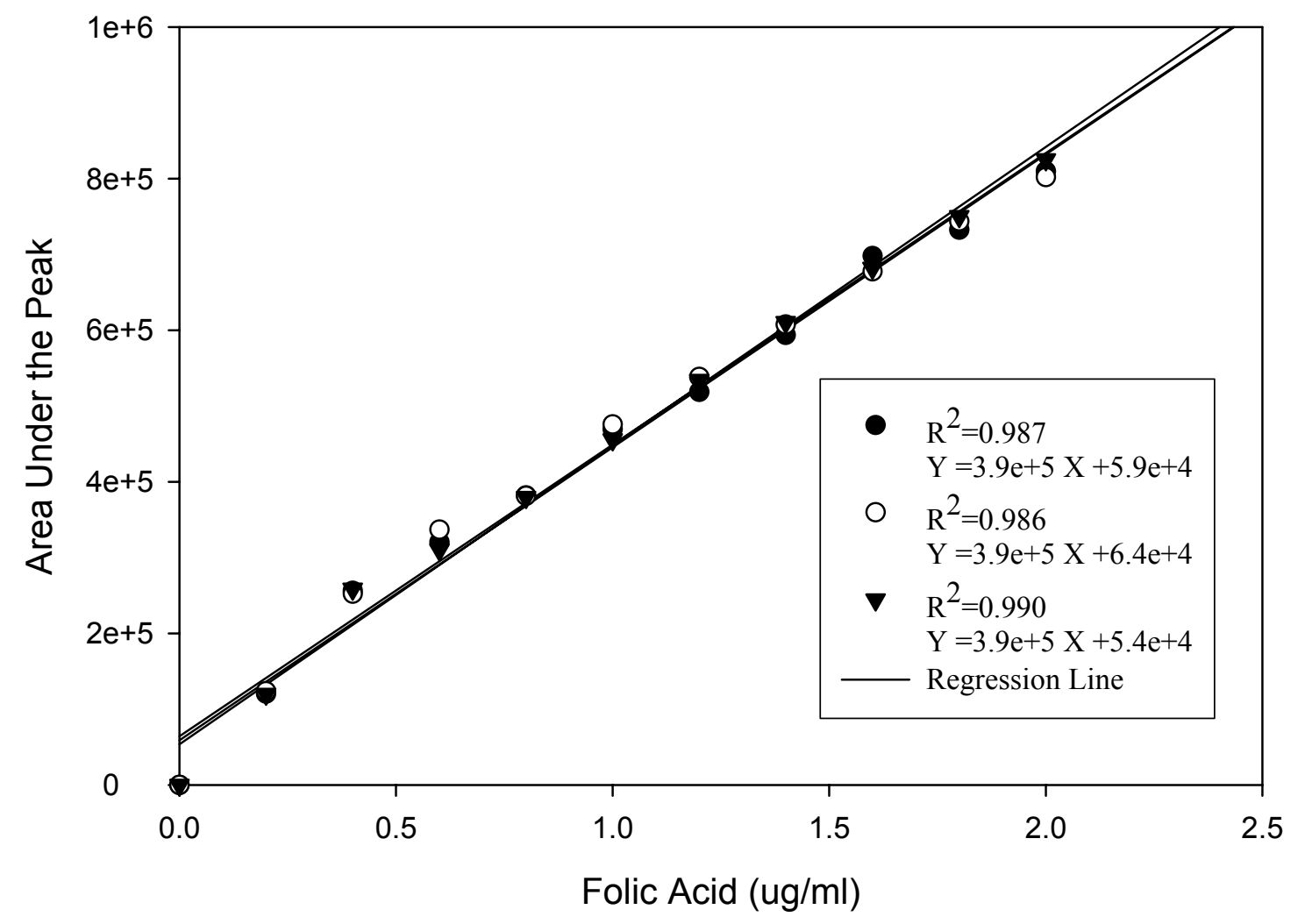

Figure 8. The linearity of folic acid HPLC assay in multivitamin dosage units. 


\section{Product Performance-Commercial}

\section{Disintegration}

The disintegration test is provided to determine compliance with the limits on disintegration stated in the individual USP monographs, except where the label states that the tablets or capsules are intended for use as troches, or are to be chewed, or are designed as a modified-release dosage form.

A tablet is generally formulated with a disintegrating agent which will cause the tablet to rupture and fall apart in water or gastric fluid. Factors affecting the disintegration of tablets include:

1. Physical and chemical properties of the granulation.

2. Tablet hardness.

3. Tablet porosity.

4. Disintegrating agent used.

Disintegration does not imply complete solution of the unit or even of its active constituents. Complete disintegration is defined as that state in which any tablet residue remaining on the screen of the disintegrating apparatus is a soft mass having no palpably firm core.

To meet the USP requirement, the dosage unit should disintegrate, in the specified disintegration medium in the individual USP monograph for that dosage unit, in less than thirty minutes. This time has some in vivo relevance in that, dosage units with excessively long disintegration times ( $>>30$ minutes) will likely have minimal area available to dissolute, minimizing product bioavailability.

Tables 6 and 7 and Figures 9 and 10 show the average disintegration time $(n=3)$ for the tested products. Unlike the USP requirements for the disintegration medium to be distilled water (DW), the test was also performed in simulated gastric fluid (SGF) and simulated intestinal fluid (SIF) to characterize the product disintegration at different $\mathrm{pH}$ values. Thirteen out of the fourteen products passed the USP requirement for disintegration (less than 30 minutes).Few products exhibited increased or decreased disintegration time trend with increasing $\mathrm{pH}$. In 
general, disintegration was faster in acidic conditions and slower in neutral conditions. Disintegration showed sensitivity to $\mathrm{pH}$ which reflects the influence of varying excipients of the various formulations (Figures 11, 12).

\begin{tabular}{|c|c|c|c|c|}
\hline \multirow{2}{*}{ Product } & \multicolumn{3}{|c|}{ Mean Disintegration Time \pm SD (min) } & \multirow{2}{*}{ Pass/Fail } \\
\cline { 2 - 4 } & DW & SGF & SIF & \\
\hline 1 & $138 \pm 138.5$ & $18.0 \pm 11.9$ & $267 \pm 207.6$ & Fail \\
\hline 2 & $0.4 \pm 0.04$ & $0.43 \pm 0.07$ & $0.53 \pm 0.1$ & Pass \\
\hline 3 & $8.0 \pm 0.31$ & $9.7 \pm 0.5$ & $8.6 \pm 0.2$ & Pass \\
\hline 4 & $0.7 \pm 0.1$ & $1.05 \pm 0.1$ & $1.28 \pm 0.1$ & Pass \\
\hline 5 & $0.25 \pm 0.03$ & $0.185 \pm 0.02$ & $0.19 \pm 0.02$ & Pass \\
\hline 6 & $7.3 \pm 0.5$ & $8.4 \pm 0.4$ & $8.8 \pm 0.3$ & Pass \\
\hline 7 & $10.5 \pm 0.4$ & $12.92 \pm 0.9$ & $8.83 \pm 0.8$ & Pass \\
\hline
\end{tabular}

Table 8. Single entity folic acid tablets average disintegration time in minutes.

\begin{tabular}{|c|c|c|c|c|}
\hline \multirow{2}{*}{ Product } & \multicolumn{3}{|c|}{ Mean Disintegration Time \pm SD (min) } & \multirow{2}{*}{ Pass/Fail } \\
\cline { 2 - 4 } & DW & SGF & SIF & \\
\hline PMV1* $^{*}$ & $8.12 \pm 1.3$ & $8.7 \pm 1.2$ & $10.5 \pm 0.9$ & Pass \\
\hline PMV 2* & $10.0 \pm 1.8$ & $8.5 \pm 1.3$ & $9.5 \pm 1.7$ & Pass \\
\hline PMV 3* & $8.4 \pm 0.5$ & $8.5 \pm 0.4$ & $10.9 \pm 0.9$ & Pass \\
\hline PMV 4* & $19.3 \pm 0.6$ & $18.8 \pm 2.0$ & $22.3 \pm 0.9$ & Pass \\
\hline PMV 5* & $11.0 \pm 0.5$ & $10.1 \pm 0.7$ & $10.7 \pm 0.7$ & Pass \\
\hline NMV1** & $4.3 \pm 0.7$ & $4.4 \pm 0.8$ & $3.8 \pm 0.7$ & Pass \\
\hline NMV2** & $14.5 \pm 1.4$ & $14.5 \pm 1.3$ & $15.5 \pm 1.3$ & Pass \\
\hline NMV3** & $25.5 \pm 1.6$ & $22.2 \pm 1.6$ & $24.2 \pm 3.4$ & Pass \\
\hline
\end{tabular}

* Prenatal multivitamin Tablet. ** Nephritic Multivitamin dosage Unit.

Table 9. Multivitamin dosage units containing folic acid average disintegration time in minutes. 


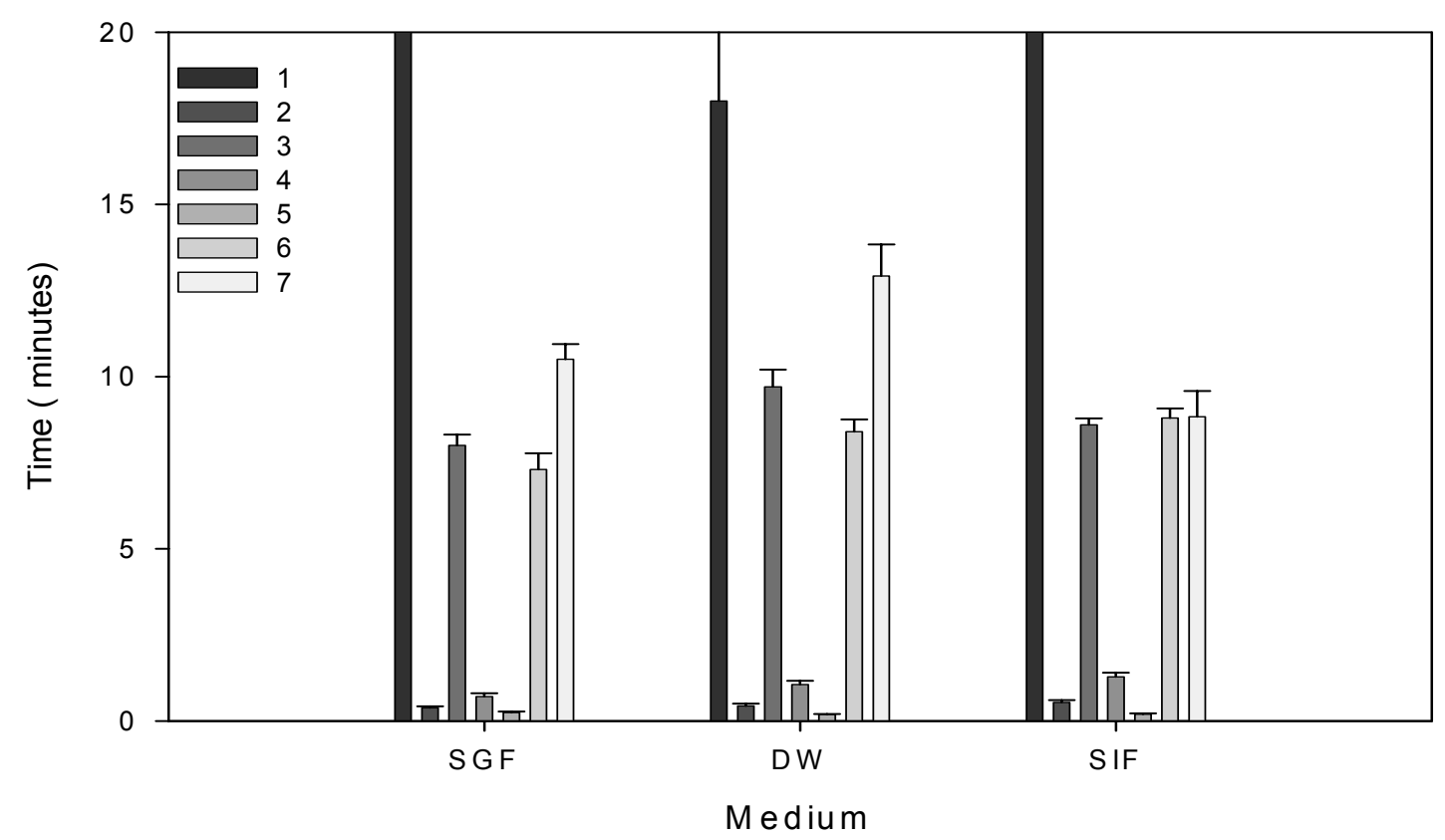

Figure 9. Single Entity folic acid tablets average disintegration.

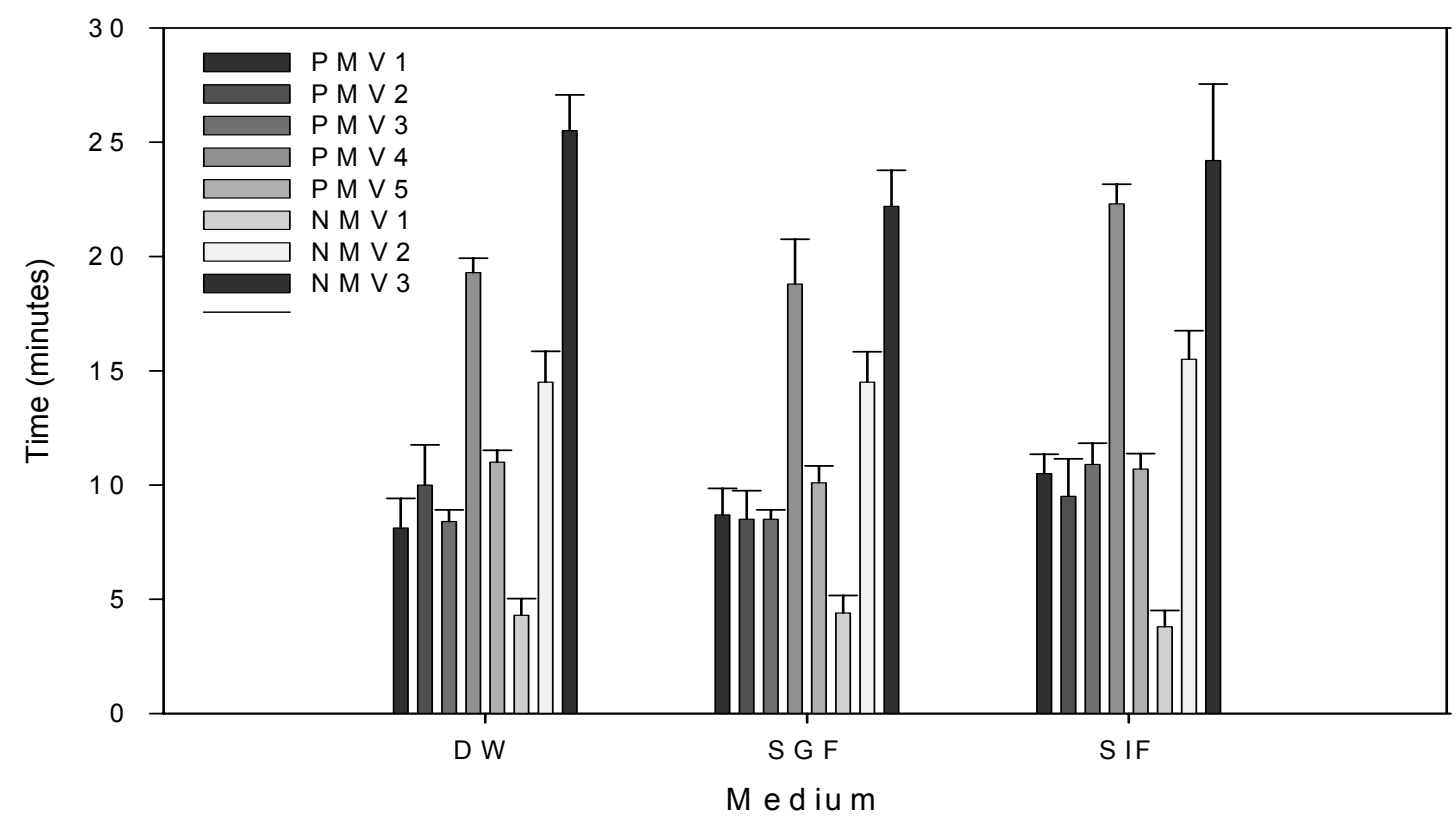

Figure 10 . Multivitamin dosage units containing folic acid average disintegration. 


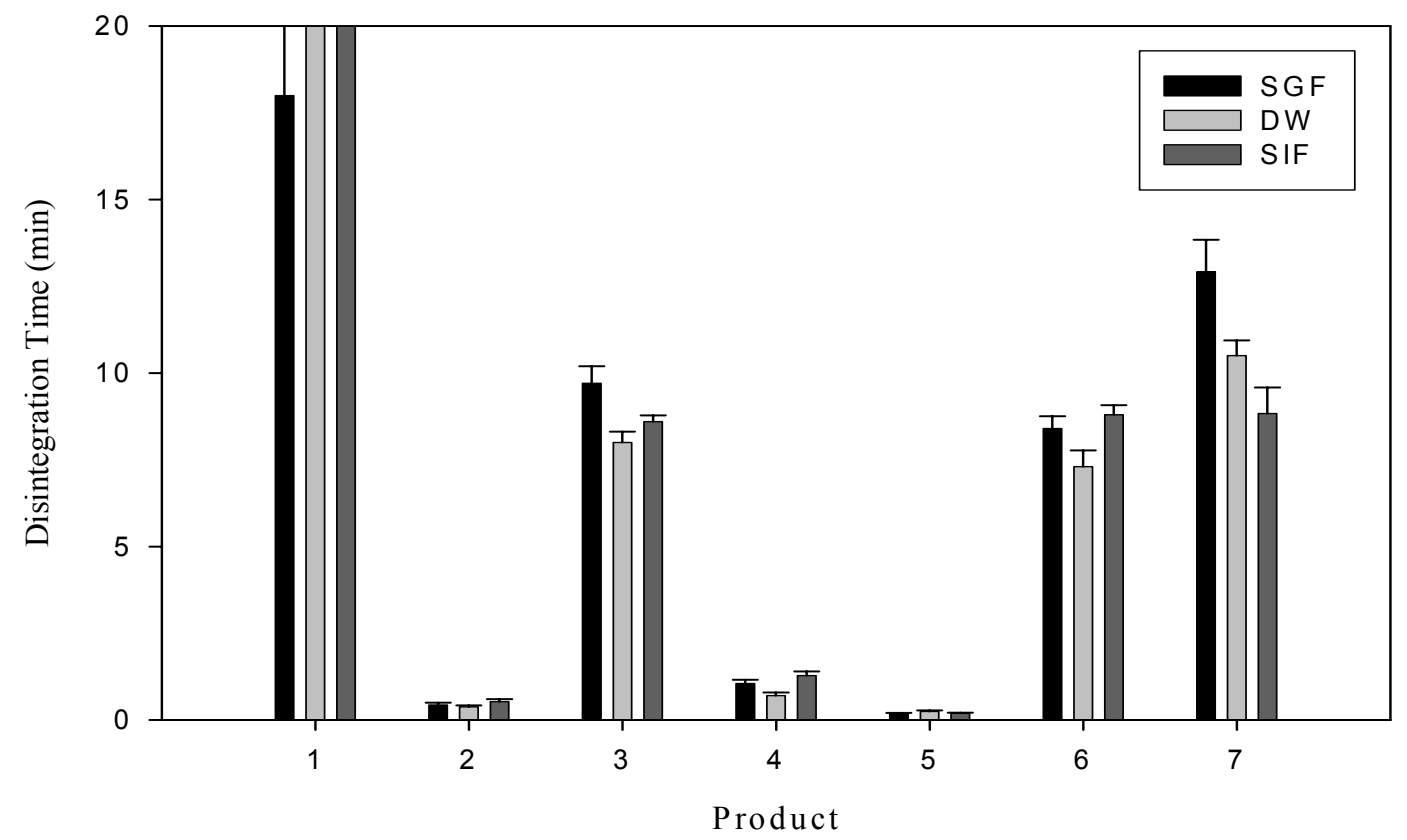

Figure 11. Single entity folic acid tablets average disintegration as a function of $\mathrm{pH}$.

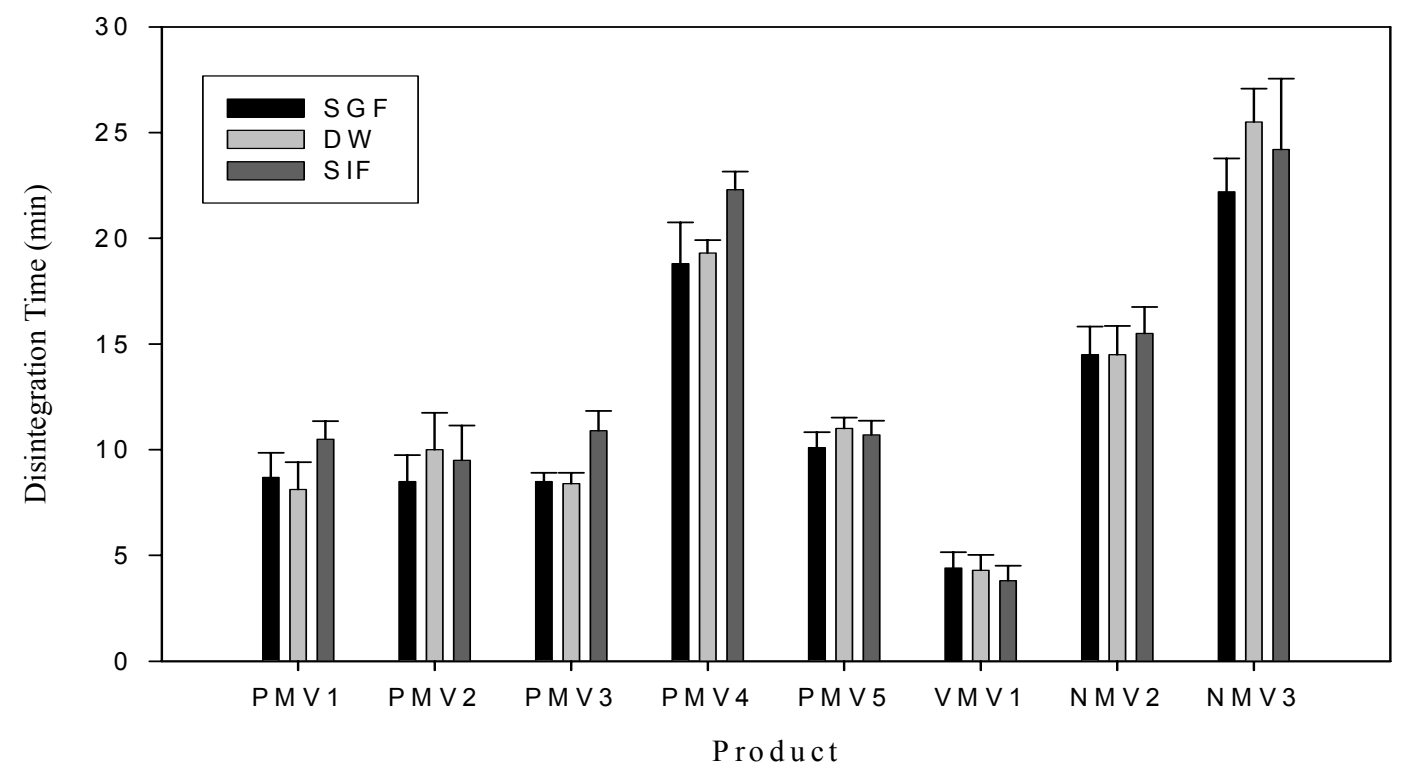

Figure 12. Multivitamin dosage units containing folic acid average disintegration as a function of $\mathrm{pH}$.. 
Of the fifteen products tested, only one, a single entity folic acid tablet formulation \#1, failed to pass the USP requirements and exhibited unpredicted disintegration behavior (11->480 minutes). The reason for this might be in the formulation as the label claims the absence of starch, yeast and preservative in the product. The first two could contribute to the disintegration process. This might also be attributed to the characteristics of the excipients at different $\mathrm{pH}$ values. Hardness may also be a factor, as the measured hardness $(9.81 \pm 0.87 \mathrm{Kp})$ is somewhat high for immediate release tablets; the small variability in hardness, however, did not explain the wide variability in disintegration time. The second slowest disintegrating product (NMV3) did not demonstrate as a wide range in disintegration time (20.8-27.8 minutes).

. All the tablets disintegrated in less than thirty minutes in SGF.This was not the case in DW. Since the tablet spends about two hours in the stomach before being transported to the small intestine, the question as to whether the disintegration test for folic acid containing dosage units should be carried out in DW, as currently required by USP, or SGF, which is more physiologically relevant, needs to be considered.

\section{Content Uniformity}

This test is designed to provide compliance of the dosage units with USP specifications for the uniformity of the dosage unit. The uniformity of the dosage unit can be demonstrated by either one of two methods, weight variation or content uniformity.

Content uniformity of single entity folic acid tablets.

To meet the USP requirements for the uniformity of the dosage form, single entity folic acid tablets should contain on average not less than $90.0 \%$ and not more than $115.0 \%$ of the label claim and the relative standard deviation should be less than $6 \%$. The average percent per tablet $(n=25)$ and the relative standard deviation were calculated as follows: 
Percent average $=(\text { Average amount per tablet/Label claim })^{*} 100$ Relative standard deviation $=(100 *$ Average amount per tablet $) /$ Standard deviation

Table 10 contains the percent amount of folic acid per tablet (all tablets labeled as containing $400 \mathrm{mcg}$ ) and the relative standard deviation for the tested products. Six out of the seven products passed the USP requirement for the content uniformity of single entity folic acid products. One of the tested products (\#2) contained 141\% (564 mcg) of the labeled amount; this is considered a failure in the dosage form and has a significant clinical importance since pharmacological doses of folic acid may interfere with the efficiency of certain anticonvulsants and/or mask vitamin B deficiencies. Samples analysis did not show any major degradation in the formulations tested.

\begin{tabular}{|c|c|c|c|}
\hline Product & $\begin{array}{c}\text { Average Percent } \\
\text { Per Tablet }\end{array}$ & RSD & Pass/ Fail \\
\hline 1 & $105.5 \%$ & 3.6 & Pass \\
\hline 2 & $141.0 \%$ & 5.1 & Fail \\
\hline 3 & $102.8 \%$ & 5.3 & Pass \\
\hline 4 & $102.5 \%$ & 2.7 & Pass \\
\hline 5 & $102.3 \%$ & 2.1 & Pass \\
\hline 6 & $101.3 \%$ & 5.9 & Pass \\
\hline 7 & $101.5 \%$ & 1.9 & Pass \\
\hline
\end{tabular}

Table 10. Average percent of folic acid in single entity folic acid tablets.

Content uniformity of folic acid in multivitamin preparations:

To meet the USP requirements for the uniformity of the dosage form, folic acid containing multivitamin tablets should contain on average not less than $90.0 \%$ and not more than $150.0 \%$ of the label claim and the relative standard deviation should be less than $6 \%$. The average percent per tablet $(n=30)$ and the relative standard deviation (RSD) were calculated as follows:

Percent average $=($ Average amount per tablet $/$ Label claim $) * 100$ Relative Standard Deviation $=(100 *$ Average amount per tablet $) /$ Standard deviation 
Table 11 contains the percent amount of folic acid per tablet (all tablets labeled as containing $800 \mathrm{mcg}$, with the exception of NMV1 and NMV3 labeled as $1 \mathrm{mg}$ ) and the relative standard deviation for the tested products. All the products tested passed the USP requirement for the content uniformity of folic acid in multivitamins dosage units. It is of note that, while all products passed, five of the products tested had a content $>120 \%$. In theory this allows for a range of 984$1230 \mathrm{mcg}$ of folic acid in dosage units in this category.

\begin{tabular}{|c|c|c|c|}
\hline Product & Average Percent & RSD & Pass/Fail \\
\hline MV1* & $105.5 \%$ & 4.9 & Pass \\
\hline MV 2* & $147.0 \%$ & 3.0 & Pass \\
\hline MV 3* & $130.1 \%$ & 3.0 & Pass \\
\hline MV 4* & $126.9 \%$ & 1.6 & Pass \\
\hline MV 5* & $123.2 \%$ & 1.6 & Pass \\
\hline NMV1** & $123.2 \%$ & 3.6 & Pass \\
\hline NMV2** $^{*} \%$ & $104.3 \%$ & 3.0 & Pass \\
\hline NMV3** & $98.6 \%$ & 3.5 & Pass \\
\hline
\end{tabular}

* Multivitamin Tablet (Prenatal). ** Nephritic Multivitamin Dosage Unit.

Table 11. Average percent of folic acid in multivitamin dosage units.

\section{Dissolution}

Single entity folic acid tablets dissolution.

To meet the USP requirements for dissolution, not less than $75 \%$ of the labeled amount of folic acid should be released in 45 minutes. Dissolution was measured using USP apparatus II and test conditions specified under the folic acid tablet monograph in USP 24. Unlike the USP requirement that the dissolution is to be performed in distilled water, the measurement was performed in three different media: simulated intestinal fluid ( $\mathrm{pH} 1.5)$, distilled water $(\mathrm{pH} \mathrm{5-6)}$ and simulated intestinal fluid ( $\mathrm{pH}$ 7.5). Percent released was calculated as follows:

Percent released $=($ amount measured/label claim $) * 100$ 
The amount measured/time point was from pooled samples of six products per dissolution run $(\mathrm{n}=6)$.

All the tested products met the USP requirement of folic acid dissolution in distilled water. More than $75 \%$ of the folic acid labeled amount was released in 45 minutes (Table 12). The dissolution range was $85 \%-143 \%$ (Figure 13). Of note is the performance of product \# 1 ; while it passed the dissolution test, it was the slowest performing product, similar to its disintegration.

All the tested products released more than $75 \%$ of the labeled amount in 45 minutes in simulated intestinal fluid (Table 13). The dissolution profile of folic acid in simulated intestinal fluid for each product was almost the same as the dissolution profile obtained in distilled water (Figure 14). The dissolution range was $89 \%-135 \%$.

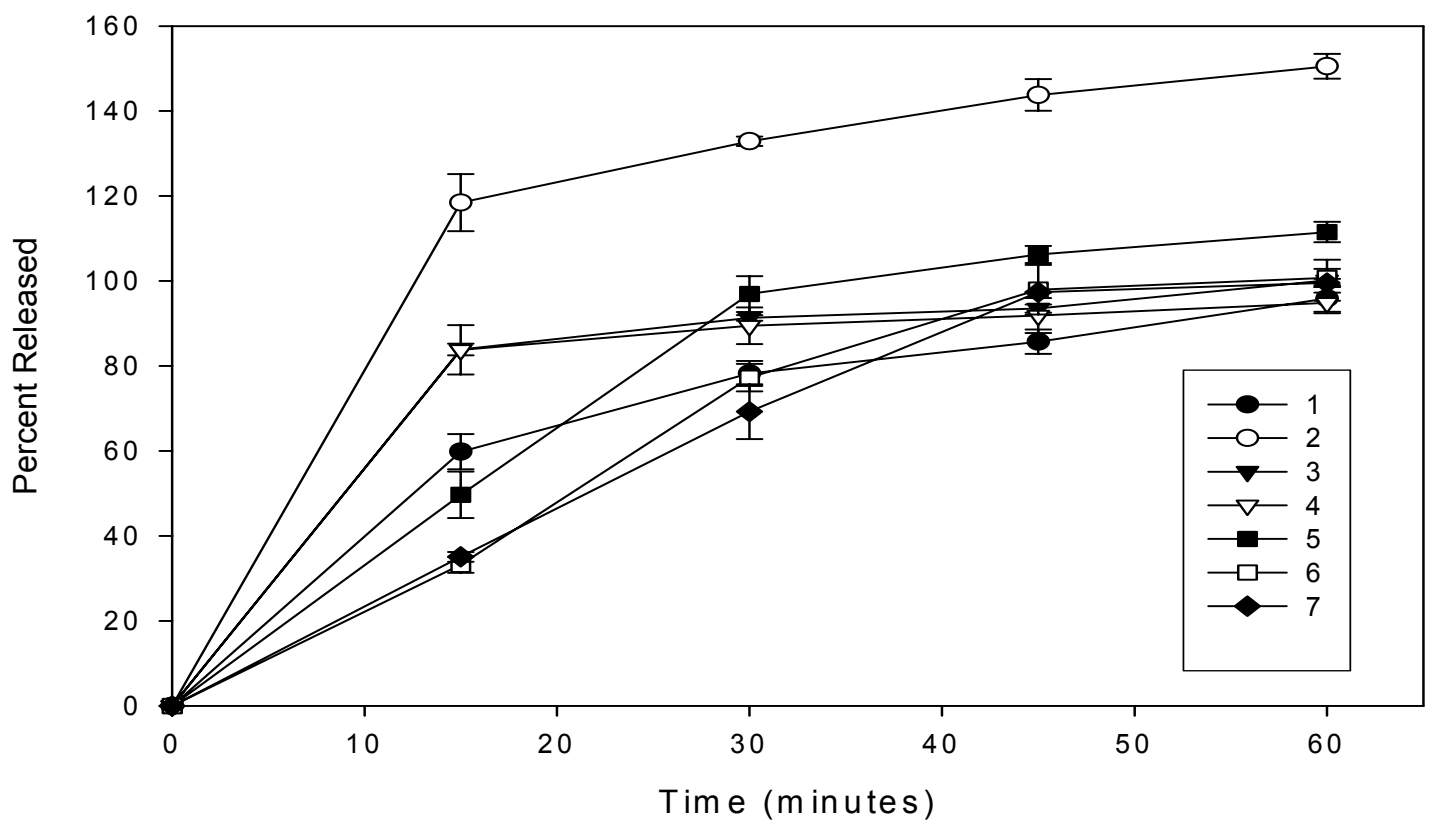

Figure 13. Folic acid (in single entity folic acid tablets) dissolution profile in distilled water. 


\begin{tabular}{|c|c|c|c|}
\hline Product & $\begin{array}{c}\text { Percent Released } \\
(45 \text { minutes })\end{array}$ & RSD & Pass/Fail \\
\hline 1 & $85.7 \%$ & 2.9 & Pass \\
\hline 2 & $143.8 \%$ & 3.7 & Pass \\
\hline 3 & $93.5 \%$ & 1.0 & Pass \\
\hline 4 & $91.9 \%$ & 4.1 & Pass \\
\hline 5 & $106.3 \%$ & 2.0 & Pass \\
\hline 6 & $97.9 \%$ & 5.8 & Pass \\
\hline 7 & $97.4 \%$ & 0.1 & Pass \\
\hline
\end{tabular}

Table 12. Percent release of folic acid (in single entity folic acid tablets) in distilled water

\begin{tabular}{|c|c|c|c|}
\hline Product & $\begin{array}{c}\text { Percent Released } \\
(45 \text { minutes })\end{array}$ & RSD & Pass/Fail \\
\hline 1 & $89.7 \%$ & 2.5 & Pass \\
\hline 2 & $135.8 \%$ & 3.5 & Pass \\
\hline 3 & $112.3 \%$ & 1.2 & Pass \\
\hline 4 & $101.3 \%$ & 1.7 & Pass \\
\hline 5 & $101.5 \%$ & 2.5 & Pass \\
\hline 6 & $116.1 \%$ & 0.8 & Pass \\
\hline 7 & $110.1 \%$ & 2.4 & Pass \\
\hline
\end{tabular}

Table 13. Percent release of folic acid (in single entity folic acid tablets) in SIF. 


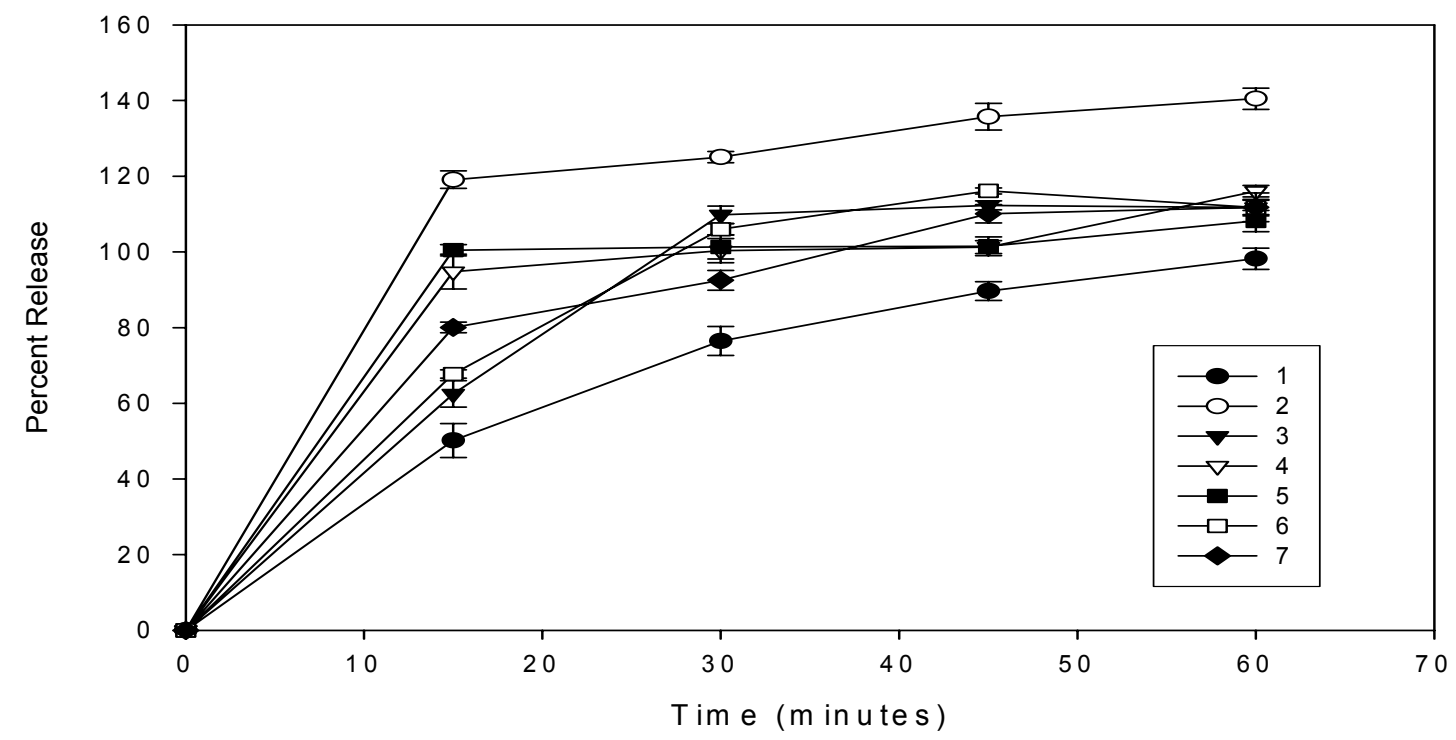

Figure 14. Folic acid (in single entity folic acid tablets) dissolution profile in SIF.

All the tested products failed to release $75 \%$ of the labeled folic acid in 45 minutes in simulated gastric fluid (Table 14). Dissolution as low as $23 \%$ was observed, where the highest percent released obtained for a product tested was $68 \%$ (Figure 15).

\begin{tabular}{|c|c|c|c|}
\hline Product & $\begin{array}{c}\text { Percent Released } \\
(45 \text { minutes })\end{array}$ & RSD & Pass/Fail \\
\hline 1 & $23.6 \%$ & 6.9 & Fail \\
\hline 2 & $56.6 \%$ & 8.7 & Fail \\
\hline 3 & $38.0 \%$ & 3.0 & Fail \\
\hline 4 & $46.5 \%$ & 7.1 & Fail \\
\hline 5 & $51.9 \%$ & 5.0 & Fail \\
\hline 6 & $68.1 \%$ & 6.8 & Fail \\
\hline 7 & $34.1 \%$ & 5.1 & Fail \\
\hline
\end{tabular}

Table 14 . Percent release of folic acid (in single entity folic acid tablets) in SGF. 


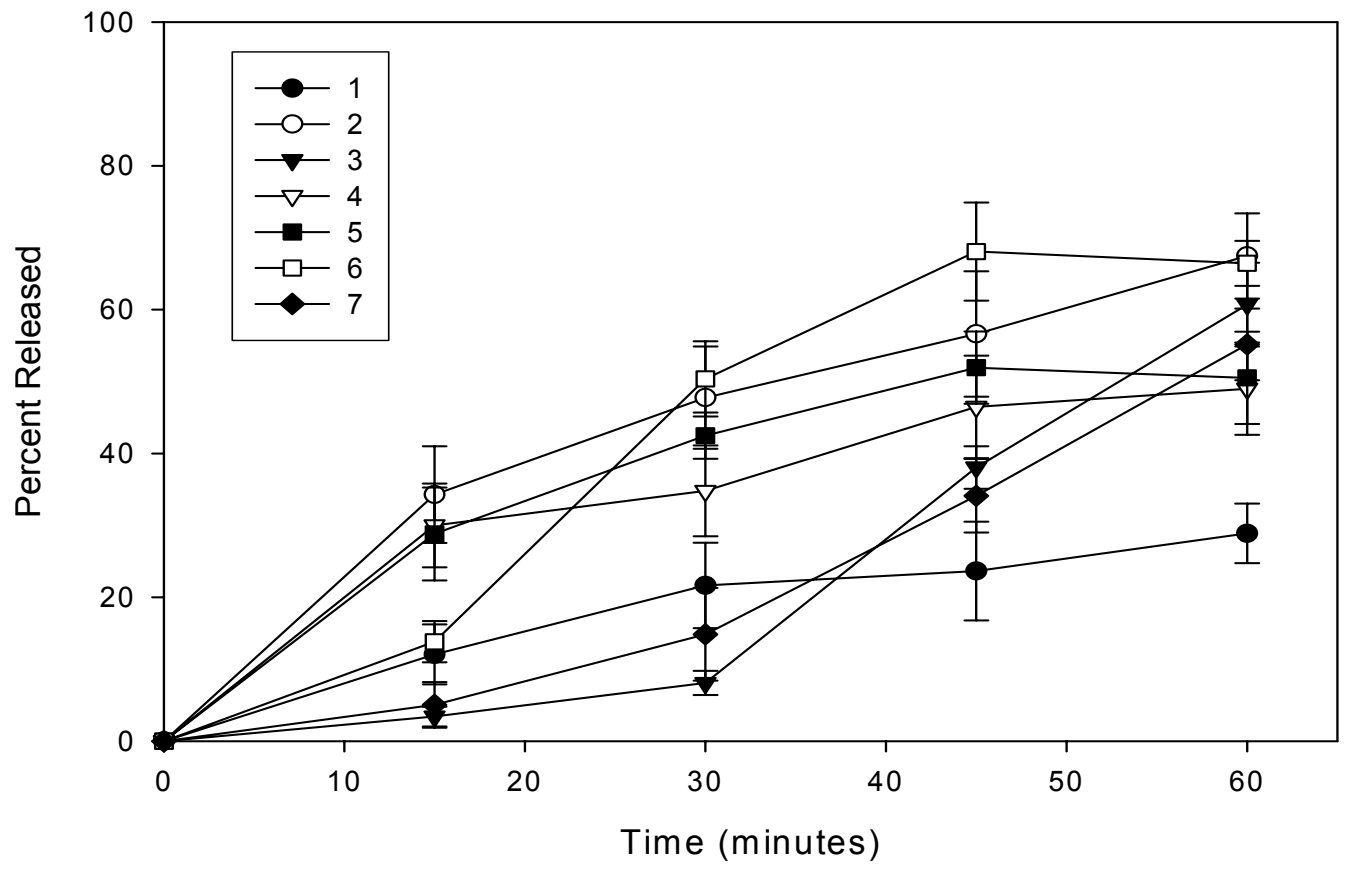

Figure 15. Folic acid (in single entity folic acid tablets) dissolution profile in SGF.

In contrast with the disintegration results, these results demonstrate that the dissolution of the folic acid tablets is sensitive to $\mathrm{pH}$, with all products dissolution rate being significantly diminished in the acidic conditions of SGF. The results of the single entity folic acid tablet studies also suggest that degradation does not contribute to product failure, as no significant degradation peaks were observed during product assay.

Dissolution of folic acid in multivitamin dosage units.

This test is provided to determine compliance with the dissolution requirements where stated in the individual class monographs for a tablet or capsule dosage form. All nutritional supplements belonging to USP class II 
(water-soluble vitamins), class III (water-soluble vitamins with minerals), class IV (oil- and water- soluble vitamins), class V (oil- and water- soluble vitamins with minerals) and class VI (minerals), prepared as tablets or capsules are subject to the dissolution test and criteria, described in the "Nutritional Supplements" chapter of USP, for folic acid (43). This test is also required if the product labeling includes a health claim concerning the relationship between folate deficiency and the risk of neural tube defects.

To meet the USP requirements for dissolution of multivitamin dosage unit, not less than $75 \%$ of the labeled amount of folic acid should be released in 60 minutes. Dissolution was measured using USP apparatus II for tablets or apparatus I for capsules, and the test conditions specified under the folic acid USP 24 (disintegration and dissolution of nutritional supplements) (43). The measurement was performed in three different media: simulated intestinal fluid $(\mathrm{pH} 1)$, distilled water ( $\mathrm{pH}$ 5-6) and simulated intestinal fluid (pH 7.5). Percent release was calculated as follows:

$$
\text { Percent released }=(\text { amount measured/label claim }) * 100
$$

The amount measured/time point was from pooled samples of six products per dissolution run $(\mathrm{n}=6)$.

Most of the tested products released more than $75 \%$ of folic acid in distilled water in one hour. Only one of the products (NMW3) failed to pass the USP requirement for folic acid dissolution in multivitamin dosage units. The 
dissolution range was 38\%-145\% (Table 15).All the tested products except one released more than $60 \%$ by 15 minutes (Figure 16 ).

\begin{tabular}{|c|c|c|c|}
\hline Product & Percent Release & RSD & Pass/Fail \\
\hline MV1 & $100.6 \%$ & 4.1 & Pass \\
\hline MV 2* & $145.5 \%$ & 2.4 & Pass \\
\hline MV 3* & $106.1 \%$ & 1.5 & Pass \\
\hline MV 4* & $108.8 \%$ & 2.5 & Pass \\
\hline MV 5* & $112.4 \%$ & 2.9 & Pass \\
\hline NMV1** & $121.9 \%$ & 2.3 & Pass \\
\hline NMV2** & $102.5 \%$ & 5.0 & Pass \\
\hline NMV3** & $38.5 \%$ & 4.6 & Fail \\
\hline
\end{tabular}

* Multivitamin Tablet (Prenatal). ** Nephritic Multivitamin Dosage Units.

Table 15. Percent release of folic acid (in multivitamin units) in distilled water in 60 minutes.

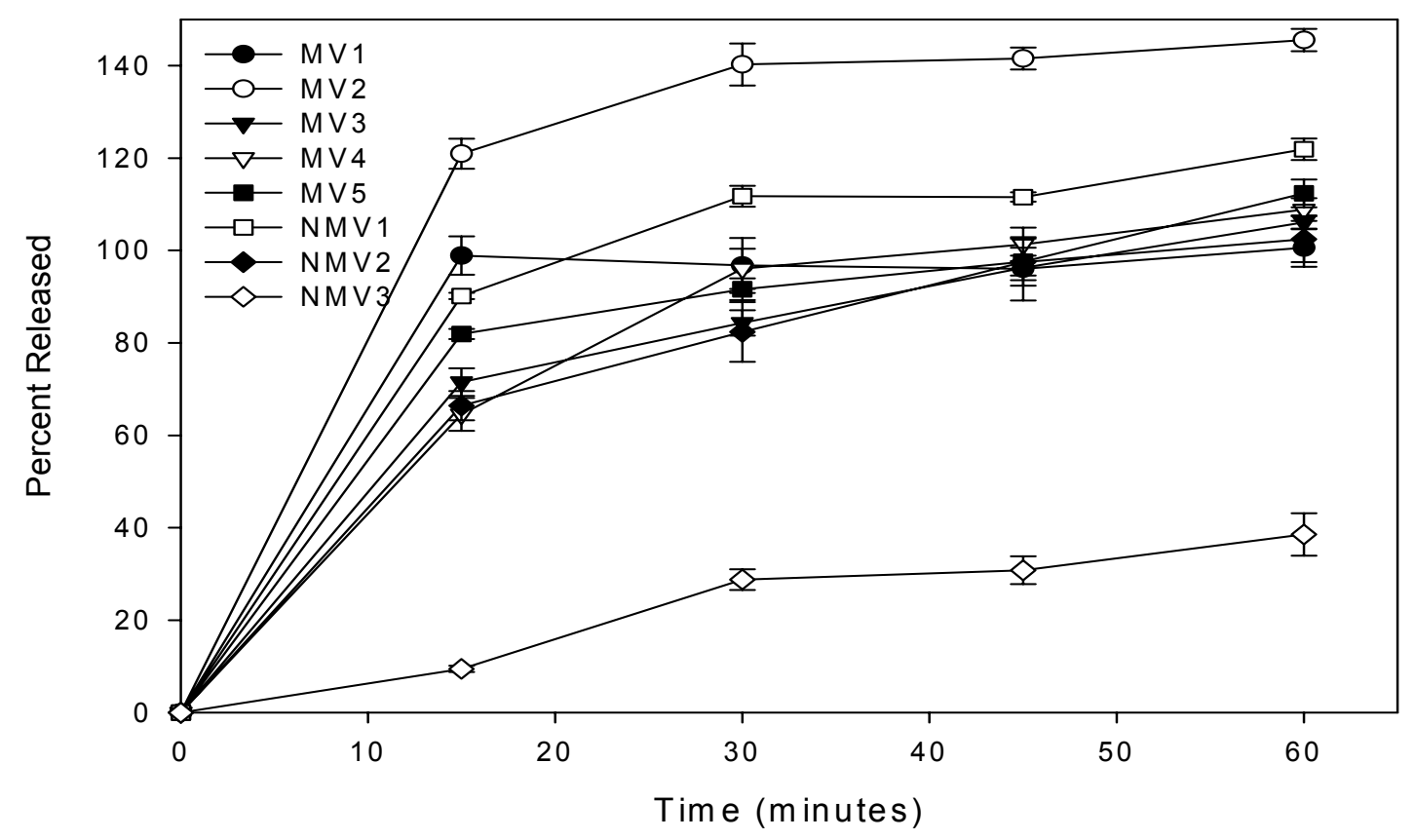

Figure16. Folic acid (in multivitamin units) dissolution profile in distilled water. 
The tested products generated almost the same dissolution profile in simulated intestinal fluid as those generated in distilled water. All products tested, except one (again NMW3), passed the USP specification for folic acid in multivitamin dosage unit dissolution. The dissolution range was 47\%-130\% (Table 16). Most of the tested products released more than $60 \%$ by 15 minutes. However, the percent released from all the tested products in 60 minutes was generally less than the percent released in distilled water (Figure 17).

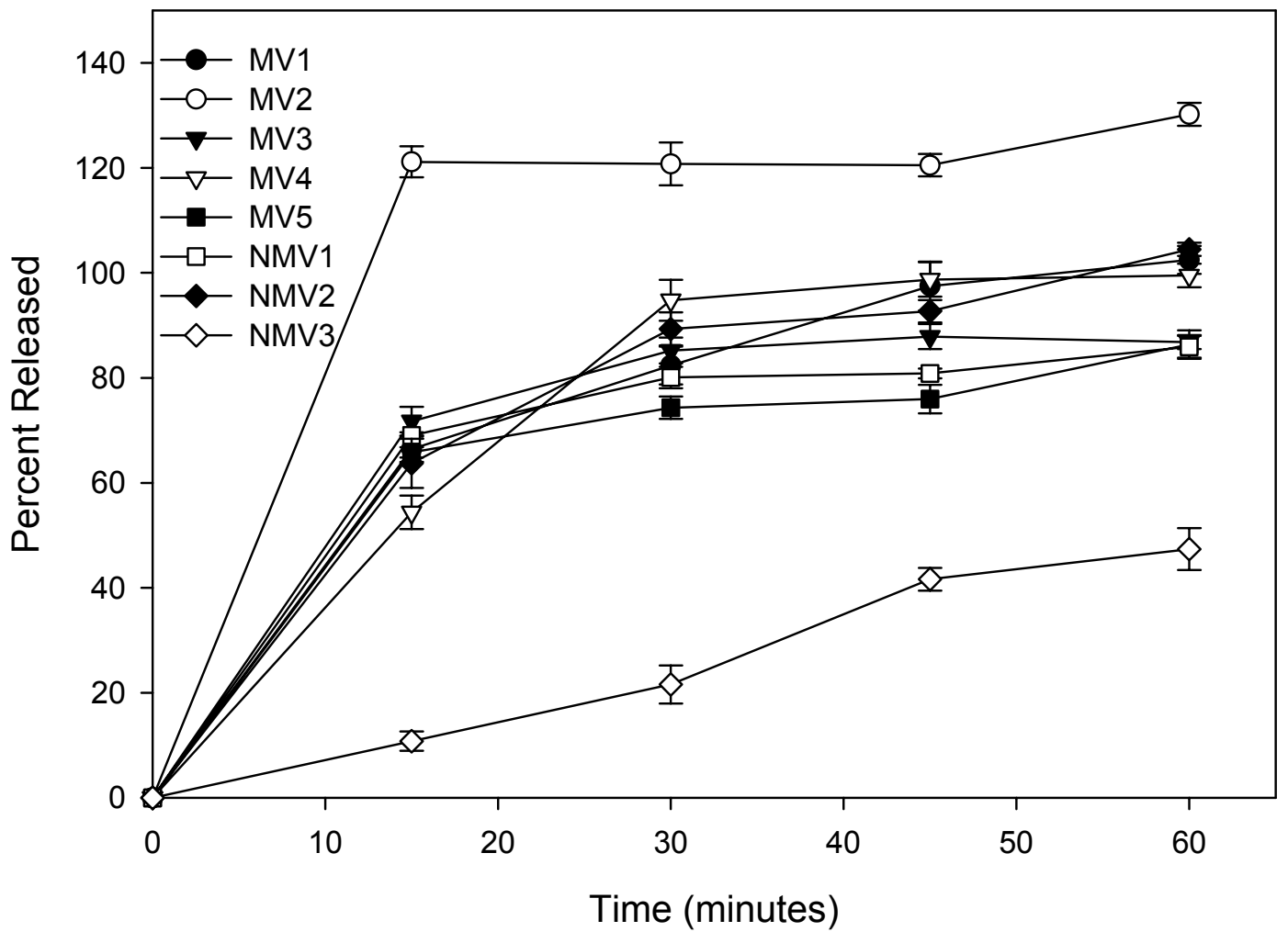

Figure 17 . Folic acid (in multivitamin units) dissolution profile in SIF. 


\begin{tabular}{|c|c|c|c|}
\hline Product & $\begin{array}{l}\text { Percent } \\
\text { Release }\end{array}$ & RSD & Pass/Fail \\
\hline MV1* & $102.5 \%$ & 2.7 & Pass \\
\hline MV 2* & $130.2 \%$ & 2.2 & Pass \\
\hline MV 3* & $86.8 \%$ & 1.3 & Pass \\
\hline MV 4* & $99.5 \%$ & 2.2 & Pass \\
\hline MV 5* & $86.3 \%$ & 2.7 & Pass \\
\hline NMV1** & $85.9 \%$ & 2.1 & Pass \\
\hline NMV2** & $104.5 \%$ & 1.3 & Pass \\
\hline NMV3** & $47.4 \%$ & 4.0 & Fail \\
\hline
\end{tabular}

* Multivitamin Tablet (Prenatal). ** Nephritic Multivitamin Dosage Unitts

Table 16. Percent release of folic acid (in multivitamin units) in SIF in 60 minutes.

All the tested products failed to release $75 \%$ of folic acid in 60 minutes in simulated gastric fluid (Table 17). The dissolution range was 15\%-61\%.

For some of the products tested the release plateaued after 45 minutes (Figure 18).

\begin{tabular}{|c|c|c|c|}
\hline Product & $\begin{array}{c}\text { Percent } \\
\text { Release }\end{array}$ & RSD & Pass/Fail \\
\hline MV1* & $61.2 \%$ & 2.7 & Fail \\
\hline MV 2* & $28.7 \%$ & 4.2 & Fail \\
\hline MV 3* & $52.9 \%$ & 1.7 & Fail \\
\hline MV 4* & $47.1 \%$ & 1.5 & Fail \\
\hline MV 5* & $45.8 \%$ & 3.0 & Fail \\
\hline NMV $^{* *}$ & $42.2 \%$ & 2.4 & Fail \\
\hline NMV2** $^{*}$ & $32.8 \%$ & 1.7 & Fail \\
\hline NMV3** & $15.2 \%$ & 4.3 & Fail \\
\hline
\end{tabular}

* Multivitamin Tablet (Prenatal). ** Nephritic Multivitamin Dosage Unit.

Table 17. Percent release of folic acid (in multivitamin units) in SGF in 60 minutes. 


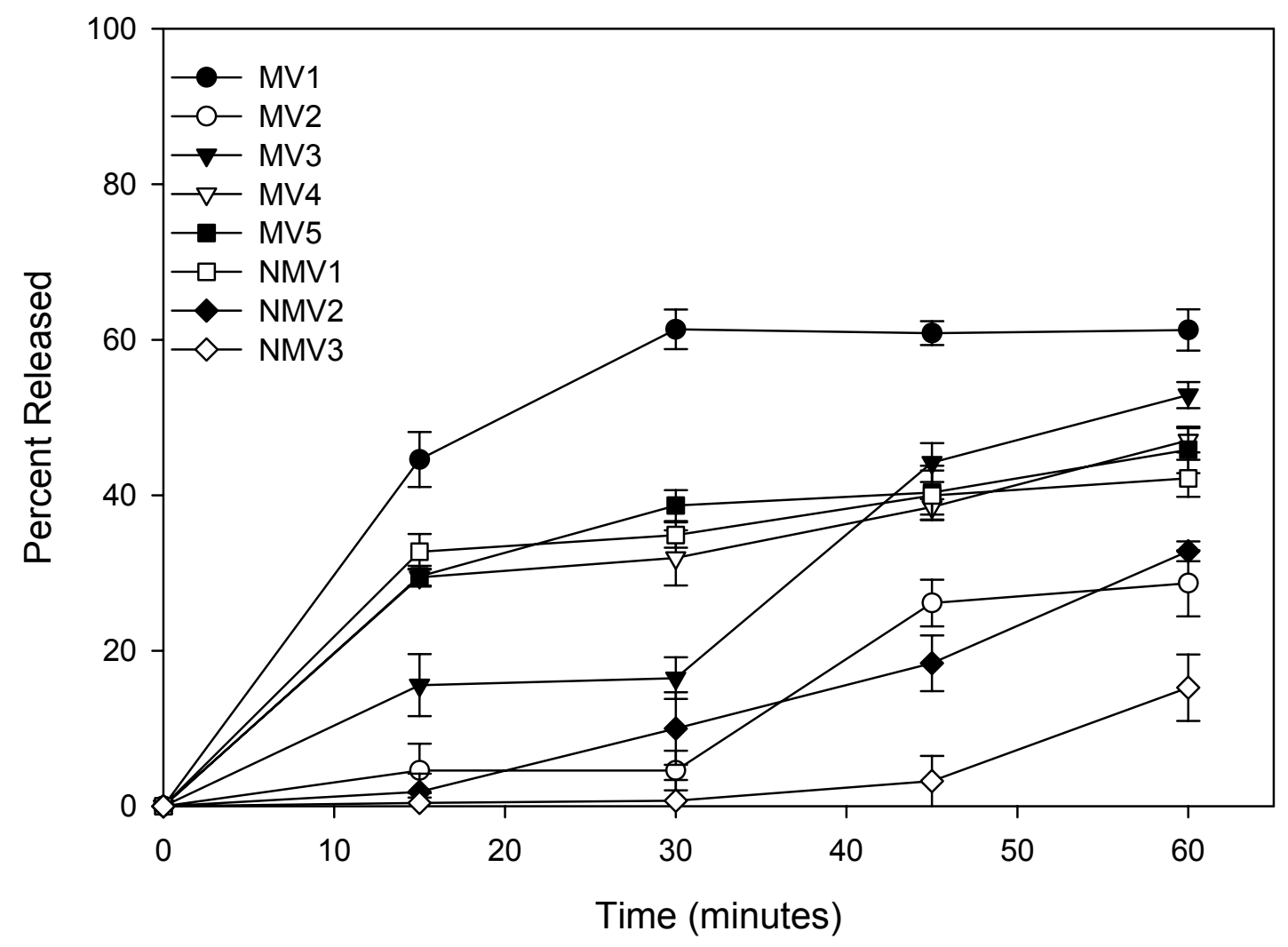

Figure 18 . Folic acid (in multivitamin units) dissolution profile in SGF.

In summary, the quality of commercially available folic acid products was evaluated in terms of disintegration, content uniformity and dissolution. For each test, at least one product failed to meet the USP specification for that test. However, no single product failed to meet the USP requirements for all three tests together.

Unlike USP requirements, disintegration and dissolution were also tested in simulated gastric fluid and simulated intestinal fluid. With one exception, all products tested passed dissolution in SIF. However, all the tested products failed to release more than $75 \%$ of label claim within sixty minutes when placed in SGF. This critical finding suggests a significant influence of acidic $\mathrm{pH}$ on product 
performance, which may be attributed, but not limited to, the $\mathrm{pH}$-dependent solubility of folic acid and/or the characteristics of the formulation excipients. This limited dissolution in simulated gastric conditions also has physiological relevance, since complete dissolution in the stomach would be preferred prior to folic acid absorption in the upper small intestine. Finally, while the multivitamin assay could not detect degradation products, single entity studies suggest that folic acid degradation is not a major contributor to product failure.

\section{Solubility of Folic Acid}

Since the solubility of folic acid at acidic $\mathrm{pH}$ might play a major role in the failure of the tested products to release more than $75 \%$ of label claim within sixty minutes, the saturation solubility of folic acid at different $\mathrm{pH}$ values was measured. A folic acid solubility-pH profile was generated (Table 18 and Figure 19). Folic acid exhibited an increased solubility with increasing $\mathrm{pH}$ at $37^{\circ} \mathrm{C}$. No signs of major degradation of folic acid in the assigned $\mathrm{pH}$ values were observed. Folic acid solutions were stable throughout the time course of the experiment (five days). Folic acid solubility was relatively low in acidic fluid and significantly higher in basic $\mathrm{pH}$ solutions. Solubility of folic acid at $\mathrm{pH} 10$ was more than 100fold more than the solubility of folic acid at $\mathrm{pH} 1$. Folic acid will be more highly ionized in basic $\mathrm{pH}$. The ionic form of folic acid is more soluble in aqueous solutions than the non-ionic free acid form. This may be a contributing factor to the distinct changes in dissolution as a function of $\mathrm{pH}$ for commercial folic acid products.

\begin{tabular}{|c|c|c|}
\hline $\mathrm{pH}$ & $\begin{array}{c}\text { Folic acid solubility } \\
(\mathrm{mg} / \mathrm{ml})\end{array}$ & RSD \\
\hline 1 & 0.029 & 4.02 \\
\hline 3 & 0.840 & 1.66 \\
\hline 4 & 1.050 & 5.33 \\
\hline 7 & 5.330 & 0.77 \\
\hline 10 & 19.47 & 2.84 \\
\hline
\end{tabular}

Table 18 . Folic acid solubility in buffers at different $\mathrm{pH}$. 


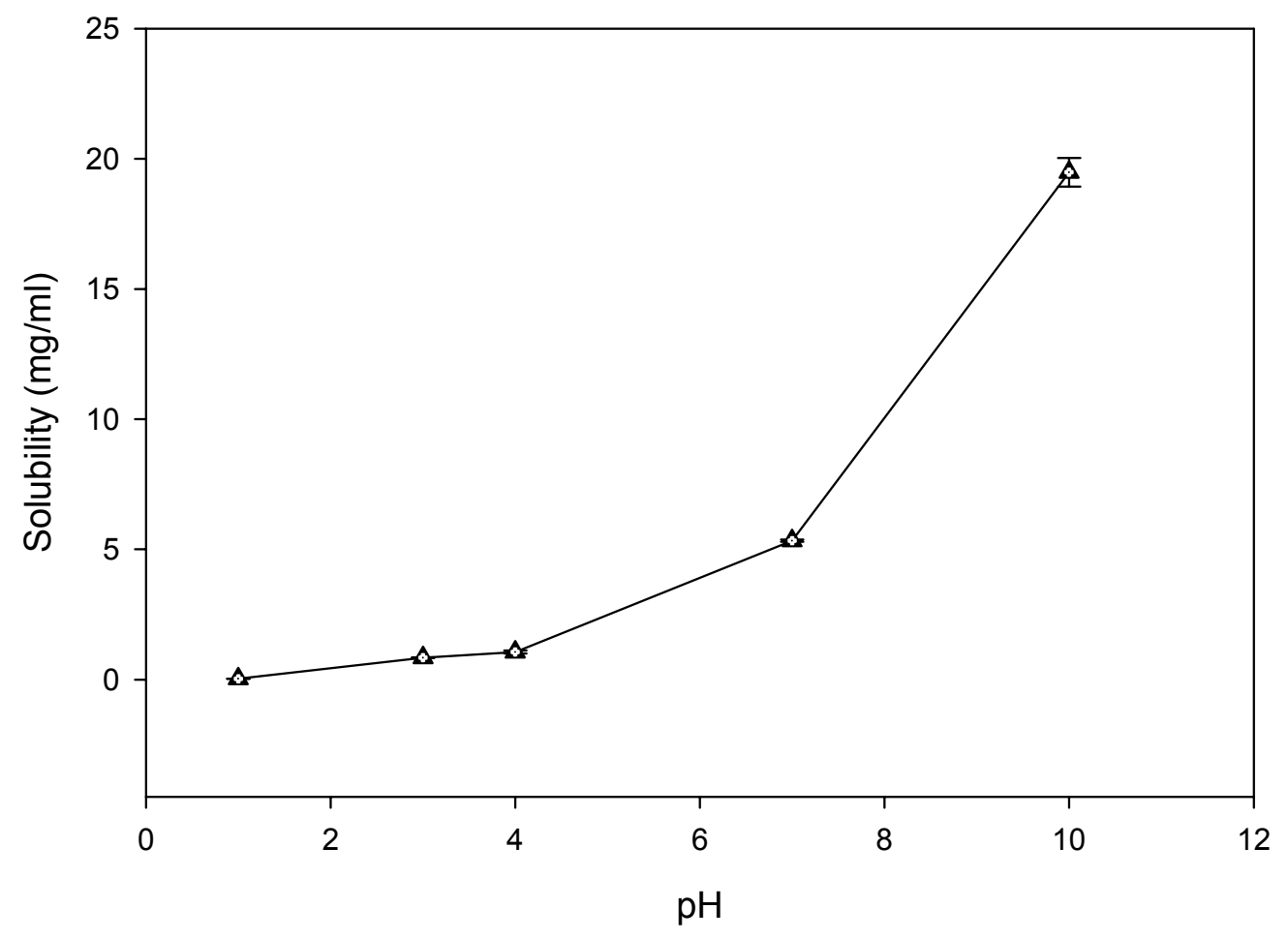

Figure 19. Folic acid solubility-pH profile.

\section{Dissolution of laboratory formulated folic acid products-Identification of Failure Mechanisms}

\section{A. Standard excipients tablets.}

To determine the contribution of folic acid tablet formulation to the dissolution behavior of the test folic acid products, different folic acid formulations were prepared in tablet dosage form. These tablets were tested for weight variation, hardness and dissolution in simulated gastric fluid and simulated intestinal fluid.

Table 19 contains the composition of each formulation, weight variation, hardness test results, and amount released in simulated gastric fluid and simulated intestinal fluid. First, folic acid was formulated in tablets containing only the 
active ingredient and a filler as a base line. The two fillers chosen were methyl cellulose and microcrystalline cellulose. Two lubricants, stearic acid and calcium stearate, were then added to the formulation, each at a time and at two different percentages, $1 \%$ and $5 \%$, to test the effect of different lubricants and lubricant percentage on the dissolution of folic acid. Lubricant levels can significantly affect drug dissolution due to their hydrophobic nature. Finally, a croscarmellose was added as a disintegrant to the formulation. These excipients constituted the most common inactive ingredients in the tested commercial single entity folic acid tablets.

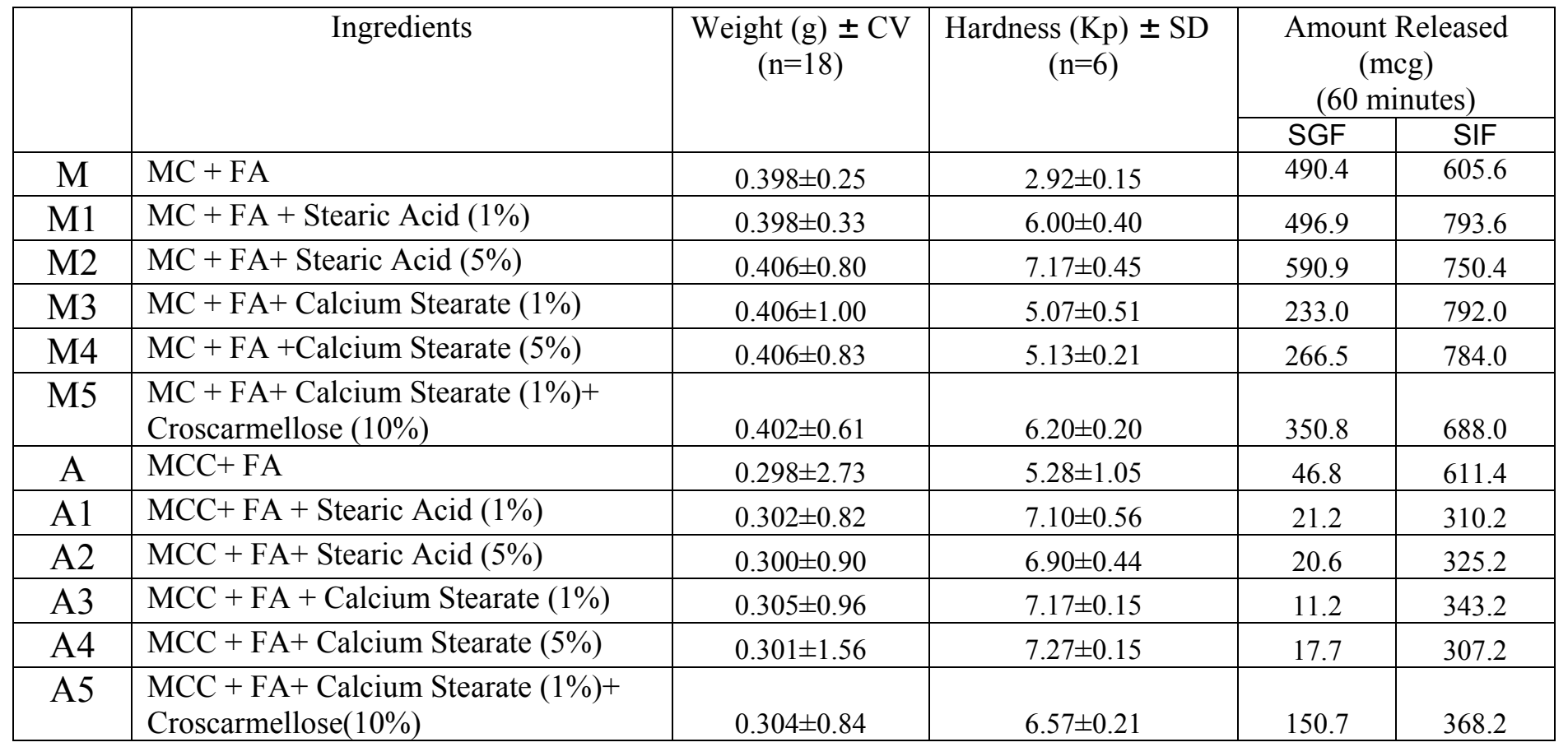

MC: Methyl Cellulose.

FA: Folic Acid.

MCC: Microcrystalline Cellulose.

Table 19 . Laboratory formulated folic acid tablets: composition, weight variation, hardness, and dissolution in SGF and SIF.

All the formulated products with methyl cellulose released more than $75 \%$ of the amount of folic acid in 60 minutes in simulated intestinal fluid (Figure 21). 
The addition of a lubricant or disintegrating agent did not affect the release. On the other hand, only one of the tablets formulated with microcrystalline cellulose released more than $75 \%$ of the amount of folic acid in 60 minutes in simulated intestinal fluid. The addition of a lubricant lowered the release of folic acid in simulated intestinal fluid (51\%- 57\% in 60 minutes); however, the addition of a disinetgrant to the formulation improved the release of folic acid (Figure 22).

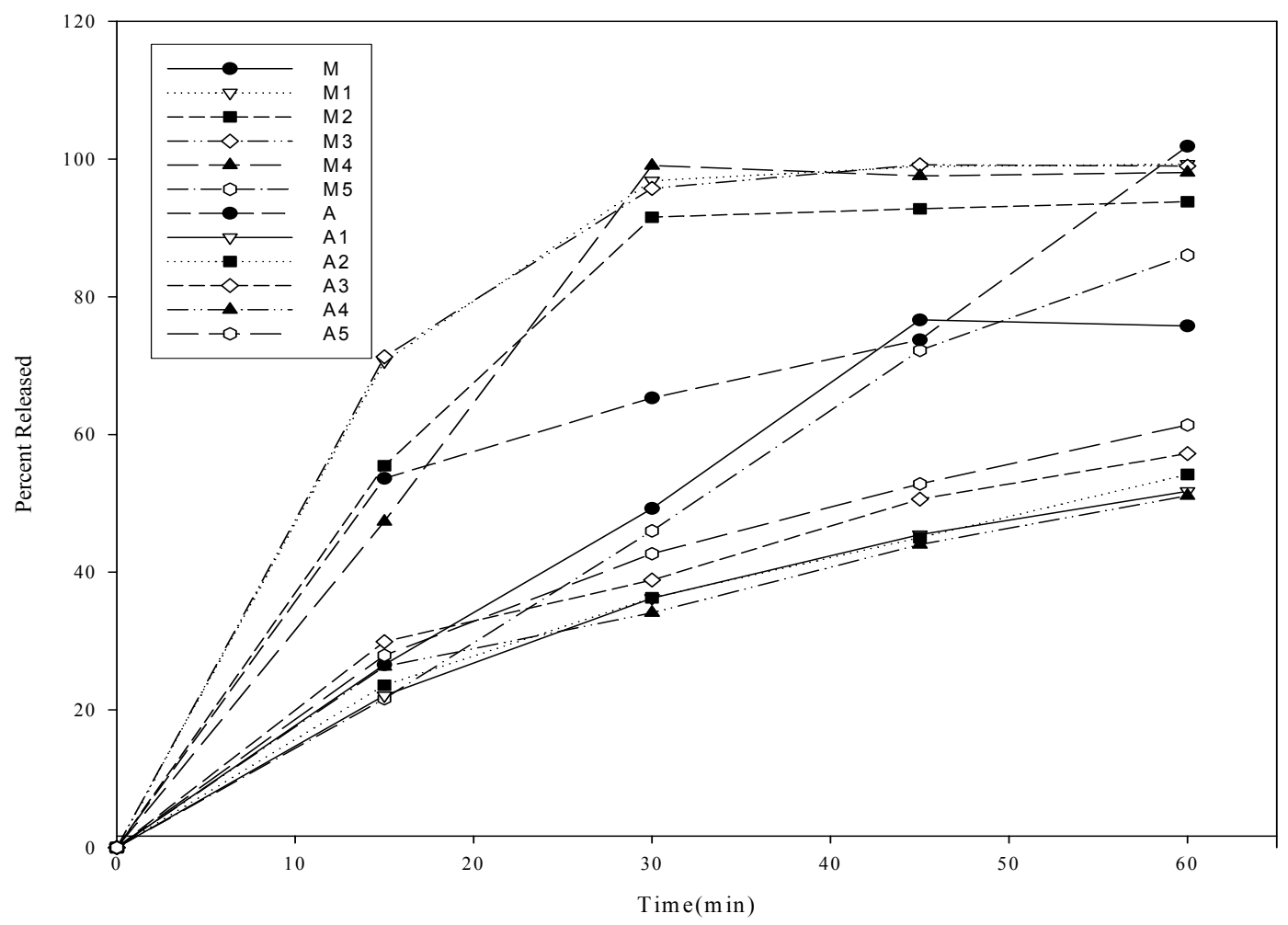

Figure 20. Laboratory formulated folic acid tablets dissolution profile in SIF

All the formulated tablets failed to release more than $75 \%$ of the amount of folic acid in 60 minutes in simulated gastric fluid (Table 19 and Figure 23). Generally, the addition of a lubricant decreased folic acid release compared to the baseline. Calcium stearate had a more pronounced effect on reducing the release of folic acid than stearic acid. This likely is because calcium stearate has smaller 
particle size than stearic acid resulting in greater coating/surface coating properties. The addition of a disintegrant improved the release of folic acid from

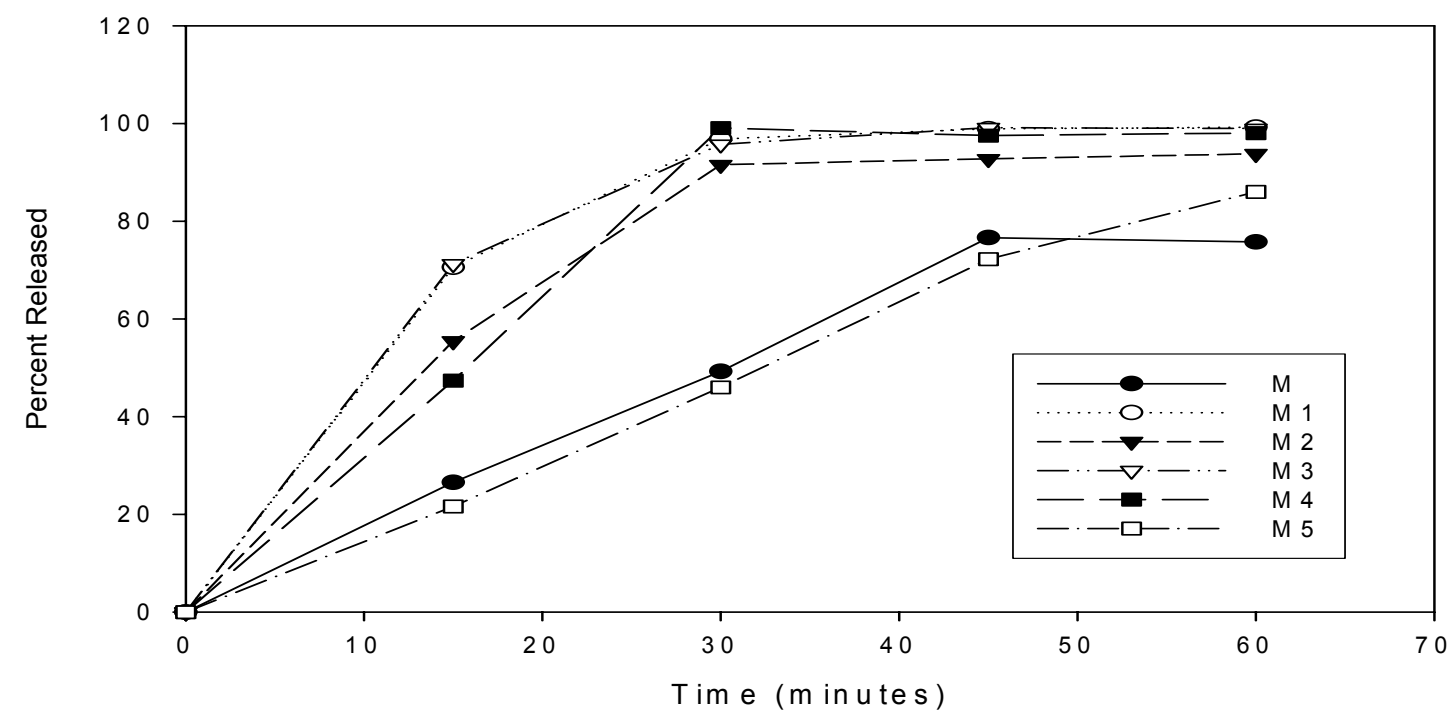

Figure 21. Methyl cellulose laboratory formulated folic acid tablets dissolution profile in SIF.

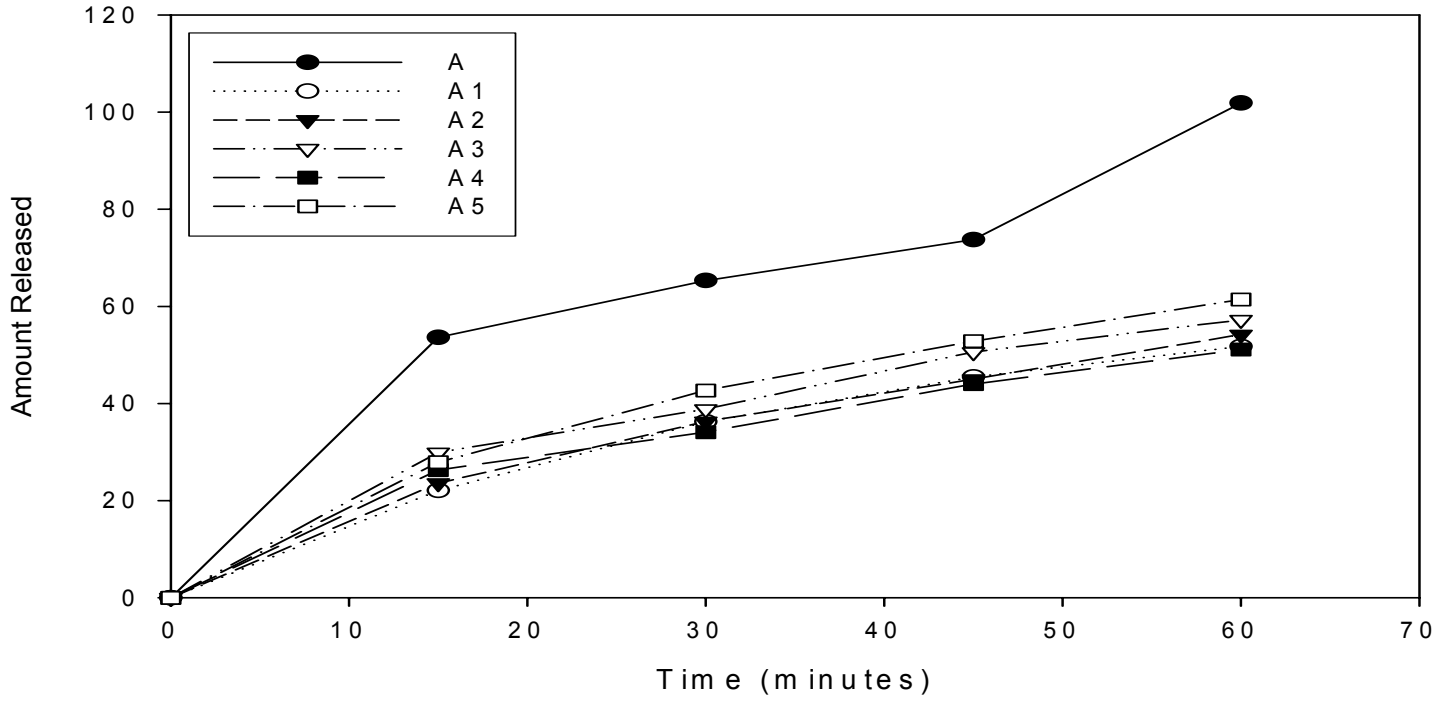

Figure 22. Microcrystalline cellulose laboratory formulated folic acid tablets dissolution profile in SIF. 
tablets containing $1 \%$ calcium stearate, which originally produced the lowest folic acid dissolution profile( Figures 24 and 25). Most of the formulated folic acid tablets with microcrystalline cellulose produced less than $10 \%$ release in 60 minutes in simulated gastric fluid. Methylcellulose, as a filler, provided better product release than did microcrystalline cellulose (Figure 26). It appears that certain excipients adversely affect folic acid dissolution, though, the acidic conditions appear to be contributing factor.

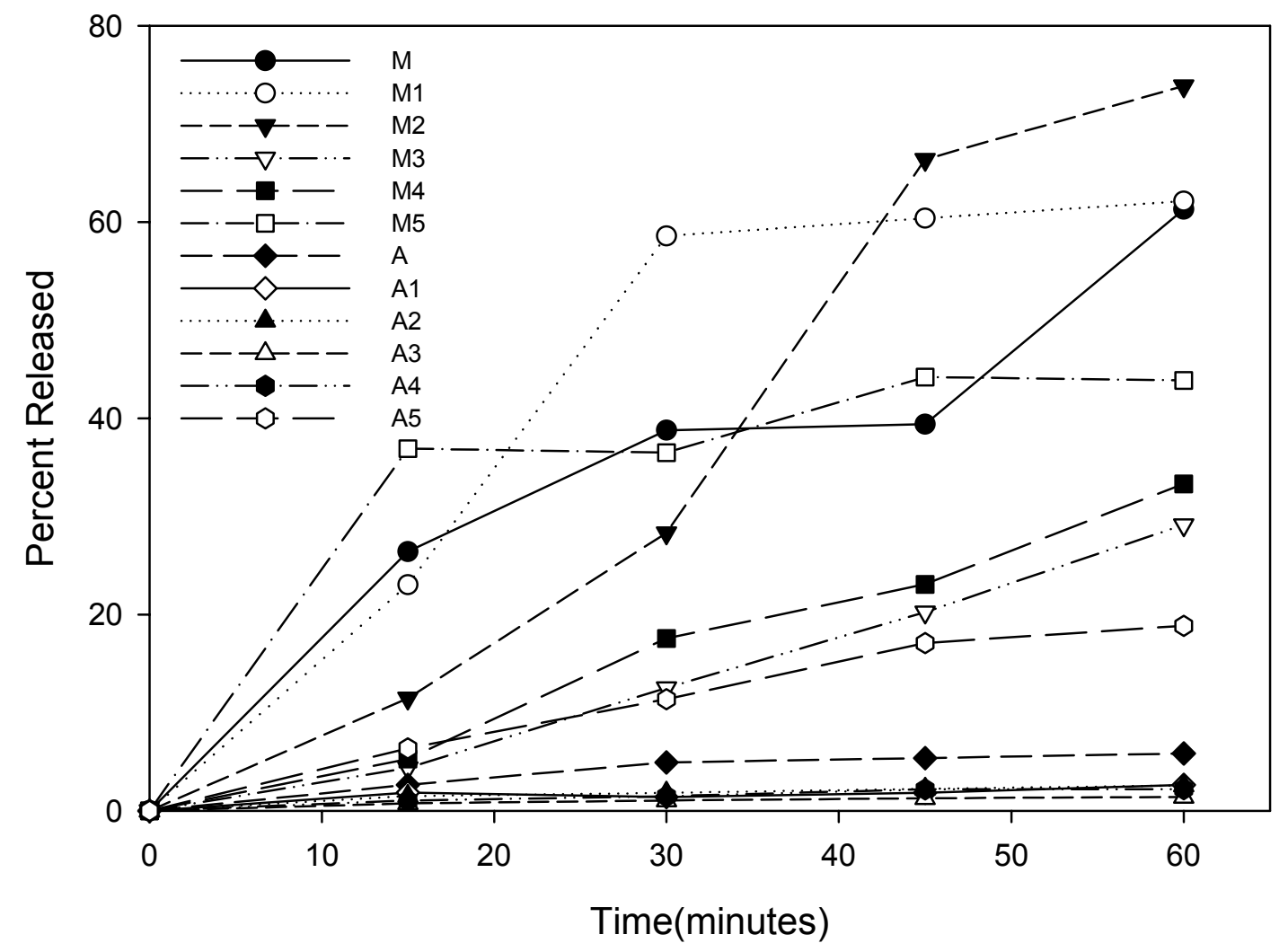

Figure 23. Laboratory formulated folic acid tablets dissolution profile in SGF. 


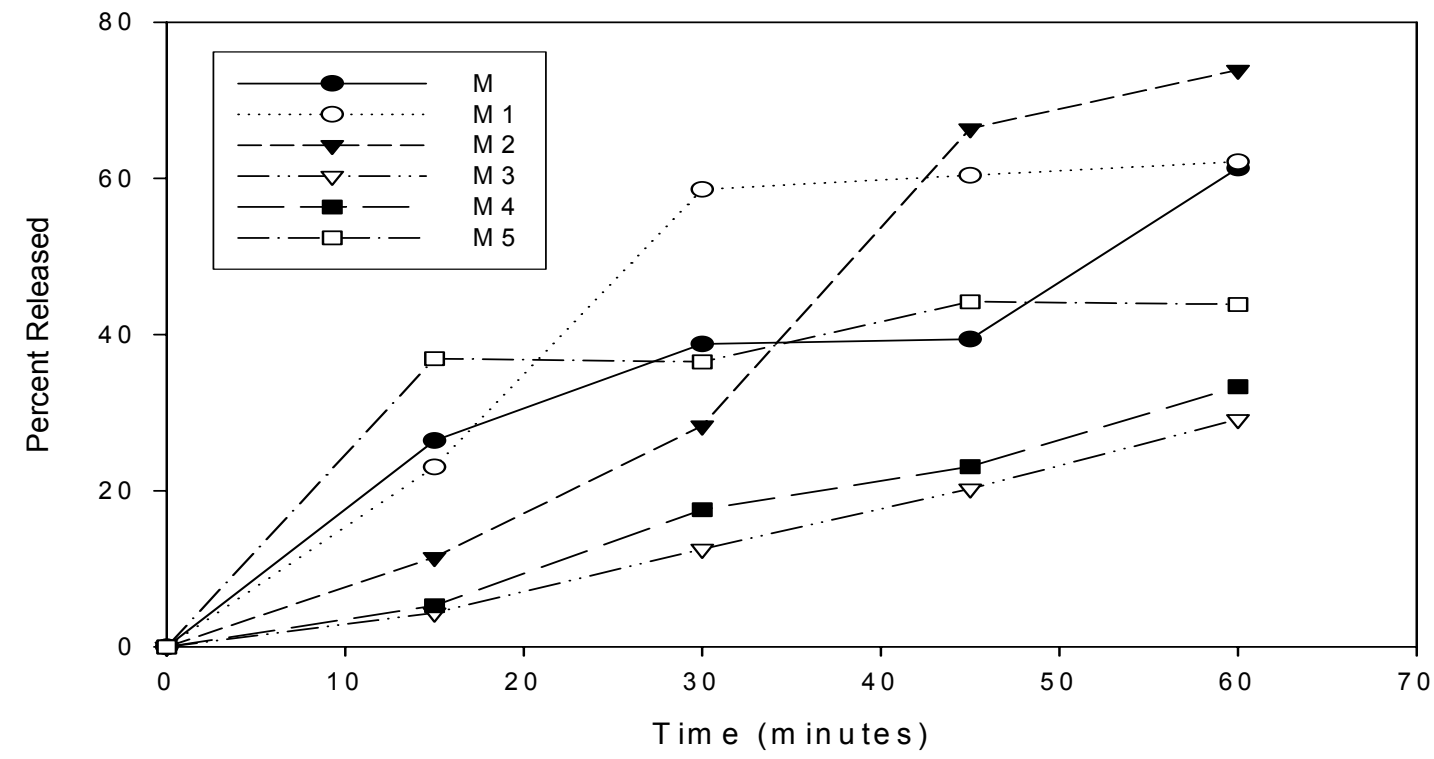

Figure 24. Methyl cellulose laboratory formulated folic acid tablets dissolution profile in SGF.

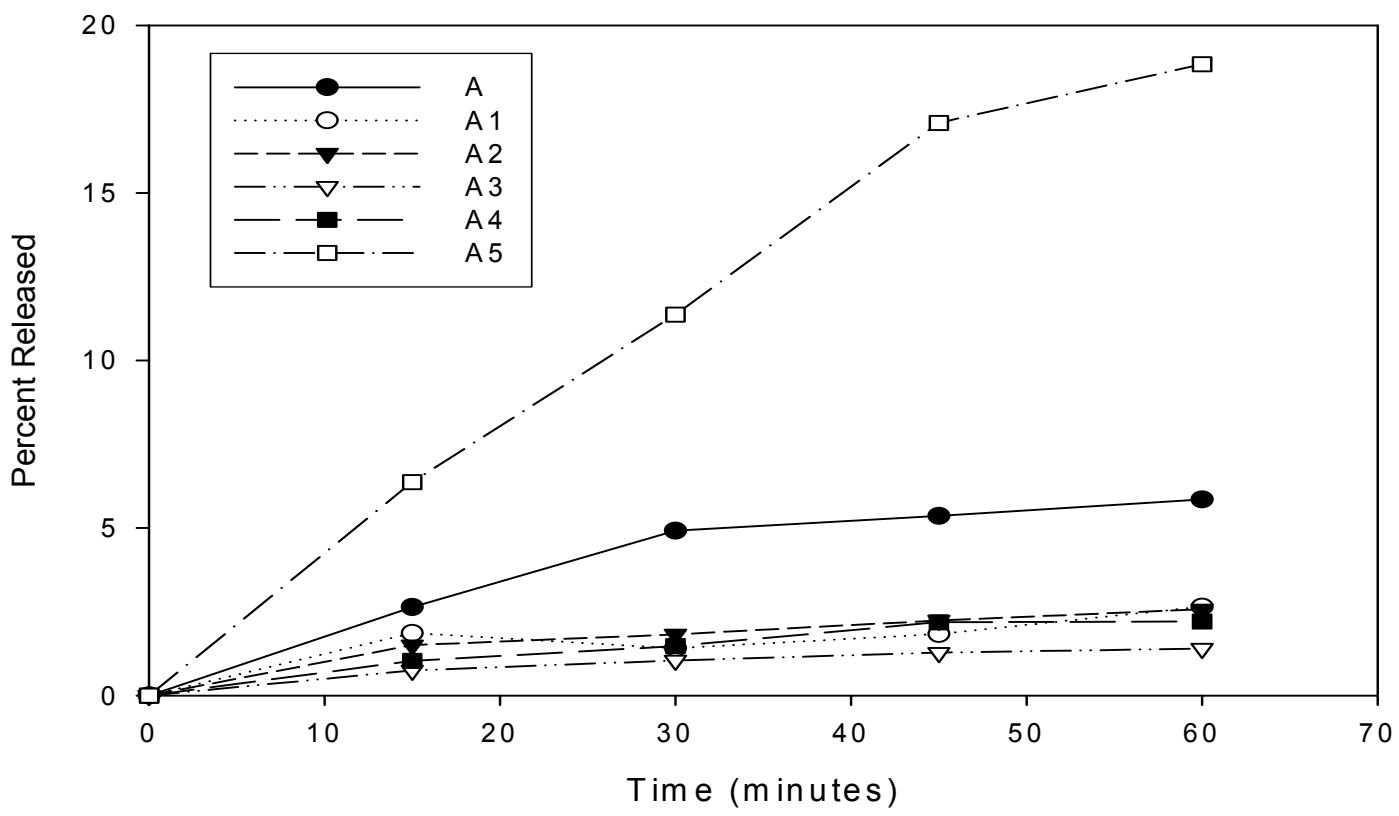

Figure 25. Microcrystalline cellulose laboratory formulated folic acid tablets dissolution profile in SGF. 


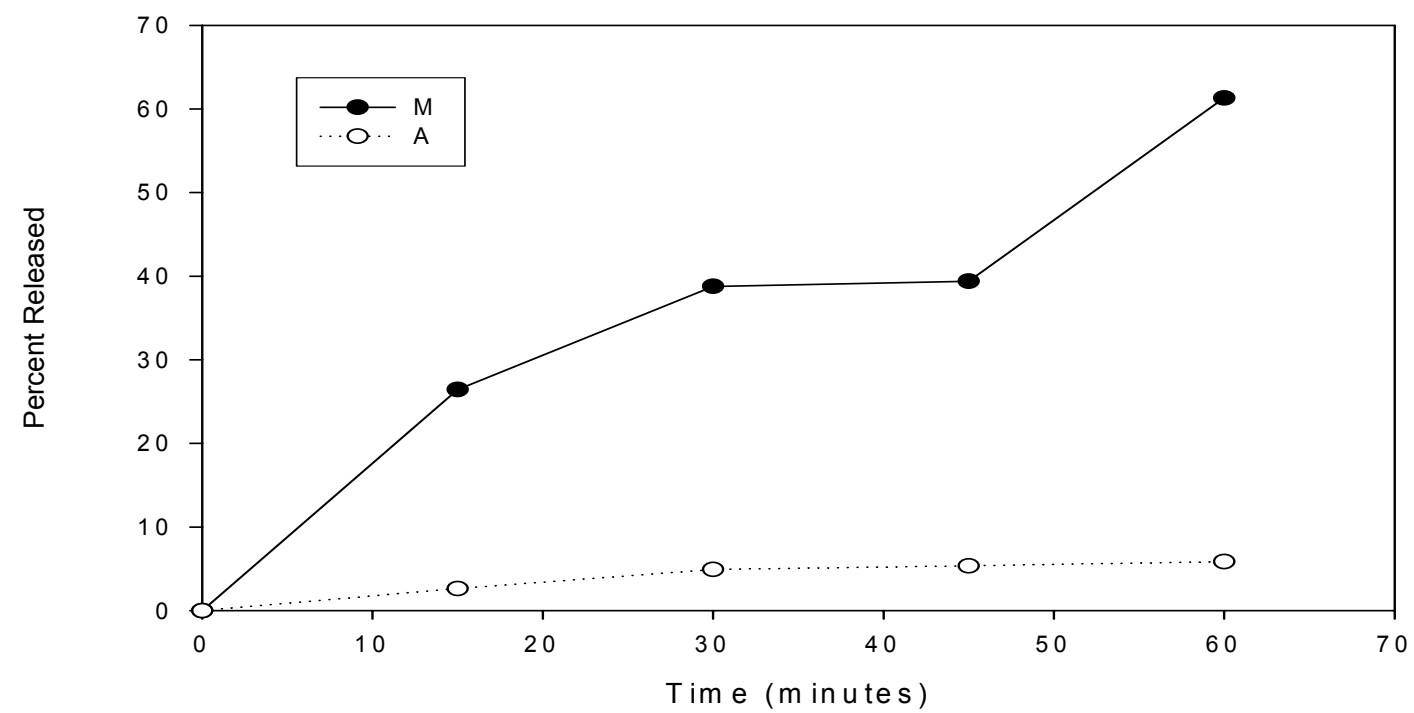

Figure 26. Comparison of fillers used in laboratory formulated folic acid tablets, dissolution profile in SGF.

\section{B. Buffered tablets.}

According to the Nernst-Brunner equation (Equation 1), three variables control the dissolution process. These three variables are the surface area of the solid drug particles, the drug diffusional properties, and the saturation solubility of the particular chemical form of the drug.

$$
\mathrm{dQ} / \mathrm{dt}=(\mathrm{DS} / \mathrm{h})\left(\mathrm{Cs}-\mathrm{C}_{\mathrm{b}}\right)
$$

Q: amount of drug (gm)

$\mathrm{T}$ : time (sec)

D: diffusion coefficient of the drug $\left(\mathrm{cm}^{2} / \mathrm{sec}\right)$

S: effective surface area of the drug particle $\left(\mathrm{cm}^{2}\right)$

$\mathrm{h}$ : thickness of the diffusion layer $(\mathrm{cm})$

Cs: saturation solubility of the drug in the diffusion layer $\left(\mathrm{gm} / \mathrm{cm}^{2}\right)$

$\mathrm{C}_{\mathrm{b}}$ : concentration of drug in the bulk fluids $\left(\mathrm{gm} / \mathrm{cm}^{2}\right)$

The solubility of the drug in the diffusion layer surrounding the drug particle has an important effect on the dissolution of the drug particle. If the drug 
has a low solubility in that layer, it will eventually produce a low dissolution rate relative to conditions in which the drug's solubility is higher. This may be a contributing factor in the reduced rate of folic acid release in simulated gastric fluid compared to simulated intestinal fluid. Folic acid has a $\mathrm{pH}$ dependent solubility profile with inherent low solubility in acidic $\mathrm{pH}$. In order to confirm this, folic acid was formulated in two different formulations: one with methyl cellulose and one in buffered tablets containing methyl cellulose and $25 \%$ citrate buffer (sodium citrate and citric acid, 2:1). The tablets were fit in the die and the die was hung in $500 \mathrm{ml}$ of simulated gastric fluid. Only one surface of the tablet is exposed to the medium, thus, dissolution occurs from a constant surface area without mixing, which eliminates other variables that might affect the dissolution process.

Normally, the $\mathrm{pH}$ of the bulk fluid may reflect the $\mathrm{pH}$ of the stationary diffusion layer. However, in the case of buffered tablet, as the buffer dissolves, it will alter the $\mathrm{pH}$ of the microenvironment of the stagnant diffusion layer to a $\mathrm{pH}$ of $\approx 4$, favoring more rapid dissolution of the active ingredient, without significantly changing the $\mathrm{pH}$ of the bulk fluid $(\mathrm{pH} \approx 1.5)$. Figure 27 shows the amount of folic acid released from each of the formulated tablets $(n=3)$. The results indicated a significant difference $(\alpha=0.05)$ between the average amount of folic acid released from the buffered and non-buffered tablets. These findings indicated a better folic acid release from buffered tablets (surface $\mathrm{pH} \approx 4$ ) than nonbuffered(surface $\mathrm{pH} \approx 1.5$ ), which supports the initial finding that the solubility of folic acid is the rate limiting step in the dissolution process of folic acid in simulated gastric fluid.

This conclusion can be achieved in another way. The dissolution rate is determined by the difference between $\mathrm{Cs}$ and $\mathrm{C}_{\mathrm{b}}$, and not solely by Cs. The higher the difference between $\mathrm{Cs}$ and $\mathrm{C}_{\mathrm{b}}$, the more rapid the dissolution rate. Sink condition, which is achieved when the $\mathrm{C}_{\mathrm{b}} / \mathrm{Cs}$ ratio is less than $10 \%$, should always be maintained to drive the dissolution process. 


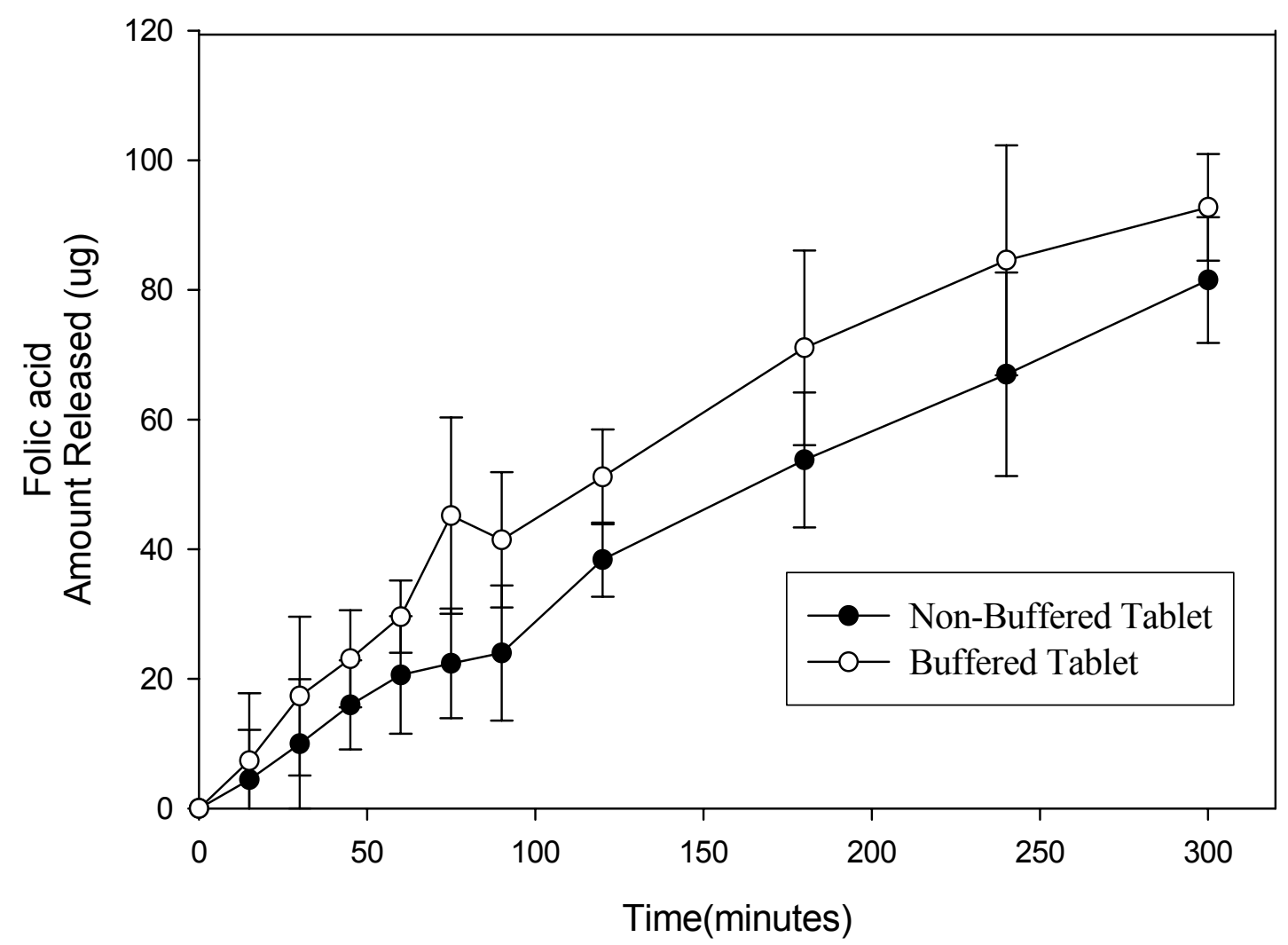

Figure 27. Constant surface area folic acid release.

In case of the buffered tablets, provided that the buffer increased the $\mathrm{pH}$ of the diffusion layer to approximately $\mathrm{pH} 4$ and hence increasing Cs by five-fold compared to that at $\mathrm{pH} 1$, the difference between $\mathrm{Cs}$ and $\mathrm{C}_{\mathrm{b}}$ is greater than that obtained when using non-buffered tablets and hence the dissolution rate is higher. Also, with higher $\mathrm{Cs}$ at $\mathrm{pH} 4$, a larger amount of drug can dissolve in the bulk $\left(\mathrm{C}_{\mathrm{b}}\right)$ before surpassing sink conditions (for further treatment of this data see Appendix IV).

We hypothesize that increasing the buffer percentage in the tablet formulation will produce a more pronounced effect on folic acid release; however, the suppression of the folic acid peaks in the HPLC assay with an increasing the buffer concentration did not allow the completion of these studies. An assay 
method that accounts for both the buffer and folic acid should be developed before conducting such experiments.

The obtained results strongly indicate that there is a contribution of folic acid solubility to its dissolution rate. However, one should also be aware of the effect of other excipients in the formulation on the dissolution process, as suggested by the variable dissolution profiles obtained with different excipients. 


\section{Chapter V}

\section{Summary and Conclusions}

Folic acid is a water-soluble vitamin that has been used to treat macrocytic anemia without neurologic disease. Folate obtained from pharmaceutical preparations is the most bioavailable, because $10 \%$ to $50 \%$ of dietary folate is lost in the cooking process.

The vitamin folic acid has received considerable attention in the 1990s because of its preventative role in birth defects and disease Significant literature exists in the area of periconceptional use of the vitamin to decrease the risk of neural tube defects (NTDs) such as spina bifida. It has also been suggested that folic acid may be effective in decreasing certain risks of cardiovascular disease and psychiatric illness, most notably dementia.

Nutraceuticals, which include folic acid, vitamins, and herbals, are regulated by the FDA as foods not as drugs. A primary concern is the quality, potency, and efficacy of nutritional supplements and label claims. Standards for nutritional supplements were first proposed in the Pharmacopeial Forum in 1993 and accepted in 1995, though, manufacturers are recommended, but not required, to follow those guidelines as long as the product is not labeled USP.

In the past, a number of commercially available folic acid products were tested for compliance with USP monographs requirements for disintegration and dissolution. A failure to meet USP requirements were observed in many of those tested products and a release percent as low as 10\% was also measured, raising questions about the poor pharmaceutical quality of these products and the potential impact on public health. 
In these studies, seven commercially available single entity folic acid products and eight folic acid containing multivitamin products were tested for disintegration, content uniformity and dissolution in three media: simulated gastric fluid, distilled water and simulated intestinal fluid. One single entity folic acid product failed to disintegrate completely in 30 minutes. Another single entity folic acid product contained more than the USP allowed amount per tablet. One of the folic acid containing multivitamin products failed to meet the USP specifications for folic acid dissolution. All of the tested products failed to release more than $75 \%$ of the labeled amount in 60 minutes in simulated gastric fluid. The results of the work showed that there appears to be great progress since the 1990's in the quality of commercially available folic acid products in meeting USP standards. There was no significant difference in the pharmaceutical quality of the different types of formulations studied (tablet vs capsule, multivitamin vs single entity). Little folic acid degradation was noted in these products.

Nutrients, which include but are not limited to water soluble vitamins such as folic acid, are absorbed by carrier-mediated membrane transport systems on the brush-border, and basolateral membranes of the gut wall facilitate this. Most of these carrier systems are present at the upper end of the small intestine. For folic acid, most absorption occurs in the proximal jejunum. Thus, when taken on an empty stomach, folic acid absorption may be altered since the gastric retention time and the time to pass through the jejunum can be short. Folic acid absorption is expected to be significantly reduced if it is not released from the dosage unit by the time it passes through the folic acid absorption window in the proximal jejunum. Thus, a fast and complete rate of folic acid dissolution in the stomach is essential.

The USP dissolution test is a monitoring tool that helps predict the rate and extent of drug release. For a drug or vitamin to be absorbed from the gastrointestinal tract, it must first be released from the dosage unit in the stomach before it passes through its absorption window in the proximal jejunum. It should 
be noted that complete release does not guarantee absorption, although it is an essential provision for absorption to occur (The same is true for the relationship between disintegration and dissolution). At present, specifications based on USP dissolution apparatus I and II are the most widely used methods to assess the drug release from a tablet or capsule. These standards are not ideal because the in vitro/ in vivo correlation for folic acid has not been established; failure to meet the dissolution specifications does not allow one to state conclusively that bioavailability of the product will be low. However, the guidelines are the best available to ensure good absorption of vitamins from nutritional supplements.

All the products tested failed to release more than $75 \%$ of the labeled amount in simulated gastric fluid in one hour. And since most of the folic acid absorption occurs at the proximal jejunum, one can expect that, if the folic acid tablet was taken on an empty stomach, most of the folic acid will pass its absorption window in the tablet body as it will not be completely released into solution for absorption. Therefore, a low extent of absorption from these folic acid tablets is possible.

These findings are important for several reasons. First, the difference in folic acid dissolution may significantly affect the adequacy of folic acid supplementation to normal healthy women who may conceive. This will increase the risk of neural tube defects, since protective blood folate levels might not be achieved. Second, women with inborn errors of folate metabolism, as well as individuals taking antiepileptic or other drug regimens that interfere with folic acid production have special supplementation needs that may go unmet because of poor dissolution levels, or excessive drug loading in these products, which could lead to toxic effects.

Laboratory formulated folic acid tablets failed to release more than $75 \%$ in 60 minutes in simulated gastric fluid. Excipients used and tableting conditions also had a significant effect on folic acid tablet dissolution. No sign of chemical degradation of folic acid was observed throughout the studies. These finding 
suggested that the folic acid dissolution process is solubility controlled. Folic acid has a $\mathrm{pH}$ dependent solubility profile with inherent low solubility in acidic $\mathrm{pH}$. This was confirmed by the result of constant surface area studies of folic acid buffered and non-buffered tablets. The increased release of folic acid from the buffered tablets compared to non buffered tablets demonstrated that the buffer's altered $\mathrm{pH}$ of the microenvironment of the stagnant diffusion layer led to a $\mathrm{pH}$ favoring rapid dissolution of the active ingredient.

In conclusion, when formulating folic acid, its solubility should be taken into consideration. Folic acid tablets should be designed in a way that ensure the release of folic acid in acidic $\mathrm{pH}$, so as it will be in solution and ready for absorption as it passes through its absorption window in the proximal jejunum. This can be achieved by formulating folic acid in buffed tablets, or by complexation of folic acid with cyclodextrins to improve folic acid solubility in acidic solutions. It should be noted if the USP changed the requirement for folic acid dissolution medium to be simulated gastric fluid rather than distilled water, the inherent low solubility of folic acid in acidic $\mathrm{pH}$ should be considered. Future studies may include the construction of folic acid in vitro/ in vivo correlation using liquid chromatography mass spectrometry techniques. The construction of this correlation will have a great impact on optimizing folic acid formulation. 


\section{Appendices}

Appendix I: Representative Folic Acid HPLC Chromatograms.

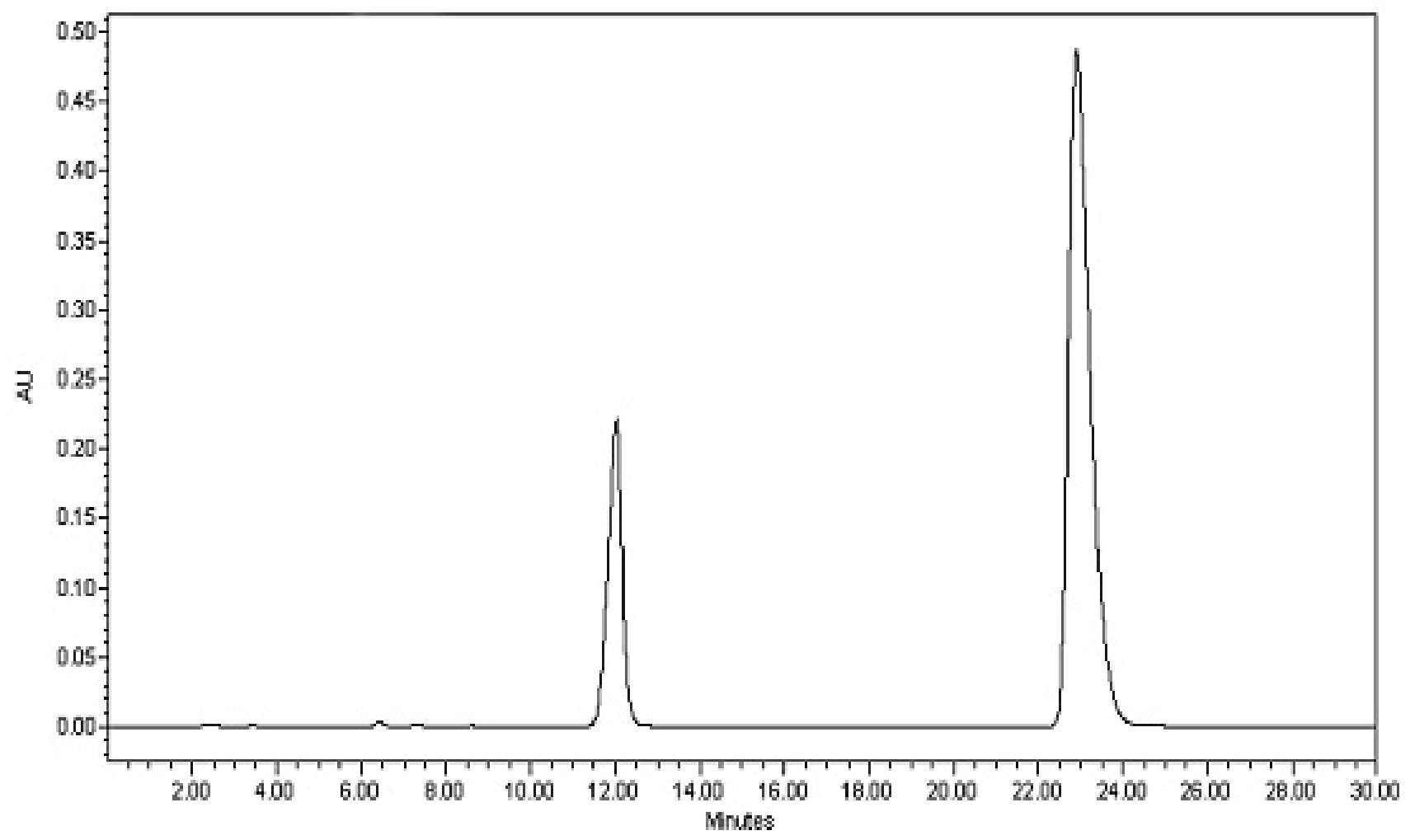

Figure I. HPLC Chromatogram of folic acid (RT $12 \mathrm{~min}$.) $(0.2 \mathrm{mg} / \mathrm{ml})$ and methylparaben (RT $23 \mathrm{~min}$.) $(0.4 \mathrm{mg} / \mathrm{ml})$ using HPLC assay method. 


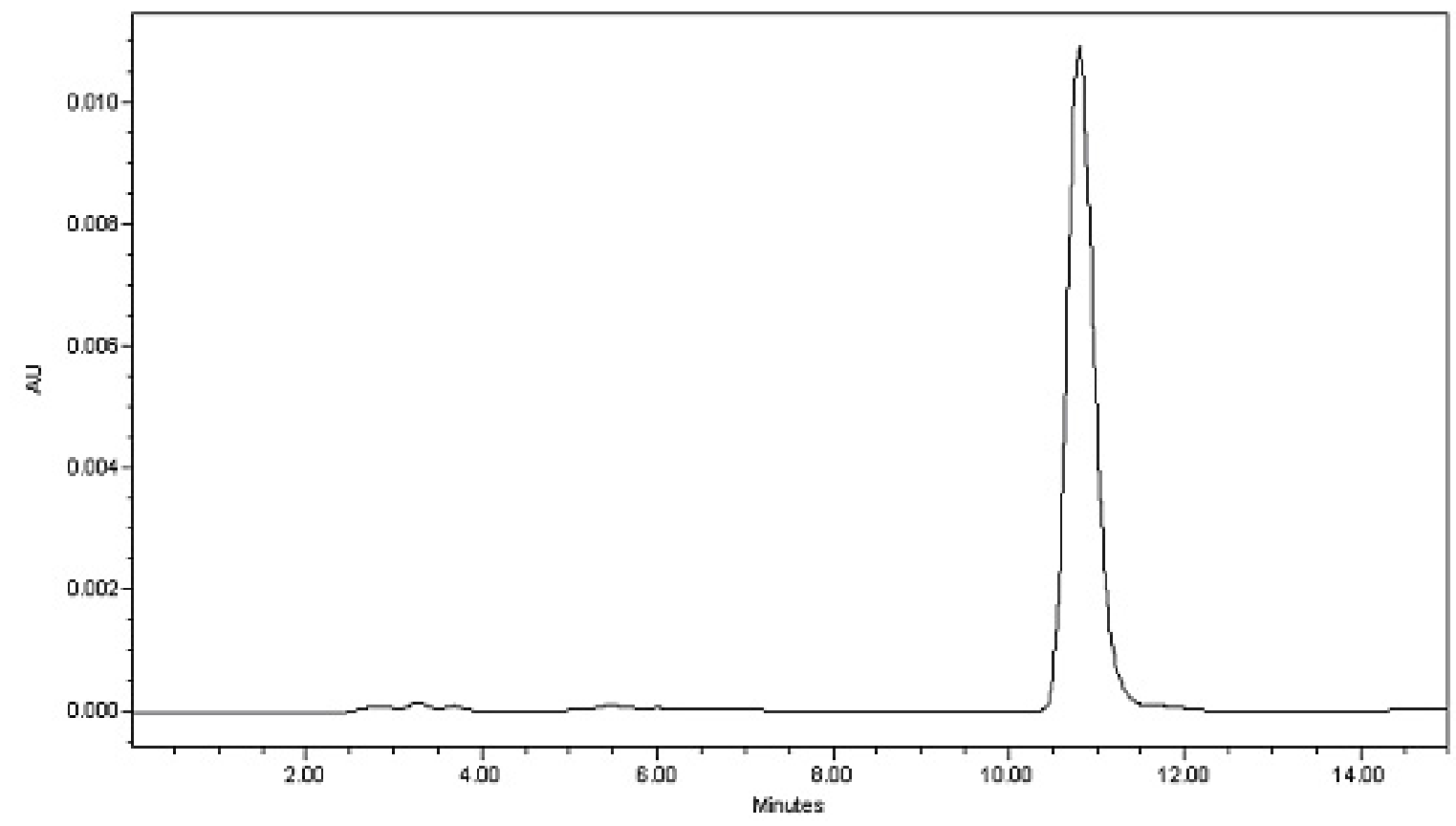

Figure II. HPLC Chromatogram of folic acid $(0.8 \mu \mathrm{g} / \mathrm{ml})$ using HPLC assay for single entity folic acid tablets.

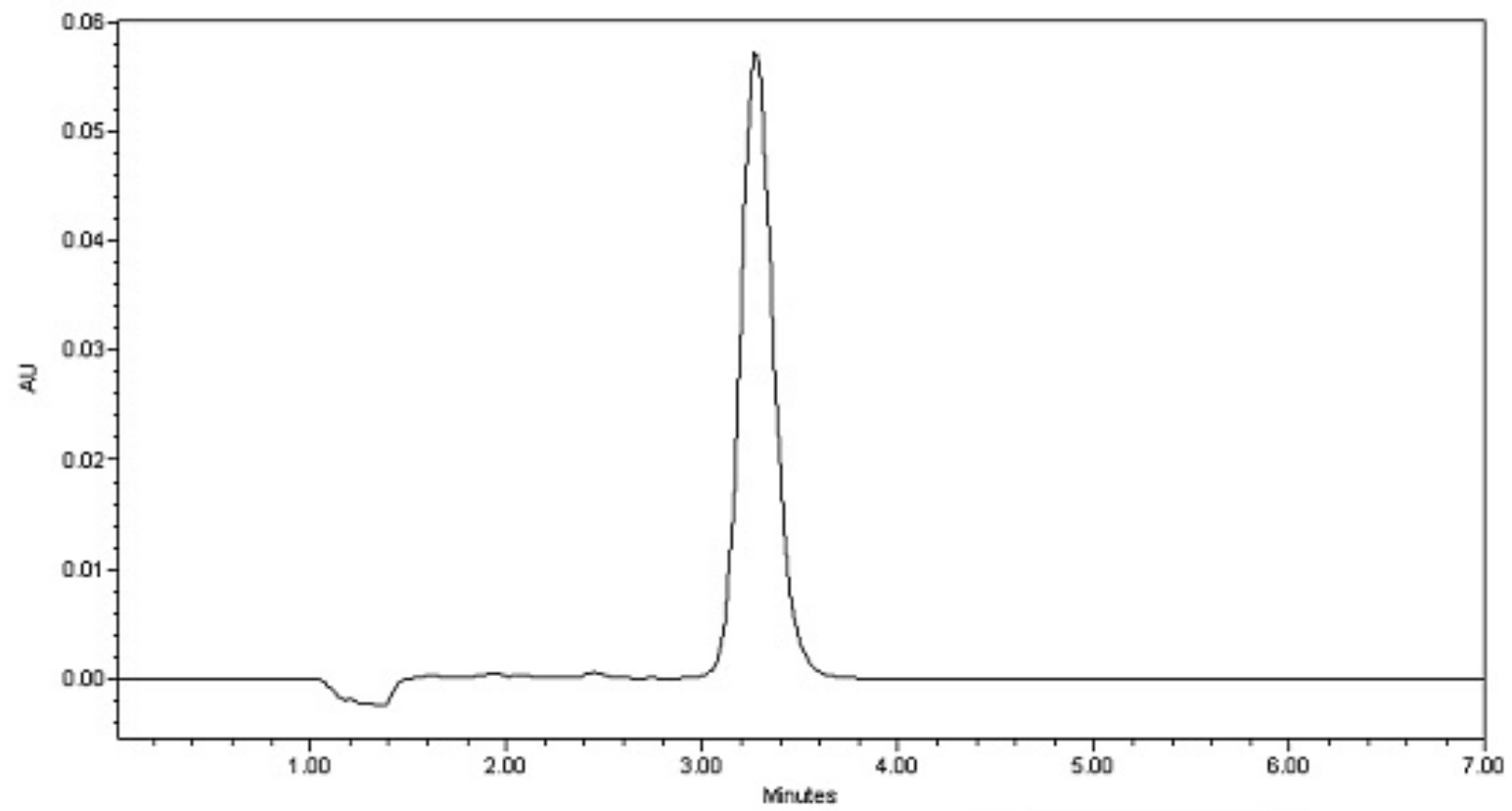

Figure III. HPLC Chromatogram of folic acid $(1.6 \mu \mathrm{g} / \mathrm{ml})$ using HPLC assay of folic acid in multivitamin dosage units. 
Appendix II: List of Commercial Drug Products Tested.

\begin{tabular}{|c|c|c|c|c|}
\hline $\begin{array}{c}\text { Product } \\
\text { Code }\end{array}$ & Product Name & Manufacturer & Lot No. & $\begin{array}{c}\text { Folic Acid } \\
\text { (mcg) }\end{array}$ \\
\hline 1 & Folic Acid & Naturally Preferred & 306095 & 400 \\
\hline 2 & Folic Acid & Nature Made & LD11007N & 400 \\
\hline 3 & Folic Acid & Rite Aid & 39013 & 400 \\
\hline 4 & Folic Acid & Kroger & 1 HB0390 & 400 \\
\hline 5 & Folic Acid & Nature's Bounty & 5253402 & 400 \\
\hline 6 & Folic Acid & PharmAssure & 94505 & 400 \\
\hline 7 & Folic Acid & GNC & 1394 Dc2560 & 400 \\
\hline MV1* & Stuart Natal Plus 3 & Integrity & 210021 & 800 \\
\hline MV 2* & Stuart Natal & Integrity & 205121 & 800 \\
\hline MV $3^{*}$ & Prenatal & Eckerd & 1 KA0322 & 800 \\
\hline MV 4* & Prenatal Tablets & Rite Aid & 94631 & 800 \\
\hline MV 5* & Prenatal Tablets & Kroger & 1 PBO541 & 800 \\
\hline NMV1** & Nephro-Vite & R \& D Laboratory & 0103 & 1000 \\
\hline NMV2** & Nephron FA & Nephro-Tech & 307054 & 800 \\
\hline NMV3* & Nephrocaps & Fleming \& Company & 6643004 & 1000 \\
\hline & Fenton & & \\
\hline
\end{tabular}


Appendix III: Calculation of \% dissolved in 45 or 60 minutes for commercial products based on their actual (determined by content uniformity), not labeled, amount.

Table I: Percent Release of folic acid (in single entity folic acid tablets) in 40 minutes..

\begin{tabular}{|c|c|c|c|}
\hline \multirow{2}{*}{ Product Code } & \multicolumn{3}{|c|}{ Percent Released (45 minutes) } \\
\cline { 2 - 4 } & SGF & DW & SIF \\
\hline 1 & $22.4 \%$ & $81.2 \%$ & $85.0 \%$ \\
\hline 2 & $40.1 \%$ & $102.0 \%$ & $96.3 \%$ \\
\hline 3 & $37.0 \%$ & $91.0 \%$ & $109.2 \%$ \\
\hline 4 & $45.4 \%$ & $89.7 \%$ & $98.8 \%$ \\
\hline 5 & $50.7 \%$ & $103.9 \%$ & $99.2 \%$ \\
\hline 6 & $67.2 \%$ & $96.6 \%$ & $114.6 \%$ \\
\hline 7 & $33.6 \%$ & $96.0 \%$ & $108.5 \%$ \\
\hline
\end{tabular}

Table II: Percent release of folic acid (in multivitamin dosage units) in 60 minutes

\begin{tabular}{|c|c|c|c|}
\hline \multirow{2}{*}{ Product Code } & \multicolumn{3}{|c|}{ Percent Released (60 minutes) } \\
\cline { 2 - 4 } & SGF & DW & SIF \\
\hline MV1 & $58.0 \%$ & $95.4 \%$ & $97.2 \%$ \\
\hline MV2 & $19.5 \%$ & $99.0 \%$ & $88.6 \%$ \\
\hline MV3 & $40.7 \%$ & $106.1 \%$ & $86.8 \%$ \\
\hline MV4 & $37.1 \%$ & $85.7 \%$ & $78.4 \%$ \\
\hline MV5 & $37.2 \%$ & $91.2 \%$ & $70.0 \%$ \\
\hline NMV1 & $34.3 \%$ & $98.9 \%$ & $69.7 \%$ \\
\hline NMV2 & $31.4 \%$ & $98.3 \%$ & $100.2 \%$ \\
\hline NMV3 & $15.4 \%$ & $39.0 \%$ & $48.1 \%$ \\
\hline
\end{tabular}

* Multivitamin Tablet (Prenatal). ** Nephritic Multivitamin Dosage Unit. 
Appendix IV: Folic Acid Solubility- Analysis of Sink Conditions.

Table I: Commercial tested products $(\mathrm{pH}=1.5 / \mathrm{Cs}=240 \mu \mathrm{g} / \mathrm{ml})$.

\begin{tabular}{|c|c|c|c|}
\hline Product & Percent Release & $\begin{array}{c}\text { Amount Released } \\
\text { (ug/ml) }\end{array}$ & $(\mathrm{Cg} / \mathrm{Cs}) \%$ \\
\hline MV1* & \multicolumn{2}{|c|}{$(60$ minutes $)$} & \\
\hline MV 2* & $28.7 \%$ & 0.54 & 0.23 \\
\hline MV 3* & $52.9 \%$ & 0.25 & 0.11 \\
\hline MV 4* & $47.1 \%$ & 0.47 & 0.20 \\
\hline MV 5* & $45.8 \%$ & 0.42 & 0.17 \\
\hline NMV1** & $42.2 \%$ & 0.41 & 0.17 \\
\hline NMV2** & $32.8 \%$ & 0.37 & 0.16 \\
\hline NMV3** & $15.2 \%$ & 0.29 & 0.12 \\
\hline & \multicolumn{2}{|c|}{$(45$ minutes) } & 0.14 \\
\hline 1 & $23.6 \%$ & 0.19 & 0.08 \\
\hline 2 & $56.6 \%$ & 0.45 & 0.19 \\
\hline 3 & $38.0 \%$ & 0.30 & 0.13 \\
\hline 4 & $46.5 \%$ & 0.37 & 0.15 \\
\hline 5 & $51.9 \%$ & 0.42 & 0.17 \\
\hline 6 & $68.1 \%$ & 0.54 & 0.23 \\
\hline 7 & $34.1 \%$ & 0.27 & 0.11 \\
\hline
\end{tabular}

From this analysis, it appears that sink conditions were maintained. This suggests sensitivity not just of folic acid to $\mathrm{pH}$ conditions, but also of the excipients which warrants further studied. 
Table II: Buffered vs Non-Buffered tablets $(\mathrm{pH}=1.5 / \mathrm{Cs}=240 \mu \mathrm{g} / \mathrm{ml} / / \mathrm{pH}=4.0 /$ $\mathrm{Cs}=1.05 \mathrm{mg} / \mathrm{ml}$ ).

\begin{tabular}{|c|c|c|c|}
\hline \multirow[b]{3}{*}{ Time } & \multicolumn{3}{|c|}{ Buffered Tablets $(n=3)$} \\
\hline & \multirow[b]{2}{*}{ Amount Released $(\mu \mathrm{g})$} & \multicolumn{2}{|c|}{$(\mathrm{Cg} / \mathrm{Cs}) \%$} \\
\hline & & $\mathrm{pH}=1 *$ & $\mathrm{pH}=4$ \\
\hline 0 & 0 & 0 & 0 \\
\hline 15 & 4.44 & 0.0037 & 0.0008 \\
\hline 30 & 9.97 & 0.0083 & 0.0019 \\
\hline 45 & 15.97 & 0.0133 & 0.0030 \\
\hline 60 & 20.60 & 0.0172 & 0.0039 \\
\hline 75 & 22.39 & 0.0187 & 0.0042 \\
\hline 90 & 23.98 & 0.0200 & 0.0045 \\
\hline 120 & 38.39 & 0.0320 & 0.0073 \\
\hline 180 & 53.77 & 0.0448 & 0.0102 \\
\hline 240 & 66.99 & 0.0558 & 0.0127 \\
\hline \multirow[t]{3}{*}{300} & 81.53 & 0.0679 & 0.0154 \\
\hline & \multicolumn{3}{|c|}{ Non-Buffered Tablets $(\mathrm{n}=3)$} \\
\hline & & \multicolumn{2}{|c|}{$(\mathrm{Cg} / \mathrm{Cs}) \%$} \\
\hline Time & Amount Released $(\mu \mathrm{g})$ & $\mathrm{pH}=1$ & $\mathrm{pH}=4 *$ \\
\hline 0 & 0 & 0 & 0 \\
\hline 15 & 7.36 & 0.0061 & 0.0014 \\
\hline 30 & 17.33 & 0.0144 & 0.0033 \\
\hline 45 & 23.09 & 0.0192 & 0.0044 \\
\hline 60 & 29.59 & 0.0247 & 0.0056 \\
\hline 75 & 45.19 & 0.0377 & 0.0085 \\
\hline 90 & 41.45 & 0.0345 & 0.0078 \\
\hline 120 & 51.14 & 0.0426 & 0.0097 \\
\hline 180 & 71.05 & 0.0592 & 0.0134 \\
\hline 240 & 84.56 & 0.0705 & 0.0160 \\
\hline 300 & 92.71 & 0.0773 & 0.0175 \\
\hline
\end{tabular}

* The assumption is made that for the non-buffered tablets the $\mathrm{pH}$ at the surface is 1.5 , and for the buffered tablets the $\mathrm{pH}$ at the surface is 4.0. From this comparison, it shows that increasing the $\mathrm{pH}$ allows for better maintaining of sink conditions, which is reflected in the increased dissolution rate of these products (Figure 27). 


\section{References}

1. Locksmith GL, "Preventing Neural Tube Defects: The Importance of

Periconceptional Folic Acid Supplements," Obstet Gynecol. 1998, 91(6): 1027-34.

2. Berg MJ, "The Importance of Folic Acid," Clinical Geriatric Magazine Online.

May 1999. (www.mmhc.com/jgsm).

3. Swain RA, St Clair L., "The Role of Folic Acid in Deficiency States and

Prevention of Disease," J Fam Pract. 1997; 44(2):138-44

4. Lewis DP, Stumbo PJ, Berg MJ, "Drug and Environmental Factors Associated with Adverse Pregnancy Outcomes, Pt II: Improvement with Folic Acid," Ann Pharmacother. 1998, 32: 947-61.

5. Lewis DP, Stumbo PJ, Berg MJ, "Drug and Environmental Factors Associated with Adverse Pregnancy Outcomes, Pt III:Pharmacology, Therapeutic Recommendations, and Economics," Ann Pharmacother. 1998, 32: 1087-95.

6. Reynolds E, "Folic acid, Aging, Depression, and Dementia," Br Med J. 2002, 324: $1512-15$.

7. Mayer EL, Jocabson DW, Robinson K, "Homocysteine and Coronary Atherosclerosis," J Am Coll Cardiol. 1996, 27(3): 517-27.

8. Hoag S, Shangraw R, "Failure of Prescription Prenatal Vitamin to Meet USP Standards for Folic Acid Dissolution," J Am Pharm Assoc. 1997, NS37 (4): 397 400 .

9. "Use of Folic Acid-Containing Supplements among Women of Childbearing Age-United States," 1997. Morb Mortal Wkly Rep. 47(7): 131-34.

10. De la Calle M, Sancha M, Magdaleno F, Herranz A, Cabrillo E, "Homocysteine, Folic Acid and B-group Vitamins in Obstetrics and Gynaecology,” Eur J Obstet Gynecol Reprod Biol. 2003, 107(2): 125-34. 
11. Moore LL, Singer MR, Rothman KJ, Milunsky A, "Folate Intake and the Risk of Neural Tube Defects: An Estimation of Dose-Response," Epidemiology. 2003, 14(2): 200-5.

12. MRC vitamin research group, "Prevention of Neural Tube Defects: Results of the Medical Research Council Vitamin Study," Lancet. 1991, 338: 131-37.

13. Epstein H, "Homocysteine and Atherothrombosis," N Engl J Med. 1998, 338(15): 1042-50.

14. Ay H, Arasva E., Tokgozoglu SL, Saribas O, "Hyperhomocysteinemia is Associated with the Presence of Left Atrial Thrombus in Stroke Pateints with Nonvalvular Atrial Fibrillation,” Stroke. 2003, 34(4): 909-12.

15. Haynes WG. Hyperhomocysteinemia, "Vascular Function and Atherosclerosis: Effects of Vitamins," Cardiovasc Drugs Ther. 2002, 16(5): 391-399.

16. Sarkar PK, Lambert . L.Can, "Lowering Homocysteine Levels Reduce the Incidence of Stroke," J Clin Pharm Ther. 1999, 24: 331-38.

17. McBride E, "Hyperhomocysteinemia and Atherosclerotic Vascular Disease," Arch. Intern. Med. 1998, 158: 1301-06.

18. Rimm EB, Willet W, Hu F, Sampson L, Colditz G, Manson J, Hennekens C, Stamfer M, "Folate and Vitamin B6 From Diet and Supplements in Relation to Risk of Coronary Heart Disease Among Women," JAMA. 1998, 279(5): 359-64. 19. Adank C, Steak C, Bariars B, "Weekly High-Dose Folic Acid is Effective in Lowering Serum Homocysteine Concentration in Women," Ann Nutr Met. 2003, 47(2):55-9.

20. Bell DS, "Drugs for Cardiovascular Risk Reduction in the Diabetic Patient," Curr Diab Rep. 2001, 1(2): 133-9.

21. Weir G, Scott J, "Colonic Mucosal Folate Concentration and their Association with Colorectal Cancer," Am J Clin Nutr. 1998, 68: 763-4.

22. Kim Y, Karim F, Knox T, Lee Y, Norton R, Arora S, Pavia L, Mason J, "Colonic Mucosal Concentrations of Folate Correlate Well with Blood 
Measurments of Folate Status in Persons with Colorectal Polyps," Am J Clin Nutr 1998, 68: 866-72.

23. La Vecchia C, Negri E., Pelucchi C, Franceschi S, "Dietry Folate and Colorectal Cancer," Int J Cancer. 2002, 102(5): 545-7.

24. Stocker P, Lesgards J., Vidal N, Chalier F, Prost M, "ESR Study of a Biological Assay on Whole Blood: Antioxidant Efficiency of Various Vitamins," Boichim Biophys.Acta. 2003, 162(1): 1-8.

25. Zhu S, Mason J, Shi Y, Hu Y, Li R, whang M, Zhou Y, Jin G, Xie Y, Wu G, Xia D, Qian Z, Sohg H, Zhang L, Russell R, Xiao S, "The Effect of Folic Acid on the Development of Stomach and Other Gastrointestinal Cancers," Chin Med J (Eng). 2003, 116(1): 15-9.

26. Christian P, Kharty S, Katz J, Pradhan EK, LeClerq SC, Shrestha SR, Adhikari RK, Sommer A, West KP Jr, "Effects of Alternative Maternal Micronutrient Supplements on Low Birth Weight in Rural Nepal: Double Blind Randomized Community Trial,” Br Med J. 2003, 326 (7389): 571.

27. Zhang SM, Willet W., Selhub J, Hunter DJ, Giiovannucci EL, Holmes MD, Colditz GA, Hankinson SE, "Plasma Folate, Vitamin B6, Vitamin B12, Homocysteine, and Risk of Breast Cancer," J Natl Cancer Inst. 2003, 95(5): 37380 .

28. Miller AL, "The Methionine-Homocysteine Cycle and its Effects on Cognitive Diseases," Altern Med Rev. 2003, 8(1): 7-19.

29. Aisen PS, Egelko S, Andrews H, Diaz-Arrastia R, Weiner M, DeCarli C, Jagust W, Miller JW, Green R, Bell K, Sano M, “A Pilot Study of Vitamins to Lower Plasma Homocysteine Levels in Alzheimer Disease," Am J Geriatr Psych. 2003, 11(2): 246-9.

30. Mattson MP, "Will Caloric Restriction and Folate Protect Against AD and PD,” Neurology. 2003, 60 (4): 690-5.

31. Prucell WT, Ettinger DS, "Novel Antifolate Drugs," Curr Onc Resp. 2003, Mar, 5(2): 114-25. 
32. Taborsky J, "Hanson R. Dissolution Testing of Nutritional Supplements." (www.dissolutiontech.com).

33. USP 22/ NF 17, Supplements 8 (United States Pharmacopeial Convention, Rockville. MD, 1993).

34. USP 23/ NF 18, Supplements 8 (United States Pharmacopeial Convention, Rockville. MD, 1995).

35. "Nutritional Supplements", in USP 25/NF 20(United States Pharmacopeial Convention, Rockville. MD, 2002). p.2421-2490.

36. Stout PJ, Brun J, Kesner J, Glover D, stamatakis M, "Performance Assesment of Vitamin Supplements: Efficacy Issues," Pharm Res. 1996 13(S-71).

37. Al-Achi A, Greenwood R, York L, "Testing Commercially Available Folic Acid Capsules," Am J Health-Syst Pharm. 1998, 55:1415-16.

38. Giebe K, Carl C, "Comparison of Prenate Advance with Other Prescription Prenatal Vitamins: A Folic Acid Dissolution Study," Adv Ther. 2002, 17(4): 17983.

39. Scuthrope N, Davies B, Asthon T, Allison S, McGuire D, Malhi J, "Commercially Available Folic Acid Supplements and Their Compliance with the British Pharmacopoeia Test for Dissolution,” J Public Health Med. 2001, 23(3): $195-7$.

40. "Simulated gastric fluid and simulated intestinal fluid," in USP 25/NF 20.

(United States Pharmacopeial Convention, Rockville. MD, 2002). p. 2347.

41. "Dissolution and disintegration," in USP 24/NF 19 ( United States

Pharmacopeial Convention, Rockville. MD, 2002) p.1941-43.

42. "Folic acid tablets," in USP 25/NF 20( United States Pharmacopeial Convention, Rockville. MD, 2002) p.753.

43. "Nutritional supplements," (disintegration and dissolution), in USP 25/NF 20( United States Pharmacopeial Convention, Rockville. MD, 2002) p.2663.

44. "Folic acid assay," in USP 25/NF 20( United States Pharmacopeial Convention, Rockville. MD, 2002) p.1872. 
45. "Folic acid," in USP 25/NF 20 (United States Pharmacopeial Convention, Rockville. MD, 2002) p. 752.

46. Klaczkow G, Anuszewska E, "The Use of HPLC Method for Determination of Folic Acid in Multi-Component Vitamin Preparation," Acta Poloniae

Pharmaceutica-Drug Res. 2000, 57(4):257-260.

47. Akhtar MJ, Khan MA, Ahmad I, "Photodegradation of Folic Acid in Aqueous Solution.” J Pharm Biomed Anal. 1999, 19:269-275.

48. Florey K, “Analytical Profiles of Drug Substances,” Academic Press, Inc. 1990, Vol.19:251-54. 